Pacific Northwest

National Laboratory

Operated by Battelle for the

U.S. Department of Energy

\title{
Analysis of Ignition Testing on K-West Basin Fuel
}

J. Abrefah

F. H. Huang

W. M. Gerry

August 1.999
W. J. Gray

S. C. Marschman

T. A. Thornton
RECEVIV

AUG 231999

OSTI

Prepared for the U.S. Department of Energy under Contract DE-AC06-76RLO 1830 


\title{
DISCLAIMER
}

This report was prepared as an account of work sponsored by an agency. of the United States Government. Neither the United States Government nor any agency thereof, nor Battelle Memorial Institute, nor any of their employees, makes any warranty' express or implied, or assumes any legal liability or responsibility for the accuracy, completeness, or usefulness of any information, apparatus, product, or process disclosed, or represents that its use would not infringe privately owned rights. Reference herein to any specific commercial product, process, or service by trade name, trademark, manufacturer, or otherwise does not necessarily constitute or imply its endorsement, recommendation, or favoring by the United States Government or any agency thereof, or Battelle Memorial Institute. The views and opinions of authors expressed herein do not necessarily state or reflect those of the United States Government or any agency thereof.

\author{
PACIFIC NORTHWEST NATIONAL LABORATORY \\ operated by \\ BATTELLE \\ for the \\ UNITED STATES DEPARTMENT OF ENERGY \\ under Contract DE-AC06-76RLO 1830
}

Printed in the United States of America

Available to DOE and DOE contractors from the

Office of Scientific and Technical Information, P.O. Box 62, Oak Ridge, TN 37831;

prices available from (615) 576-8401.

Available to the public from the National Technical Information Service, U.S. Department of Commerce, 5285 Port Royal Rd., Springfield, VA 22161 


\title{
Analysis of Ignition Testing on K-West Basin Fuel
}

\author{
J. Abrefah \\ F. H. Huang ${ }^{(a)}$ \\ W.M. Gerry \\ W. J. Gray \\ S. C. Marschman \\ T. A. Thornton
}

August 1999

Prepared for the U.S. Department of Energy under Contract DE-AC06-76RLO 1830

Pacific Northwest National Laboratory

Richland, Washington 99352

(a) Fluor Daniel Northwest, Inc. 


\section{DISCLAIMER}

Portions of this document may be illegible in electronic image products. Images are produced from the best available original document. 


\section{Summary}

Ignition tests and analyses of damaged/corroded N-Reactor spent nuclear fuel (SNF) were performed by Pacific Northwest National Laboratory as part of a series of studies on the deteriorating spent fuel in the Hanford K-Basins. The ignition temperature tests were conducted to assess the pyrophoric properties of selected spent fuel elements from K-West Basin. The objective of these tests was to determine pyrophoric characteristics of samples cut from both damaged and undamaged regions of fuel elements. Furnace ignition tests were also performed on samples subjected to the conditioning process proposed by the Independent Technical Assessment and the Integrated Process Strategy to establish any significant effect on the SNF pyrophoric performance parameters. Part of the analysis of the ignition data in this report was performed by Fluor Daniel Northwest. One of the safety issues being evaluated is the possibility of a fuel ignition during processing, handling, and transportation to the interim storage facility.

Seventeen ignition tests were performed on specimens (also referred to as samples) cut from two K-West SNF elements: SFEC5,4378, which had been "breached" with an extensively corroded end (referred to herein as corroded fuel), and SFEC10,4366, which had one end sheared off (referred to herein as broken fuel). Ten specimens were taken from Element 4378 and seven from Element 4366 . The specimens taken from Element 4378 included some from an undamaged region. The results of the ignition tests are summarized in Table S.1.

The tests on specimens sectioned from the corroded end of Element 4378 showed that the potential for ignition is quite high. The corroded specimens had consistently lower ignition temperatures (regardless whether conditioned or not) than the mid-section specimens. Overall, the ignition temperatures of the damaged/corroded samples were in the temperature range of $277^{\circ} \mathrm{C}$ to $500^{\circ} \mathrm{C}$, whereas for the undamaged samples ignition temperatures were around $650^{\circ} \mathrm{C}$. These tests confirm that small pieces of corroded fuel with a large specific area can ignite at a temperature lower than the expected literature ignition temperature (approximately $600^{\circ} \mathrm{C}$ ) for metallic uranium.

Dried and conditioned samples with similar pre-test conditions were tested and were found to ignite at temperatures higher than as-cut samples of corroded fuel. Thus, the proposed conditioning process appears capable of reducing the combustion potential for the corroded fuel. However, the same tests performed on the sheared fuel with less corrosion did not yield favorable results. Less-irregular surfaces of fuel samples and the inability of conditioning to decompose hydrides in occluded areas in the broken fuel may explain the different responses from the two types of fuel. The tests were conducted with some uncertainties concerning the initial specimen conditions. 
Table S.1. Summary Results of K-West SNF Ignition Tests

\begin{tabular}{|c|l|c|c|c|l||}
\hline Run & \multicolumn{1}{|c|}{ Specimen ID } & Damaged & Conditioned & $\begin{array}{c}\text { Ignition } \\
\text { Temp. }\left({ }^{\circ} \text { C) }\right.\end{array}$ & \multicolumn{1}{|c|}{ Remark } \\
\hline 11 & SFEC5,4378-S2-E3A & No & No & 640 & Hydrogen release low but increased after ignition. \\
\hline 12 & SFEC5,4378-S2-E4A & No & No & 640 & Low hydrogen release during temperature ramp. \\
\hline 13 & SFEC5,4378-S2-H & No & Yes & $\sim 670$ & Ignition temperature difficult to discern. \\
\hline 14 & SFEC5,4378-S2-D & No & Yes & 650 & Both Runs 13 and 14 have low hydrogen release. \\
\hline 15 & SFEC5,4378-S2-I & No & Yes & $\sim 650$ & Ignition temperature difficult to discern. \\
\hline 17 & SFEC5,4378-S1A-D & Yes & No & 278 & High hydrogen release during temperature ramp. \\
\hline 19 & SFEC5,4378-S1A-H & Yes & No & 277 & High hydrogen release during temperature ramp. \\
\hline 22 & SFEC5,4378-S1A-G & Yes & Yes & $\sim 400$ & Ignition temperature not clearly defined. \\
\hline 24 & SFEC5,4378-S1A-B1 & Yes & Yes & 485 & Low hydrogen release when ignition occurred. \\
\hline 26 & SFEC5,4378-S1A-I & Yes & Yes & 310 & Specimen was dried but not oxidized. \\
\hline 30 & SFEC10,4366-S1-D & Yes & No & $400-500$ & $\begin{array}{l}\text { Sample cut from the "extended" portion; ignition } \\
\text { temperature not clearly defined. }\end{array}$ \\
\hline 32 & SFEC10,4366-S2-D & Yes & No & $400-500$ & $\begin{array}{l}\text { Sample does not contain corroded surface; ignition } \\
\text { temperature not clearly defined. }\end{array}$ \\
\hline 37 & SFEC10,4366-S3-G & Yes & No & 473 & High hydrogen release before ignition occurred. \\
\hline 29 & SFEC10,4366-S1-A & Yes & Yes & $400-500$ & Ignition temperature is not clearly defined. \\
\hline 33 & SFEC10,4366-S2-A & Yes & Yes & $400-500$ & $\begin{array}{l}\text { Sample does not contain corroded surface; ignition } \\
\text { temperature not clearly defined. }\end{array}$ \\
\hline 36 & SFEC10,4366-S3-E1 & Yes & Yes & 329 & High hydrogen release at ignition. \\
\hline 39 & SFEC10,4366-S3-H & Yes & Yes & 394 & Low hydrogen released. \\
\hline
\end{tabular}

Other observations from the ignition tests are given below:

- Ignition events were usually preceded by a period where the heating rate of the sample exceeded the heating rate of the furnace (although a few instances occurred where ignition was reached when the sample heating rate lagged behind the furnace heating rate).

- Consistently, when the heating rate of an SNF sample exceeded the furnace heating rate, there was a corresponding release of hydrogen gas from the sample.

- Hydrogen was released any time an sample was observed to reach ignition.

- Specimens sectioned from the corroded end of the SNF exhibited well-defined ignition temperatures, and an ignition event was observed to have started in one case from the corroded surface of the specimen.

- The burning curve results of some specimens did not show distinct inflection points for determining the ignition point, and the point where the specimen heating rate exceeded the furnace heating rate is denoted as the point of rapid oxidation. 
These observations can be used to support the development of a premise regarding the pyrophoric behavior of these fuels. When an SNF sample is heated, oxidation proceeds at an overall rate that is influenced by several factors, including:

- reaction rate of the base uranium metal alloy

- presence of oxide layers on the surface of the fuel

- number of cracks in the fuel and their morphology

- concentration and reaction rate of subsurface uranium hydrides

- size (mass) and configuration of the sample.

Depending on the heat dissipation characteristics of the furnace system and the sample configuration, the exothermic reaction of the fuel sample could lead to an ignition event or simply rapid oxidation of the sample. The implication of these tests to the proposed Multi-Canister Overpacks for packaging the SNF is that direct correlation of the measured ignition temperatures will not be applicable. However, the test results suggest there is potential for ignition of the SNF if appropriate thermal conditions exist. 


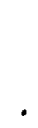




\section{Acknowledgments}

The campaign to ship spent nuclear fuel (SNF) samples from the K-West canisters to Pacific Northwest National Laboratory (PNNL) for characterization activities, including the ignition tests, was made possible through the dedicated efforts of the operations staff at the K-Basins and the Duke Engineering \& Services Hanford, Inc., SNF characterization group under the management of Ronald P. Omberg and his associates, Bruce J. Makenas, David W. Bergmann, and Leo A. Lawrence. The authors also extend an appreciation to the staff of the PNNL Postirradiation Testing Laboratory, who were involved in preparation of the test samples. 


\section{Quality Assurance}

This work was conducted under the Quality Assurance Program, Pacific Northwest National Laboratory SNF-70-001, SNF Quality Assurance Program, as implemented by the PNNL SNF Characterization Project Operation Manual. This QA program has been evaluated and determined to effectively implement the requirements of DOE/RW-0333P, Office of Civilian Radioactive Waste Management Quality Assurance Requirements and Description (QARD). Compliance with the QARD requirements is mandatory for projects that generate data used to support the development of a permanent High-Level Nuclear Waste repository. Furthermore, the U.S. Department of Energy has determined that the testing activities, which generated the results documented in this report, shall comply with the QARD. Supporting records for the data in this report are located in the permanent PNNL SNF Characterization Project records. 


\section{Contents}

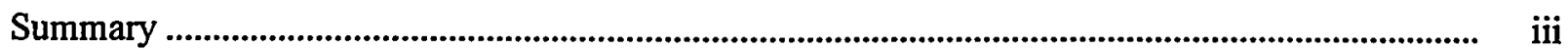

Acknowledgments ................................................................................................................................ vii

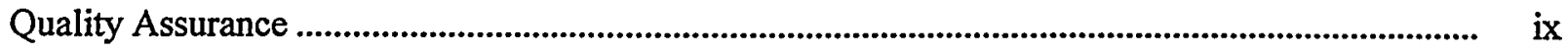

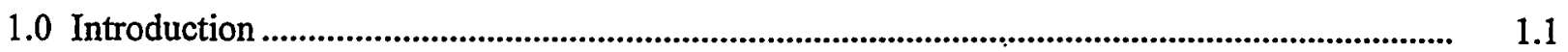

2.0 Overview of Uranium Ignition ........................................................................................... 2.1

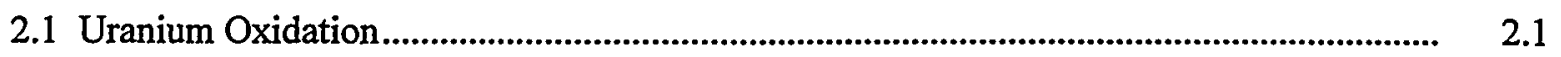

2.2 Relevant Past Work .................................................................................................. 2.2

3.0 Experimental Procedure ................................................................................................

3.1 Specimen Preparation........................................................................................................

3.2 Test System and Procedure .................................................................................................. 3.6

4.0 Results of Ignition Testing ......................................................................................................

4.1 SNF Burning Curves ....................................................................................................

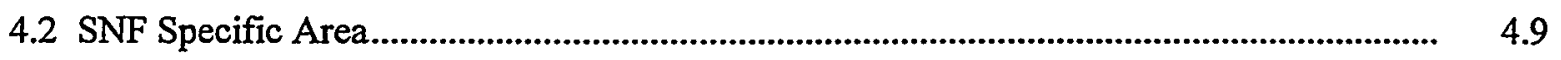

4.3 SNF Ignition Temperature............................................................................................... 4.10

4.4 Hydrogen and Moisture in the Offgas ............................................................................. 4.12

4.5 Metallography ….......................................................................................................... 4.12

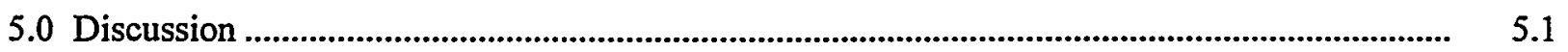

5.1 Ignition Behavior of SNF ..........................................................................................

5.2 Application of Ignition Test Results ................................................................................ 5.3

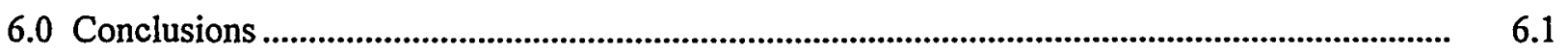

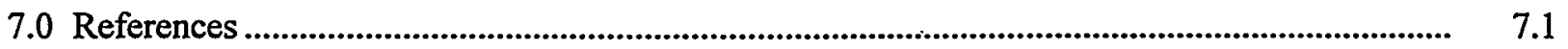


Appendix A - Specimen Dimensions....................................................................................... A.1

Appendix B - Ignition Test Results ........................................................................................... B.1

Appendix C - Summaries of Reported Uranium Metal Fuel Pyrophoricity Incidents...................... C. C.1 


\section{Figures}

3.1 Damaged Ends of K-West SNF Elements (a) SFEC5,4378 and (b) SFEC10,4366................

3.2 Sectioning Diagram of SNF Element SFEC5,4378 Showing Test Samples ............................

3.3 Sectioning Diagram of SNF Element SFEC10,4366 Showing Test Samples..........................

3.4 Polished, Conditioned Specimen SFEC5,4378-S2-B in the Longitudinal Plane Showing Loosely Adhered Uranium Oxide Scale.

3.5 Schematic of the Furnace Testing System

3.6 Specimen Dimensions for the Ignition Tests

3.7 Ignition Behavior of Uranium at a Constant Heating Rate

4.1 Ignition Results of As-Cut, Undamaged SNF Sample 5-S2-E4A

4.2 Ignition Results of Conditioned, Undamaged SNF Sample 5-S2-D

4.3 Ignition Results of As-Cut, Damaged/Corroded SNF Sample 5-S1A-D

4.4 Ignition Results of As-Cut, Damaged/Corroded SNF Sample 5-S1A-H

4.5 Ignition Results of Conditioned, Damaged/Corroded SNF Sample 5-S1A-G

4.6 Ignition Results of Conditioned, Damaged/Corroded SNF Sample 5-S1A-I.

4.7. Ignition Results of Conditioned, Damaged/Corroded SNF Sample 5-S1A-B1

4.8 Uranium Hydride Inclusions in the Damaged/Corroded Region of SNF Element 4378

4.9 Inner Cladding/Fuel Boundary of Polished, Conditioned Specimen SFEC5,4378-S2-B in the Longitudinal Plane; 50X.

4.10 Micrograph of Conditioned Specimen SFEC5,4378-S2-J1 in the Transverse Plane Showing Probable Uranium Hydride Phase and Uranium Carbide Precipitates.

5.1 Dependence of Uranium Ignition Temperature on Specific Area; Comparison of Historic Data and Results of Current SNF Tests. 


\section{Tables}

S.1 Summary Results of K-West SNF Ignition Tests......................................................... iv

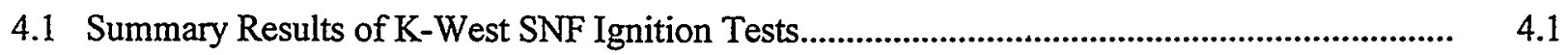

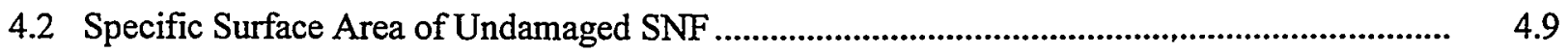

4.3 Effects of Conditioning on Fuel Ignition Temperatures................................................ 


\subsection{Introduction}

Approximately 2100 metric tons of spent nuclear fuel (SNF) discharged from the N-Reactor have been stored underwater at the K-Basins in the 100 Area of the Hanford Site. The spent fuel has been stored in the K-East Basin since 1975 and in the K-West Basin since 1981. Some of the SNF elements in these basins have corroded because of various breaches in the Zircaloy cladding that occurred during fuel discharge operations and/or subsequent handling and storage in the basins. Consequently, radioactive material in the fuel has been released into the basin water, and water has leaked from the K-East Basin into the soil below. To protect the Columbia River, which is only $380 \mathrm{~m}$ from the basins, the SNF is scheduled to be removed and transported for interim dry storage in the 200 East Area, in the central portion of the Site. However, before being shipped, the corroded fuel elements will be loaded into MultiCanister Overpacks (MCOs) and conditioned. The conditioning process will be selected based on the Integrated Process Strategy (IPS) (WHC 1995), which was prepared on the basis of the dry storage concept developed by the Independent Technical Assessment (TTA) team (ITA 1994).

During various phases of the operations, the MCOs will be exposed to one or more of the following: thermal conditions involving decay heat, the pyrophoric potential of uranium metal and hydride, and flammable hydrogen. In addition, the temperature in the MCOs will have to be raised to remove water and to decompose and passivate uranium hydride inclusions. These conditions are conducive to a potential for fuel ignition event when the heat generated in the container cannot be adequately dissipated. This potential for fuel fires during handling operations led to a study of the pyrophoric behavior of corroded SNF as a major issue in the safe handling and storing of N-Reactor metal fuel (Abrefah et al. 1994). This report discusses tests performed by Pacific Northwest National Laboratory on the ignition potential of the corroded N-Reactor fuel elements to address Data Quality Objectives established for initial fuel examinations and for the conditioning examinations of K-West Basin fuel (Lawrence 1995; Lawrence et al. 1995). Part of the analysis of the ignition data was performed by Fluor Daniel Northwest, Inc.

The ignition characteristic of the metallic uranium is a strong function of test specimen geometry and the experimental system configuration parameters. Some of the parameters that will influence the ignition test data of the SNF are briefly discussed in Section 2.0. Because of the configuration effect on the ignition of the test sample, the method devised to ascertain the pyrophoric enhancement characteristics of the corroded SNF is based on comparative experiments instead of absolute measurement of ignition temperature. The method stipulates using SNF specimens taken from different regions of the same fuel element. The results of the ignition tests for specimens from different regions of the fuel element were compared to determine changes in the pyrophoric characteristics of each specimen. This comparative study technique was extended to determine the effect of the conditioning process on the pyrophoric behavior of the corroded SNF. By this method, the ignition temperature for as-cut specimens from the same region of fuel element are compared to sibling samples that are conditioned in the laboratory by steps similar to the proposed IPS (WHC 1995) and ITA (ITA 1994) processes. The experimental method used in this study is discussed in Section 3.0 together with detailed sectioning of the fuel element to create the test specimens. The results of the testing and analysis are presented in 
Section 4.0, and further discussed in Section 5.0. Conclusions are given in Section 6.0. The appendices provide specimen dimensions, temperature-time traces for the samples tested, and summaries of reported past uranium metal pyrophoricity events at various facilities. 


\subsection{Overview of Uranium Ignition}

This section outlines the conditions that promote uranium ignition and summarizes relevant studies on ignition temperature. Uranium metal-based nuclear fuel, both irradiated and unirradiated, often demonstrates "pyrophoric behavior." Pyrophoric behavior can be described as ignition followed by a rapid, uncontrolled oxidation of the uranium and/or cladding metal, resulting in nearly complete consumption and physical degradation of the fuel form. The observed pyrophoric behavior of uranium metal-based fuel has ranged from slow smoldering, to burning with a flame, to exploding. The burning temperature of uranium metal has been measured to be in excess of $2000^{\circ} \mathrm{C}$ (Mouradian and Baker 1963; Baker et al. 1966). Ignition has been postulated to be initiated by temperature, mechanical trauma, friction, sparks, or a combination of these parameters. Initiation also requires exposure to an oxidizing atmosphere, such as oxygen, air, or high-temperature steam.

The N-Reactor fuel elements basically consist of annuli of uranium metal clad in Zircaloy-2. The uranium metal and Zircaloy cladding are intimately bonded by coextrusion. Since both the uranium fuel core and the cladding are metal, they are susceptible to rapid oxidation or combustion in an oxidizing environment. At temperatures over $1000^{\circ} \mathrm{C}$, uranium can even react exothermically with (i.e., burn in) nitrogen. When either metal corrodes in water, it can form metal hydrides as a result of the chemical combination of the metal with the hydrogen generated by the corrosion reaction.

\subsection{Uranium Oxidation}

The oxidation of uranium is exothermic, increasing the temperature at and near the reaction area. This temperature increase can, in turn, further accelerate the oxidation reaction. Ignition, or pyrophoricity, occurs when the heat of the oxidation reaction cannot be dissipated quickly enough to prevent the reaction from becoming self-sustaining and uncontrolled. It is generally acknowledged that monolithic, uncorroded, nearly theoretically dense uranium or zirconium does not ignite or display pyrophoric properties at temperatures below about $600^{\circ} \mathrm{C}$, primarily because the metal itself provides for rapid conduction of heat away from the reaction area.

The oxidation and consequent heat generation rate of the metal can be enhanced through one or a combination of several possible effects such as:

- introduction of heat from an outside source, which increases the temperature and thus the intrinsic oxidation rate

- exposure of large metal surface areas, thereby increasing the surface-area-to-volume ratio and, consequently, the effective quantity of metal available for reaction

- exposure of previously unreacted metal through sudden removal of protective surface oxide layers 
- formation of chemical species or phases, such as hydrides, which have higher intrinsic oxidation rates than the metal.

\subsection{Relevant Past Work}

Fuel pyrophoricity and ignition incidents have been hazards of serious concern in handling uranium. As summarized in Appendix $\mathrm{C}$, there has been a history of pyrophoric events involving metallic uranium and/or zirconium metal, some serious enough to result in fatalities. These unexpected events were often inexplicable, due to the complex and interactive nature of the.ignition mechanism. Common to these incidents was the virtually unlimited access of the exposed uranium metal surfaces to the oxidant. The burning of fuel may degrade the structural integrity of the container and may even cause explosions (Smith 1956). To control and prevent such accident potential, studies have been undertaken by various researchers to understand the factors that lead to ignition and burning. As discussed below, the basic theory of ignition was developed to define the ignition temperature. Experiments were conducted to determine the ignition temperature of uranium under various conditions, and were then used to verify the theoretical analysis to determine ignition temperature based on a heat balance equation.

$$
\mathrm{C}_{\mathrm{p}}=\frac{d \mathrm{~T}}{d \mathrm{t}}=\frac{\mathrm{QM}_{\mathrm{u}} \mathrm{S}}{10^{3} \mathrm{M}_{\mathrm{o}}} \frac{\mathrm{dw}}{\mathrm{dt}}-\mathrm{hS}\left(\mathrm{T}-\mathrm{T}_{\mathrm{f}}\right)-\sigma \varepsilon S\left(\mathrm{~T}^{4}-\mathrm{T}_{\mathrm{f}}^{4}\right)
$$

where $C_{p}=$ specific heat of uranium

$\mathrm{T}=$ the metal temperature in $\mathrm{K}$

$T_{f}=$ the furnace temperature

$\mathrm{t}=$ time

$\mathrm{Q}=$ heat of reaction

$\mathrm{M}_{\mathrm{u}}=$ atomic weight of uranium

$\mathrm{M}_{\mathrm{o}}=$ molecular weight of oxygen

$\mathrm{S}=$ specific area in $\mathrm{cm}^{2} / \mathrm{g}$

$\mathrm{w}=$ quantity of oxygen reacted

$h=$ the heat transfer coefficient

$\sigma=$ Stefan-Boltzman constant

$\varepsilon=$ the metal surface emissivity

The second and third terms on the right-hand side of Equation (2.1) are convection and radiation heat loss, respectively. These two terms are negligible at temperatures near the ignition temperature $\left(\mathrm{T}_{\mathrm{i}}\right)$ because the value of $\left(T-T_{f}\right)$ is small. Equation (2.1) is rewritten as (Musgrave 1972):

$$
\left(\frac{d \dot{T}}{d t}\right)_{\mathrm{T}=\mathrm{T}_{\mathrm{i}}} \approx \frac{\mathrm{QM}_{\mathrm{u}} \mathrm{S}}{10^{3} \mathrm{C}_{\mathrm{p}} \mathrm{M}_{\mathrm{o}}}\left(\frac{d \mathrm{~W}}{d \mathrm{t}}\right)_{\mathrm{T}=\mathrm{T}_{\mathrm{i}}}
$$


The isothermal oxidation of uranium in the $300^{\circ} \mathrm{C}$ to $625^{\circ} \mathrm{C}$ temperature range has been studied, and the empirical rate equations for uranium oxidation have been formulated in the rate law of $w^{n}=k t$, where $\mathrm{n}$ and $\mathrm{k}$ are constants for each temperature (Baker and Bingle 1966). The Arrhenius behavior of oxidation in terms of $\mathrm{T}$ given below may be differentiated with time to derive an expression for reaction rate (Equation 2.3).

$$
\begin{aligned}
& w^{n}=t A_{n} \exp (-E / R T) \\
& \frac{d w}{d t}=\frac{A_{n}}{n w^{n-1}} \exp (-E / R T)
\end{aligned}
$$

where $A_{n}=$ the frequency factor

$E=$ the activation energy

$\mathrm{R}=$ the universal gas constant

Substituting (2.3) into (2.2) gives:

$$
\left(\frac{d T}{d t}\right)_{T=T_{i}}=\frac{Q_{u_{u}} S_{n}}{10^{3} C_{p} M_{o} n w^{n-1}} \exp (-E / R T)
$$

The rate of temperature increase at ignition in Equation (2.4) should be hundreds of degrees per minute $\left[(d \mathrm{~T} / d \mathrm{t})_{\mathrm{T}=\mathrm{T}_{\mathrm{i}}}=100 \mathrm{~K} / \mathrm{min}\right]$; with known constants of $\mathrm{Q}, \mathrm{M}_{\mathrm{u}}, \mathrm{M}_{0}$, and $\mathrm{C}_{\mathrm{p}}$, Equation (2.4) becomes:

$$
\frac{1}{T_{i}}=\frac{R}{E} \ln \left(Y \frac{A_{n} S}{n w^{n-1}}\right)
$$

where $\mathrm{Y}=\mathrm{QM}_{\mathrm{u}} / 10^{5} \mathrm{C}_{\mathrm{p}} \mathrm{M}_{\mathrm{o}}$

Equation (2.5) shows that the ignition temperature depends on the specific surface area and the oxidation rate of the metal. Thus, particulate and powder having a fairly large specific area have been observed to ignite at a relatively low ambient temperature, with the ignition temperature decreasing with an increase in the specific area (Baker et al. 1966). The activation energy of oxidation can be obtained from the linear plot of $1 / T_{i}$ vs. $\log S$ with the values of $n, A_{n}$, and $E$ for the oxidation of uranium available in Baker and Bingle (1966). As reported in Musgrave (1972), the ignition temperatures predicted from Equation (2.5) compare favorably with those found experimentally for uranium in Baker et al. (1966) and Tetenbaum et al. (1962).

The ignition temperature of uranium can be increased by the presence of an oxide coating. Studies of uranium powder have shown that pre-oxidation affects the ignition temperature of uranium (Tetenbaum et al. 1962). Powder samples were heated at approximately $150^{\circ} \mathrm{C}$ in air for varying lengths of time that controlled the extent of oxide nodule coverage. Experimental data showed that uranium powder with partial oxide coverage ignited at $235^{\circ} \mathrm{C}$, while complete nodule coverage caused the ignition temperature to increase to $250^{\circ} \mathrm{C}$. The $15^{\circ} \mathrm{C}$ increase was not insignificant, as the amount of powder sample was 
small and the sizes of the particles well defined. This finding indicates the ignition temperature of damaged fuel, such as the corroded $\mathrm{N}$-Reactor material being studied here, could be raised by oxidizing metallic surfaces through a conditioning process.

The N-Reactor SNF ignition experiments were performed by placing the metal samples in a flowing oxidizing atmosphere within a furnace and steadily increasing the temperature to a desired maximum. The ignition temperature of the sample was experimentally determined at a point when the heating rate of the sample increased abruptly. This experimental concept is discussed in detail in Musgrave (1972). 


\subsection{Experimental Procedure}

Ignition tests were performed on 17 specimens (samples) cut from two $\mathrm{K}$-West Basin fuel elements: SFEC5,4378, which had been breached with an extensive corroded end (referred to as Element 4378 or "corroded fuel," Figure 3.1a) and SFEC10,4366, in which one end had been completely sheared off (referred to as Element 4366 or "broken fuel," Figure 3.1b).

\subsection{Specimen Preparation}

The specimens used for the ignition testing were part of an overall sectioning activity to create small test samples for various destructive characterization studies. These samples were cut dry under a flowing blanket of argon to minimize any alteration that would be caused by air oxidation of the cut surfaces. The cutting diagrams are shown in Figures 3.2 and 3.3 for.Elements 4378 and 4366, respectively. The details of the sectioning methodology are given in Appendix D of Abrefah et al. (1996). The specimens sectioned from the undamaged region of the fuel element had four cut surfaces, while the specimens from damaged regions had three cut surfaces and one damaged surface. The other two surfaces had the attached inner and outer cladding surfaces. The specimens were numbered (e.g., SFEC5,4378-S2-H or " $5-\mathrm{S} 2-\mathrm{H}^{\prime}$ ) according to the fuel element locations from which they were sectioned. After sectioning, the test specimens were stored in ultra high purity (UHP) argon to minimize further degradation.

Some specimens cut from the damaged and undamaged sections of the elements were conditioned before the ignition tests. The conditioning steps involved one or the other of the following two processes:

1. IPS (WHC 1995) vacuum conditioning process: specimen was dried at $50^{\circ} \mathrm{C}$ for 10 hours at 38 Torr vacuum and for 24 hours at $300^{\circ} \mathrm{C}$ at $38 \mathrm{Torr}$, then cooled to ambient cell temperature; the specimen was then exposed to $1 \mathrm{~atm}$ of $2 \%$ oxygen in argon at $250^{\circ} \mathrm{C}$ for 11 hours.

2. ITA (ITA 1994) inert gas flowing conditioning process: specimen was dried at $50^{\circ} \mathrm{C}$ for 10 hours and for 24 hours at $300^{\circ} \mathrm{C}$ in flowing UHP argon at atmospheric pressure, then cooled to ambient cell temperature; the specimen was then exposed to $1 \mathrm{~atm}$ of $2 \%$ oxygen in argon at $250^{\circ} \mathrm{C}$ for 11 hours.

The conditioning process created a very thin, loosely adhered oxide layer (Figure 3.4) on the specimens. Most of the oxide generated by the oxidation steps in the two processes also spalled off the specimens. The conditioning process did not significantly change the geometrical shapes of the specimens to influence the dimensional measurements. These conditioned specimens were also stored in a container filled with UHP argon before being placed in the furnace for the ignition testing. 


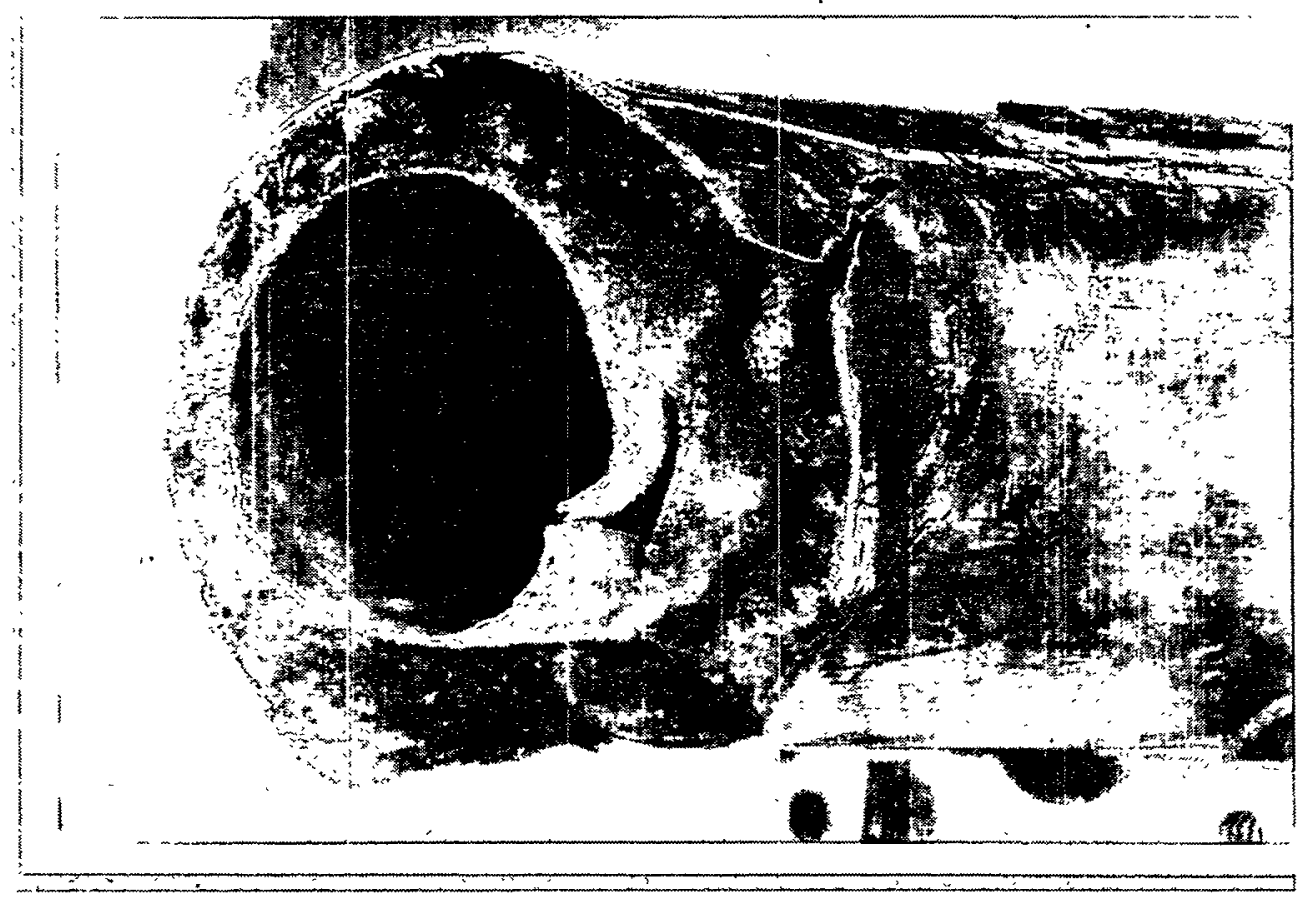

(a)

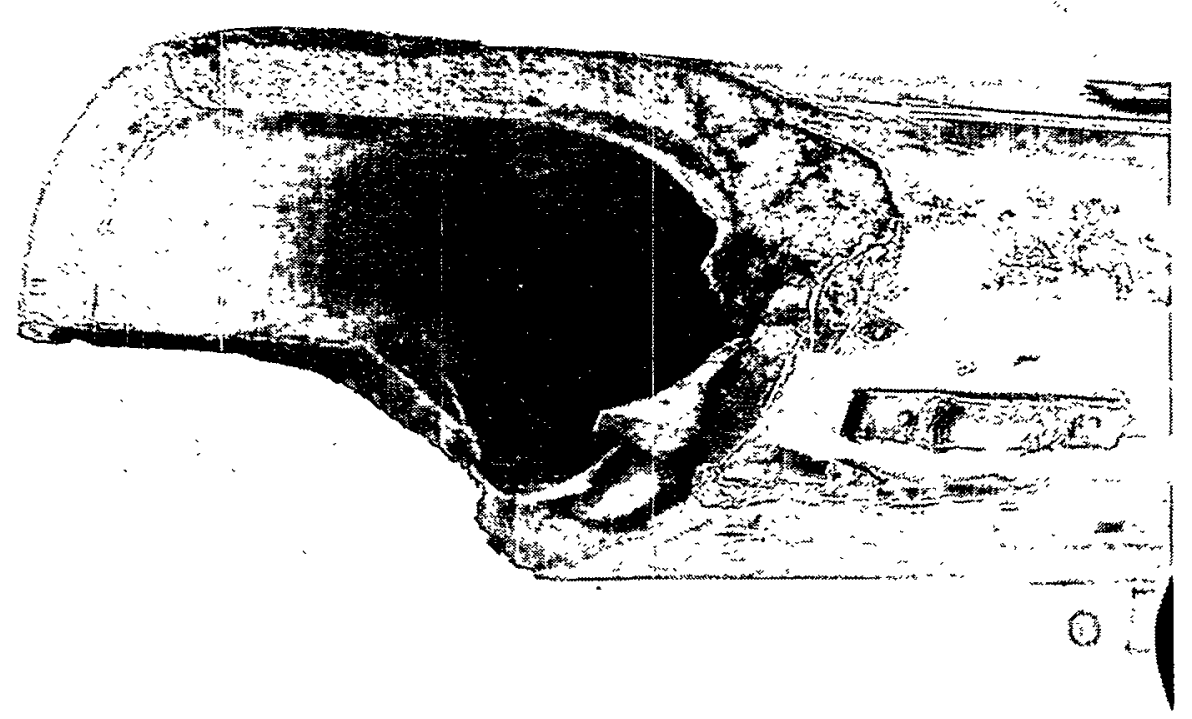

(b)

Figure 3.1. Damaged Ends of K-West SNF Elements (a) SFEC5,4378 and (b) SFEC10,4366 

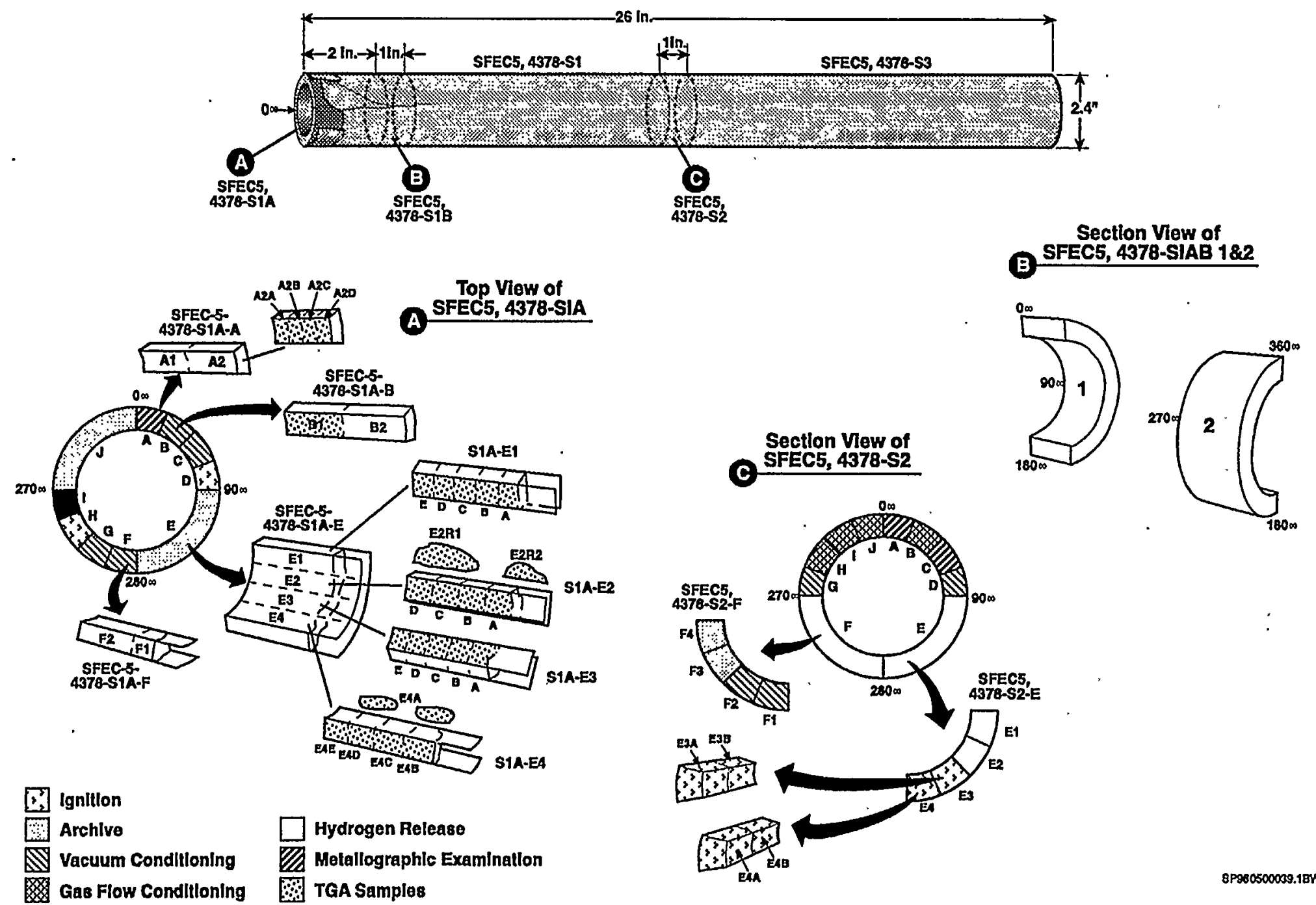

8P\$60500059.18W

Figure 3.2. Sectioning Diagram of SNF Element SFEC5,4378 Showing Test Samples 


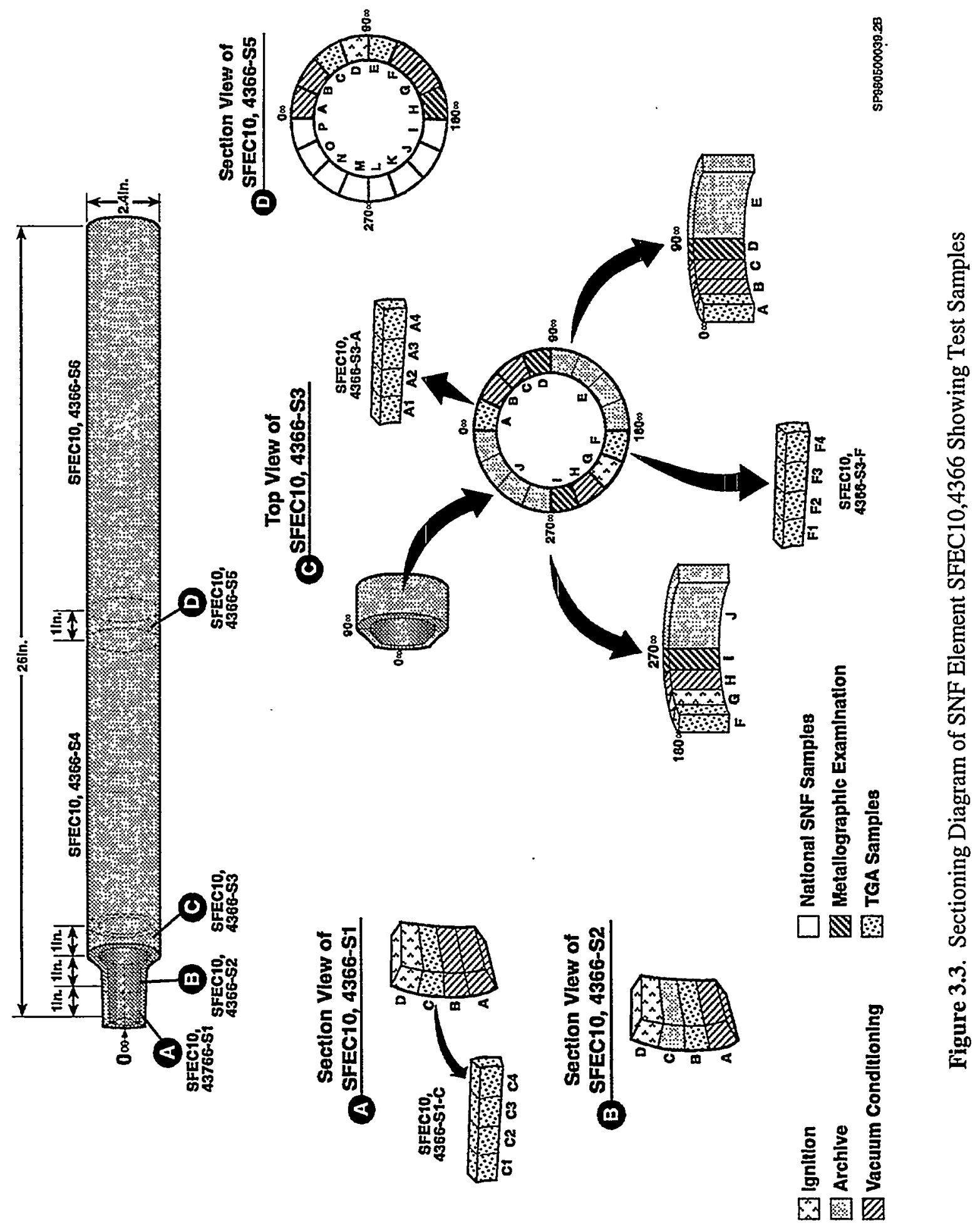




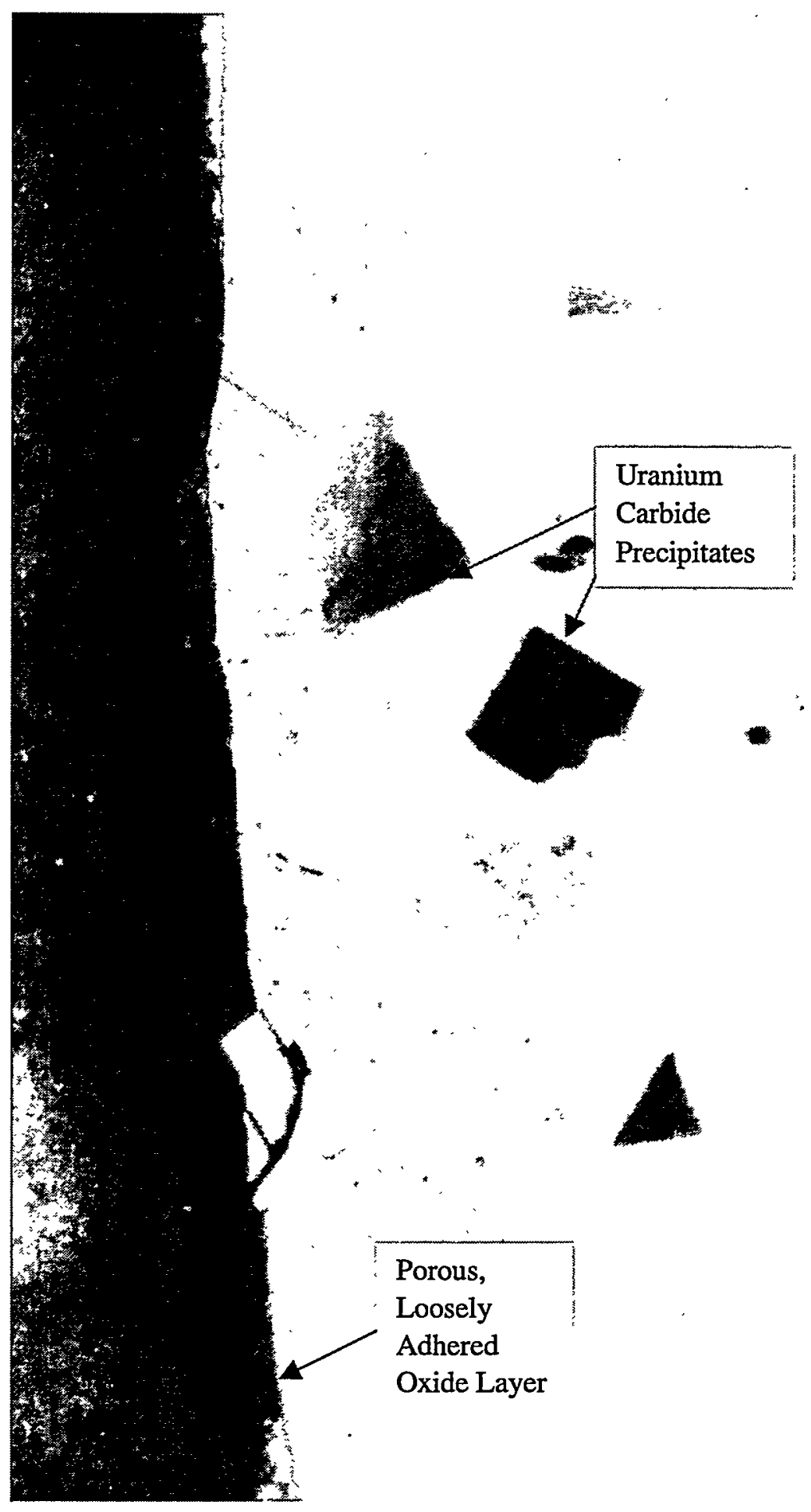

Figure 3.4. Polished, Conditioned Specimen SFEC5,4378-S2-B in the Longitudinal Plane Showing Loosely Adhered Uranium Oxide Scale 


\subsection{Test System and Procedure}

Details of test procedure are given in Abrefah et al. (1996). Figure 3.5 shows the furnace testing apparatus. The clamshell furnace and most of the piping to control the gas flow were installed in the hot cell. The control instrumentation and the analytical instruments were located outside the hot cell. Each specimen was weighed before and after the test. The dimensions of each specimen were determined from photographs taken with a calibrated ruler such as those shown in the figures for the samples in Section 4.0. The labeled test sample sketch shown in Figure 3.6 indicates the dimensions that were measured for each sample and are listed in Appendix A. The ignition tests were performed in an aluminatube $(2.5 \mathrm{~cm}$ diameter) furnace. Before the test, the furnace was evacuated to a low pressure and purged with argon. During the test, moisture in the gas stream and hydrogen released from the specimen were monitored continuously by the moisture probe and gas chromatograph (GC), respectively.

The burning curve ignition method discussed theoretically by Musgrave (1972) was used in these studies to determine the ignition temperatures of the $\mathrm{N}$-Reactor specimens. For this method, a specimen was heated from ambient temperature to between $700^{\circ} \mathrm{C}$ and $800^{\circ} \mathrm{C}$ at a constant rate of $15^{\circ} \mathrm{C} / \mathrm{min}$ in a flowing ( $500 \mathrm{cc} / \mathrm{min}) \mathrm{dry}$-air environment. The temperature-time traces of the specimen and furnace for each test were recorded. As the furnace temperature increased, the sample temperature also increased and eventually began to exceed the furnace temperature; the sample temperature would increase sharply as ignition occurred. The ignition temperature was determined graphically as the point of intersection of the two straight lines drawn through the temperature curve (see Figure 3.7). The two lines were drawn through the initial heating rate of the specimen and post-ignition (or rapid oxidation) heating rate. After the test was completed, the furnace was cooled to room temperature, and the specimen was examined visually, photographed, and weighed. 


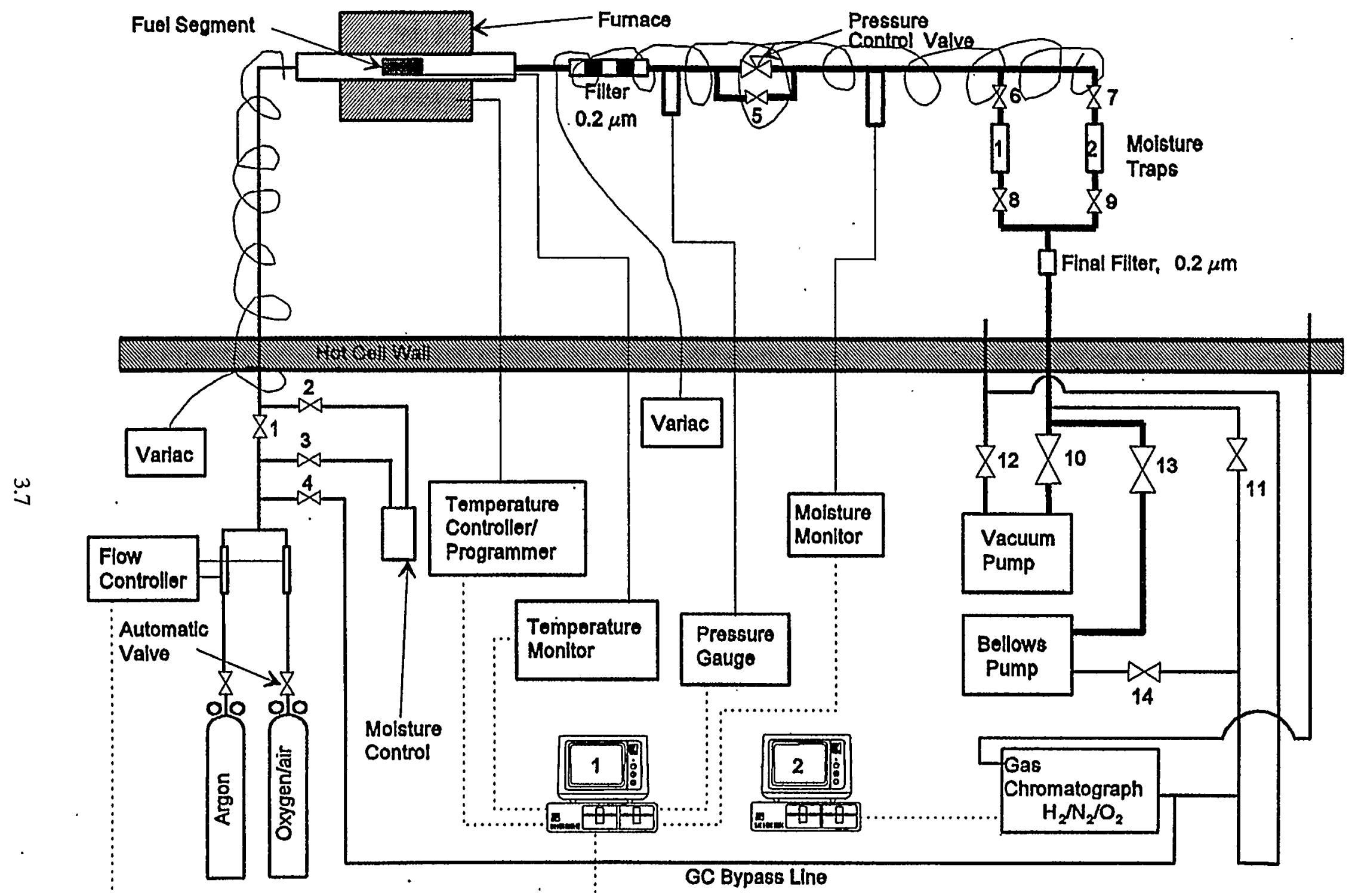

Figure 3.5. Schematic of the Furnace Testing System 


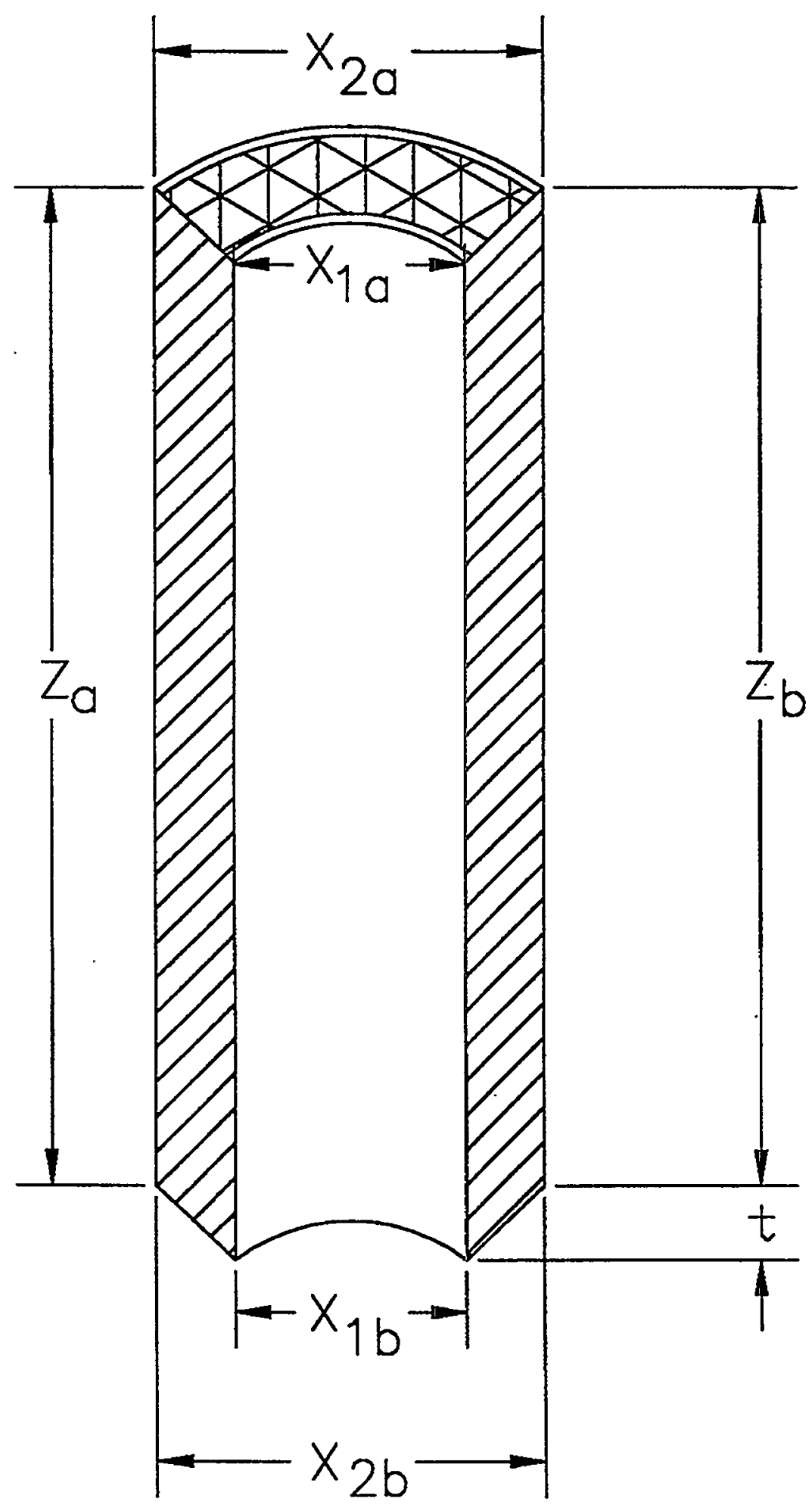

Figure 3.6. Specimen Dimensions for the Ignition Tests 


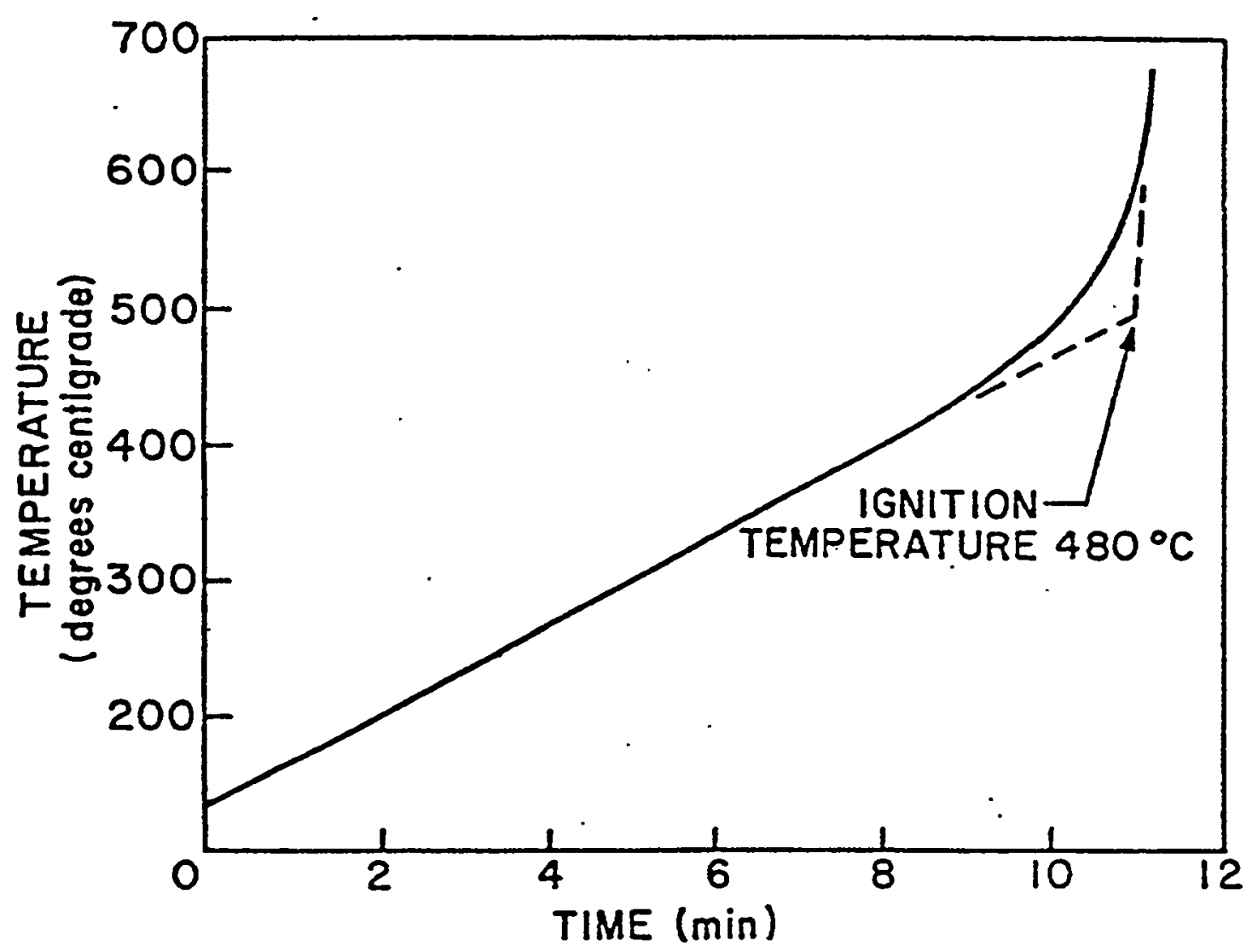

Figure 3.7. Ignition Behavior of Uranium at a Constant Heating Rate 


\subsection{Results of Ignition Testing}

Ignition tests were performed on 17 specimens cut from the two K-West SNF elements. Specimen identification numbers, pre-test conditions, furnace run numbers, and summary results of the ignition tests are listed in Table 4.1. As shown in Table 4.1, 10 of the specimens were taken from Element 4378 and seven from Element 4366. For Element 4378 specimens, five came from the undamaged region (approximately the mid-section) and five were taken from the damaged/corroded region of the element. Table 4.1 also shows the specimens that were conditioned before the ignition tests. Seven were used in the as-cut condition, and the rest were conditioned by the two processes discussed in Section 3.1.

\subsection{SNF Burning Curves}

The temperature-time profiles (burning curves) for two ignition tests in which undamaged SNF samples were used are shown in Figures 4.1 and 4.2, together with photographs of the test samples. The after-test photograph of Sample 5-S2-E4A (Figure 4.1) was not taken. Figure 4.2 shows that a small fraction of the undamaged uranium sample was oxidized, resulting in the uranium dioxide powder shown in the after-test photograph. The spring shown in that photograph was used to keep the thermocouple in firm contact with the sample during the test. For these undamaged SNF samples (Figures 4.1 and 4.2), a rapid oxidation and/or ignition event (indicated by the sudden change in the slope of the specimen temperature-time curve) occurred at temperatures above $600^{\circ} \mathrm{C}$.

Table 4.1. Summary Results of K-West SNF Ignition Tests

\begin{tabular}{|c|l|c|c|c|l|}
\hline Run & \multicolumn{1}{|c|}{ Specimen ID } & Damaged & Conditioned & $\begin{array}{c}\text { Ignition } \\
\text { Temp. }\left({ }^{\circ} \mathrm{C}\right)\end{array}$ & \multicolumn{1}{|c|}{ Remark } \\
\hline 11 & SFEC5,4378-S2-E3A & No & No & 640 & Hydrogen release low but increased after ignition. \\
\hline 12 & SFEC5,4378-S2-E4A & No & No & 640 & Low hydrogen release during temperature ramp. \\
\hline 13 & SFEC5,4378-S2-H & No & Yes & $\sim 670$ & Ignition temperature difficult to discern. \\
\hline 14 & SFEC5,4378-S2-D & No & Yes & 650 & Both Runs 13 and 14 have Iow hydrogen release. \\
\hline 15 & SFEC5,4378-S2-I & No & Yes & $\sim 650$ & Ignition temperature difficult to discern. \\
\hline 17 & SFEC5,4378-S1A-D & Yes & No & 278 & High hydrogen release during temperature ramp. \\
\hline 19 & SFEC5,4378-S1A-H & Yes & No & 277 & High hydrogen release during temperature ramp. \\
\hline 22 & SFEC5,4378-S1A-G & Yes & Yes & $\sim 400$ & Ignition temperature not clearly defined. \\
\hline 24 & SFEC5,4378-S1A-B1 & Yes & Yes & 485 & Low hydrogen release when ignition occurred. \\
\hline 26 & SFEC5,4378-S1A-I & Yes & Yes & 310 & Specimen was dried but not oxidized. \\
\hline 30 & SFEC10,4366-S1-D & Yes & No & $400-500$ & $\begin{array}{l}\text { Sample cut from the “extended" portion; ignition } \\
\text { temperature not clearly defined. }\end{array}$ \\
\hline 32 & SFEC10,4366-S2-D & Yes & No & $400-500$ & $\begin{array}{l}\text { Sample does not contain corroded surface; ignition } \\
\text { temperature not clearly defined. }\end{array}$ \\
\hline 37 & SFEC10,4366-S3-G & Yes & No & 473 & High hydrogen release before ignition occurred. \\
\hline 29 & SFEC10,4366-S1-A & Yes & Yes & $400-500$ & Ignition temperature is not clearly defined. \\
\hline 33 & SFEC10,4366-S2-A & Yes & Yes & $400-500$ & $\begin{array}{l}\text { Sample does not contain corroded surface; ignition } \\
\text { temperature not clearly defined. }\end{array}$ \\
\hline 36 & SFEC10,4366-S3-E1 & Yes & Yes & 329 & High hydrogen release at ignition. \\
\hline 39 & SFEC10,4366-S3-H & Yes & Yes & 394 & Low hydrogen release at ignition. \\
\hline
\end{tabular}




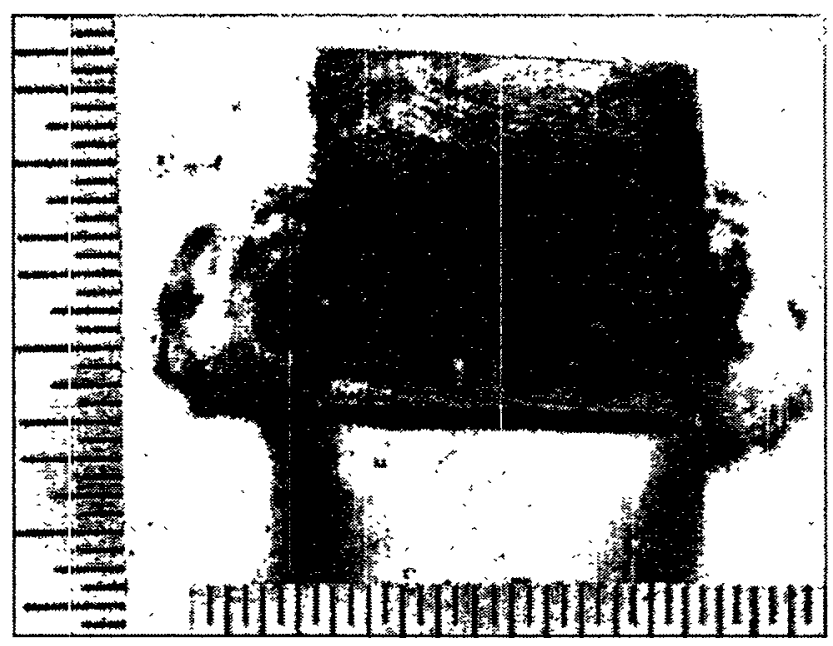

Before Test

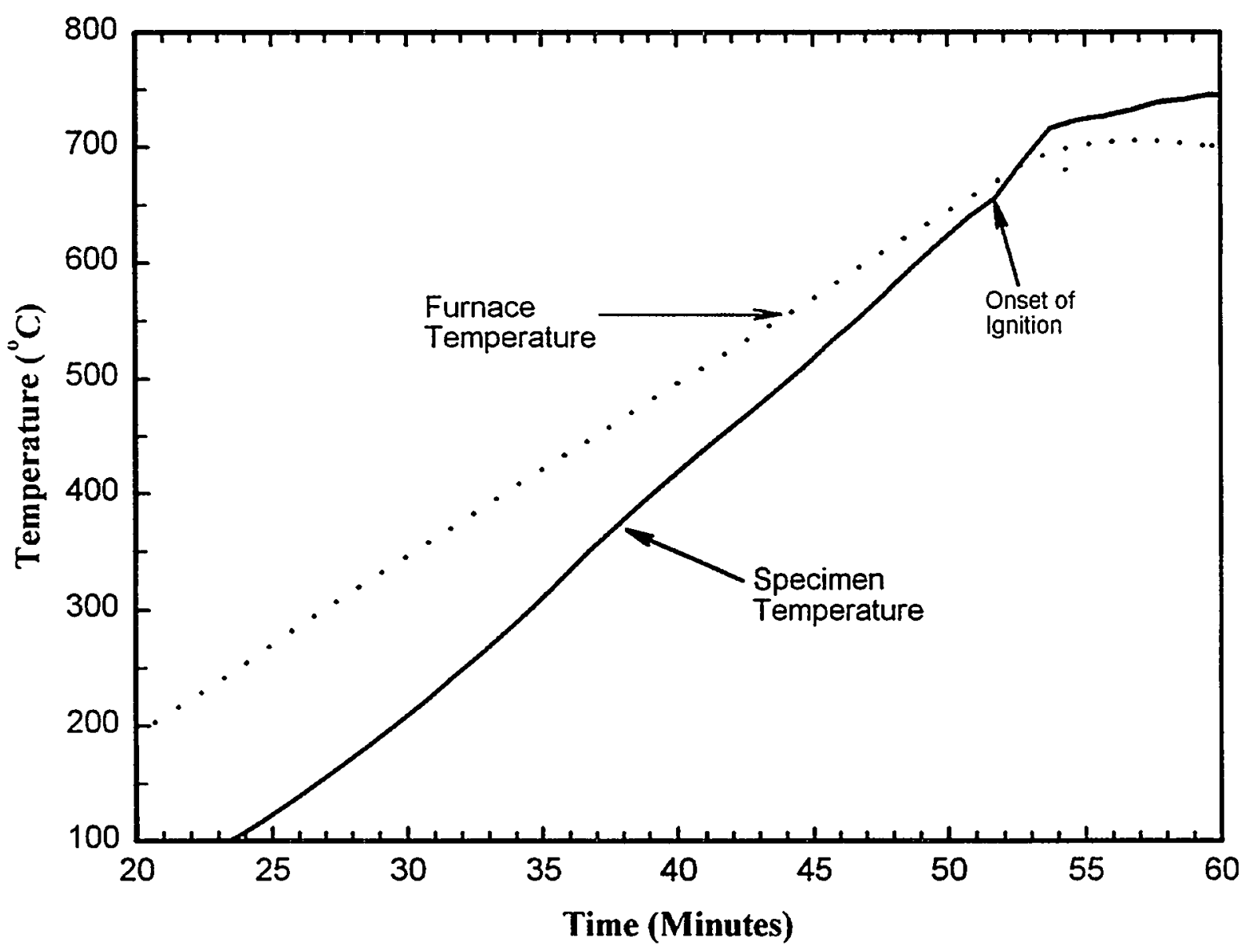

Figure 4.1. Ignition Results of As-Cut, Undamaged SNF Sample 5-S2-E4A 


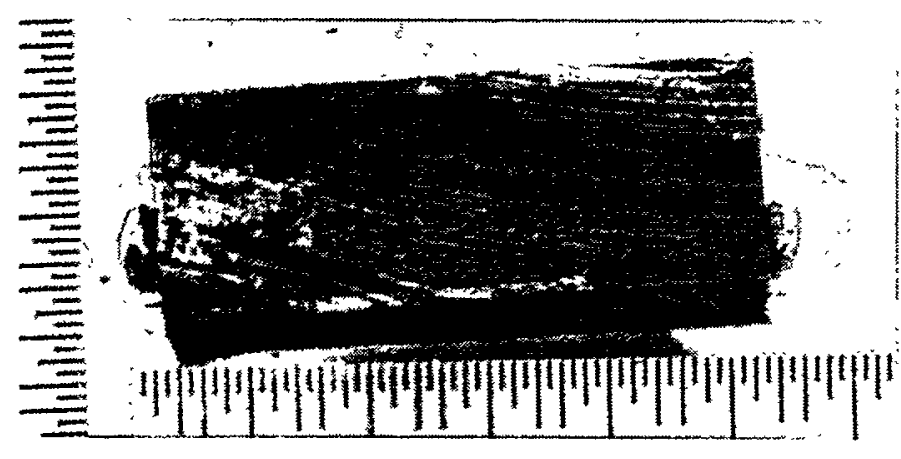

Before Test

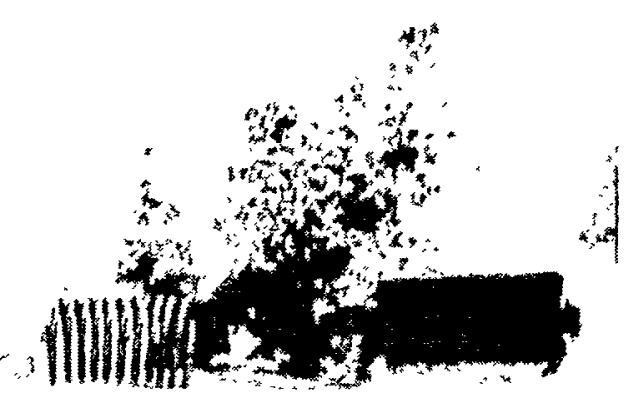

After Test

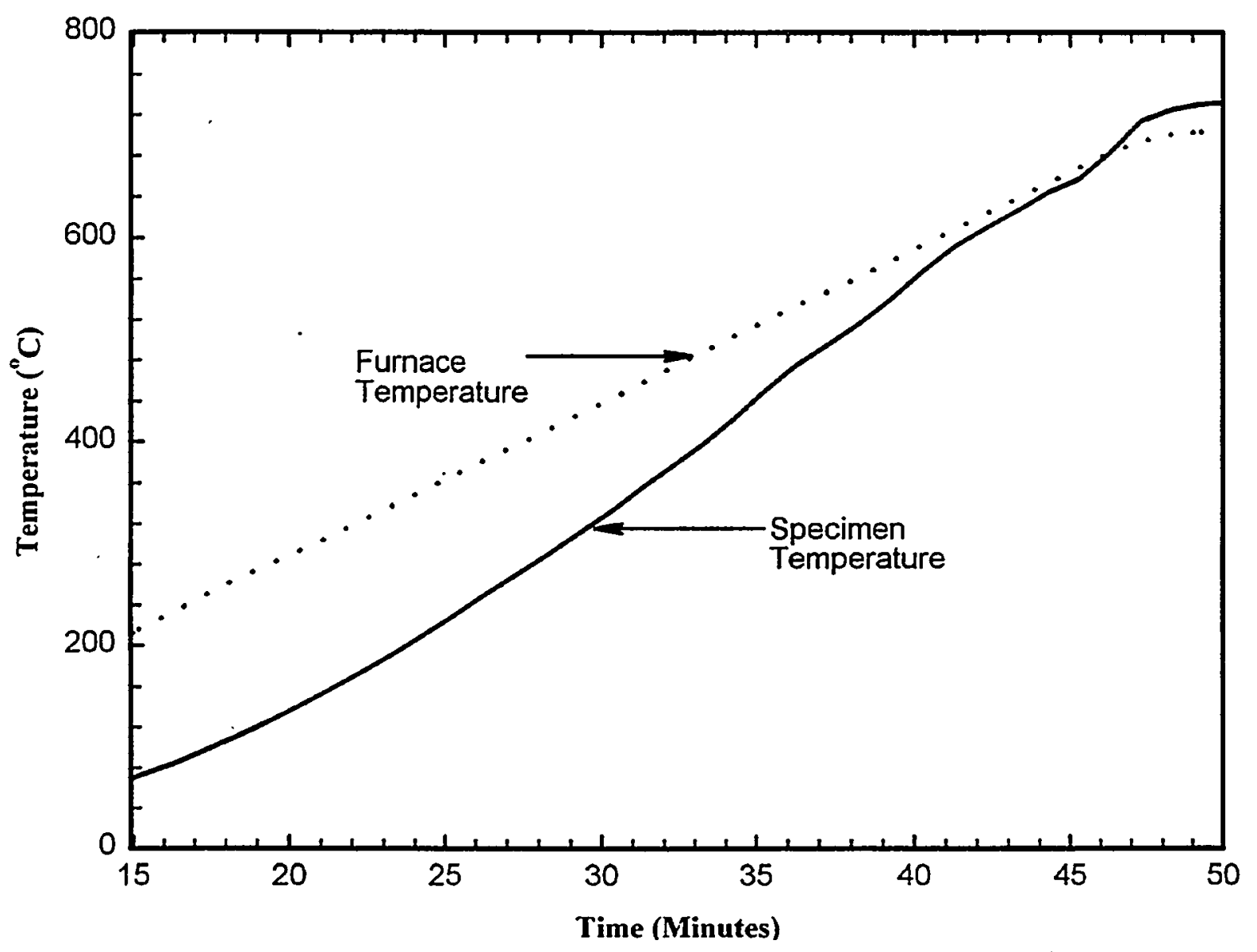

Figure 4.2. Ignition Results of Conditioned, Undamaged SNF Sample 5-S2-D

Some of the burning curves for as-cut and conditioned, damaged/corroded SNF samples are shown in Figures 4.3 through 4.7. The before- and after-test photographs of the samples are also shown in these figures. In Figures 4.3, 4.4, 4.6, and 4.7, the specimen temperature profiles indicate an ignition event resulting in a sudden increase in the temperature of the samples. The ignition event is supported by the 


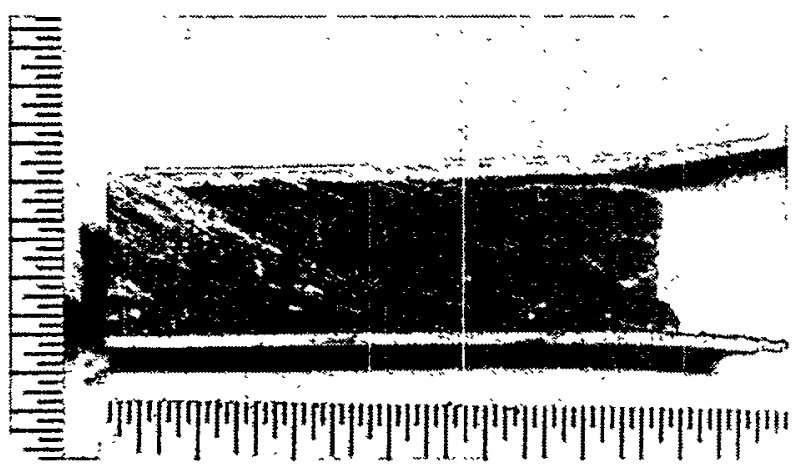

Before Test

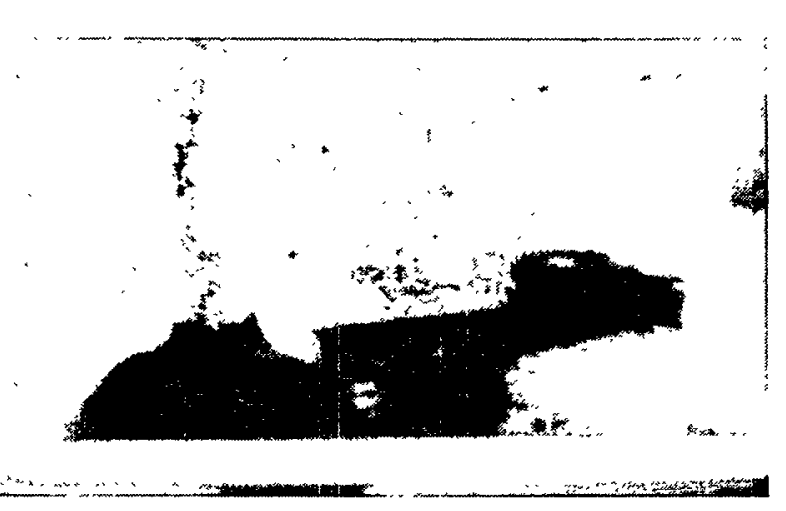

After Test

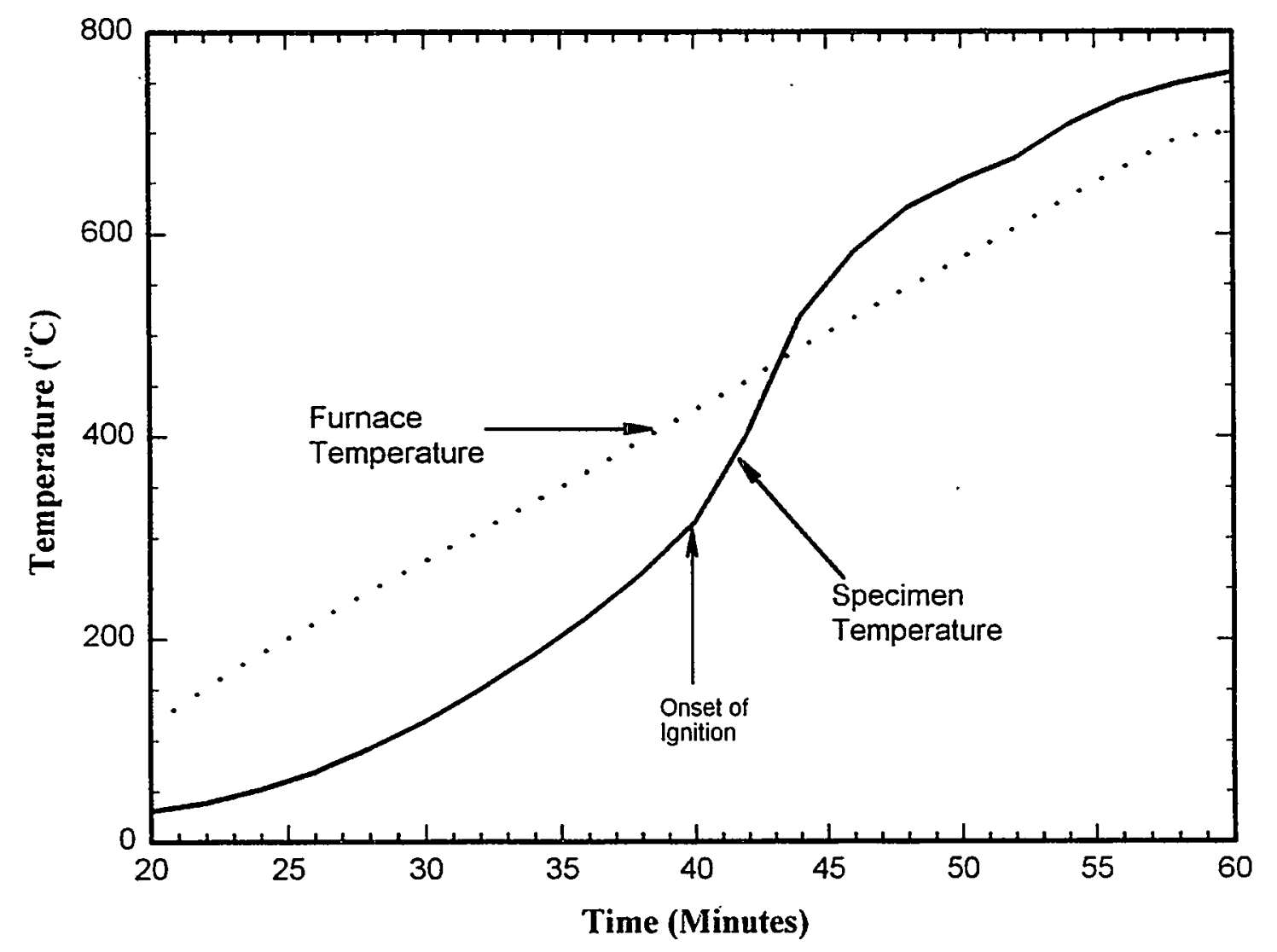

Figure 4.3. Ignition Results of As-Cut, Damaged/Corroded SNF Sample 5-S1A-D 


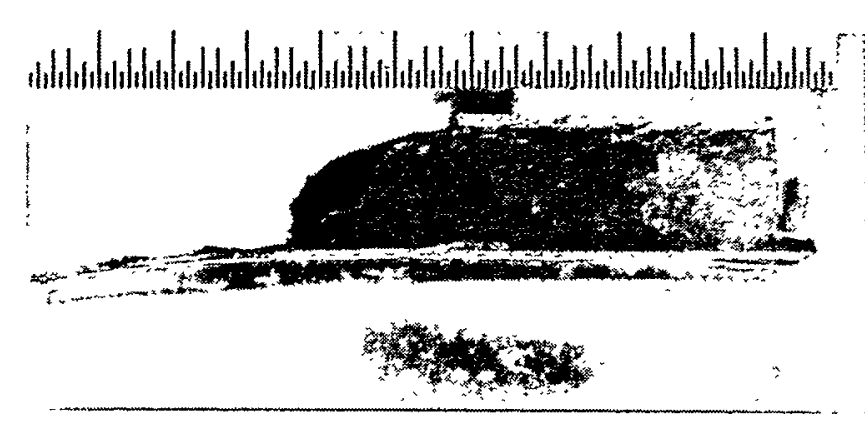

Before Test

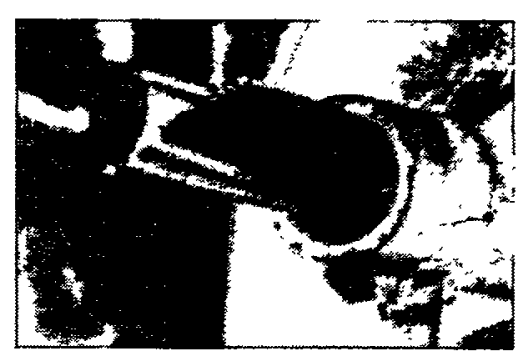

After Test

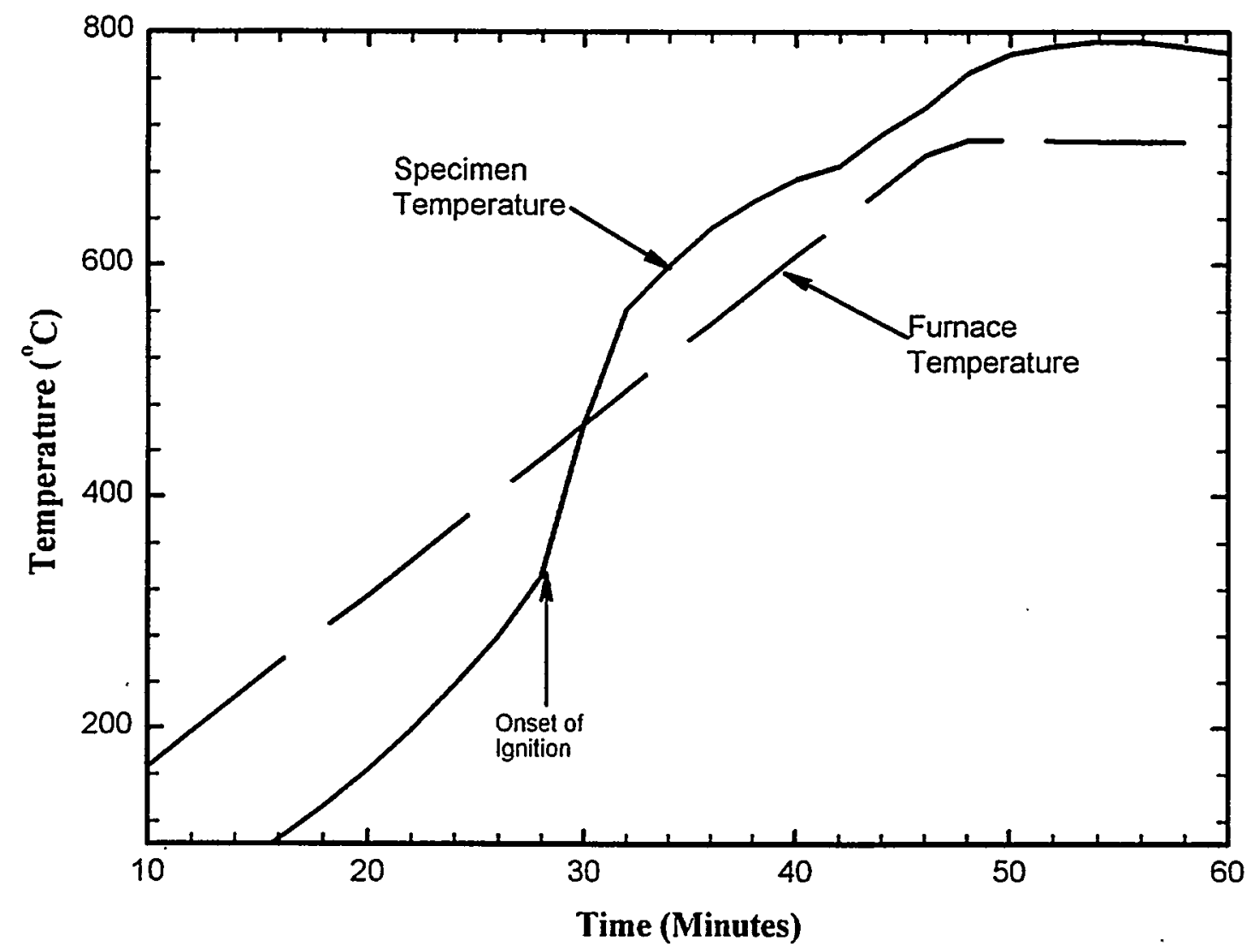

Figure 4.4. Ignition Results of As-Cut, Damaged/Corroded SNF Sample 5-S1A-H 


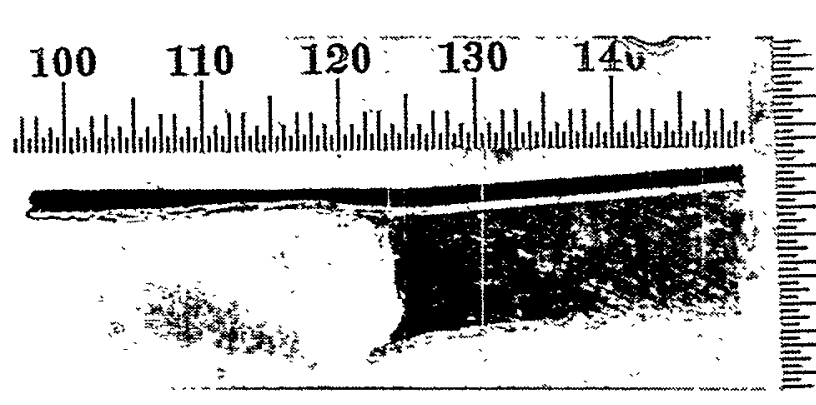

Before Test

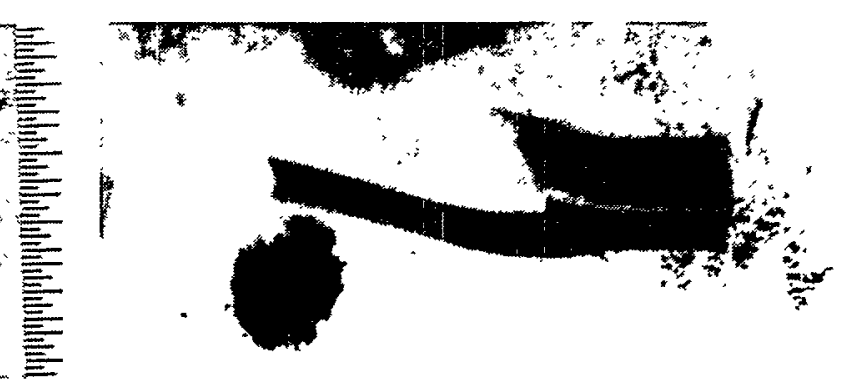

After Test

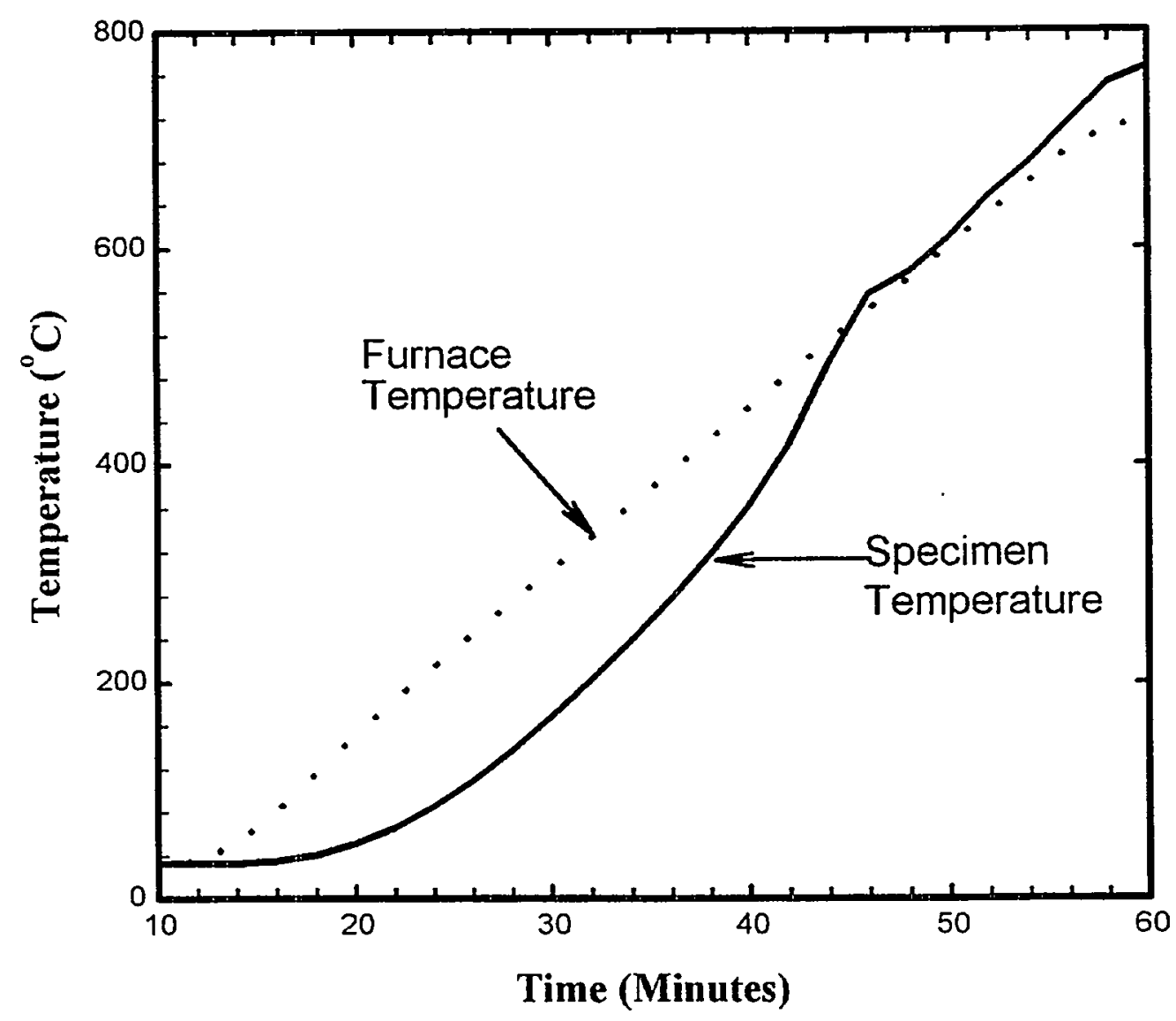

Figure 4.5. Ignition Results of Conditioned, Damaged/Corroded SNF Sample 5-S1A-G 


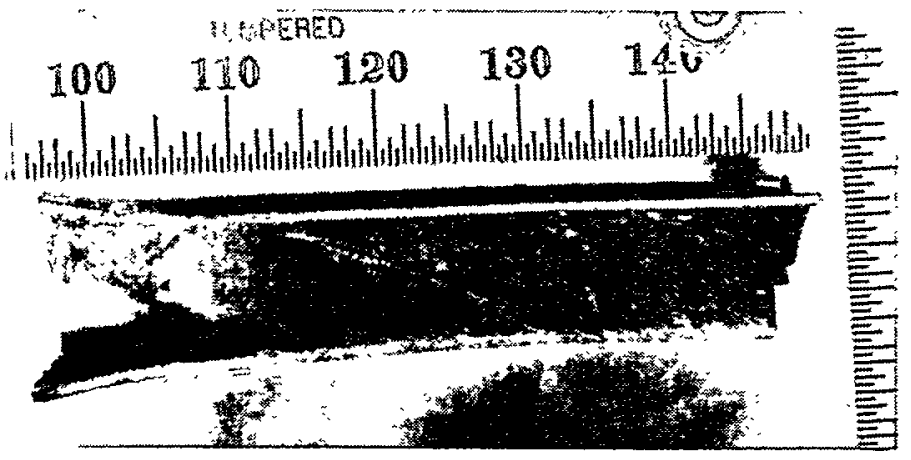

Before Test

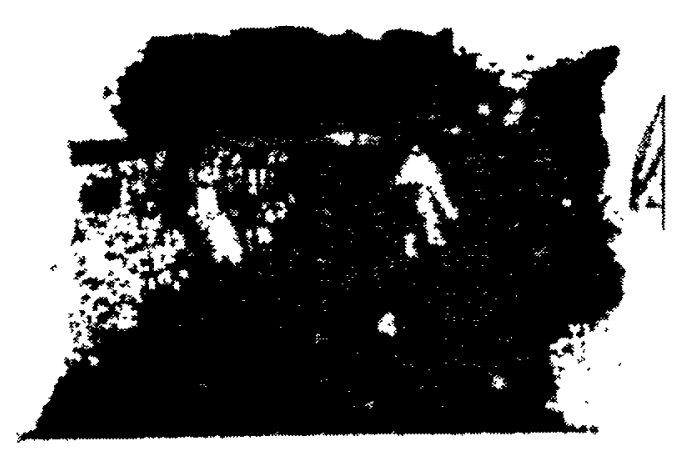

After Test

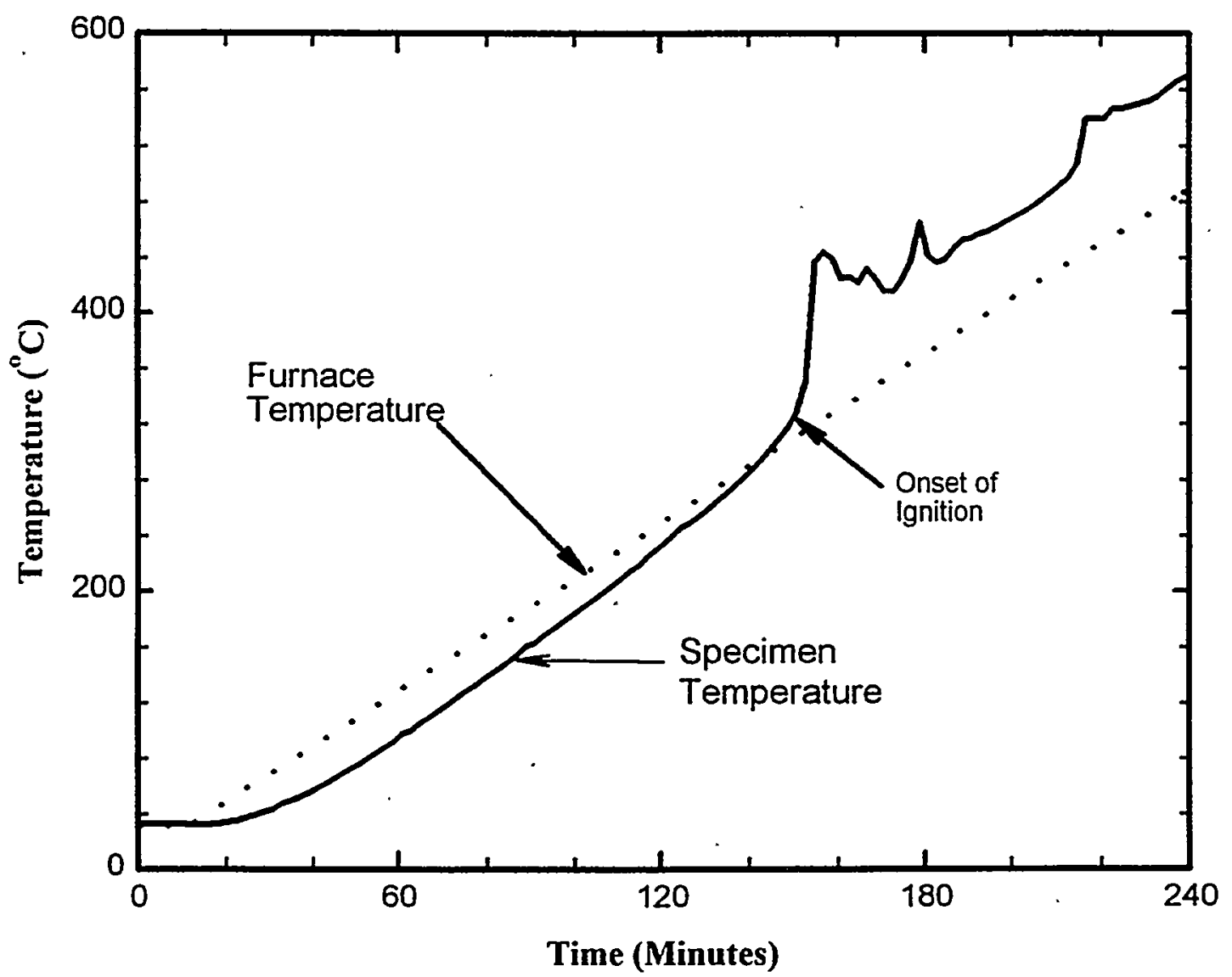

Figure 4.6. Ignition Results of Conditioned, Damaged/Corroded SNF Sample 5-S1A 

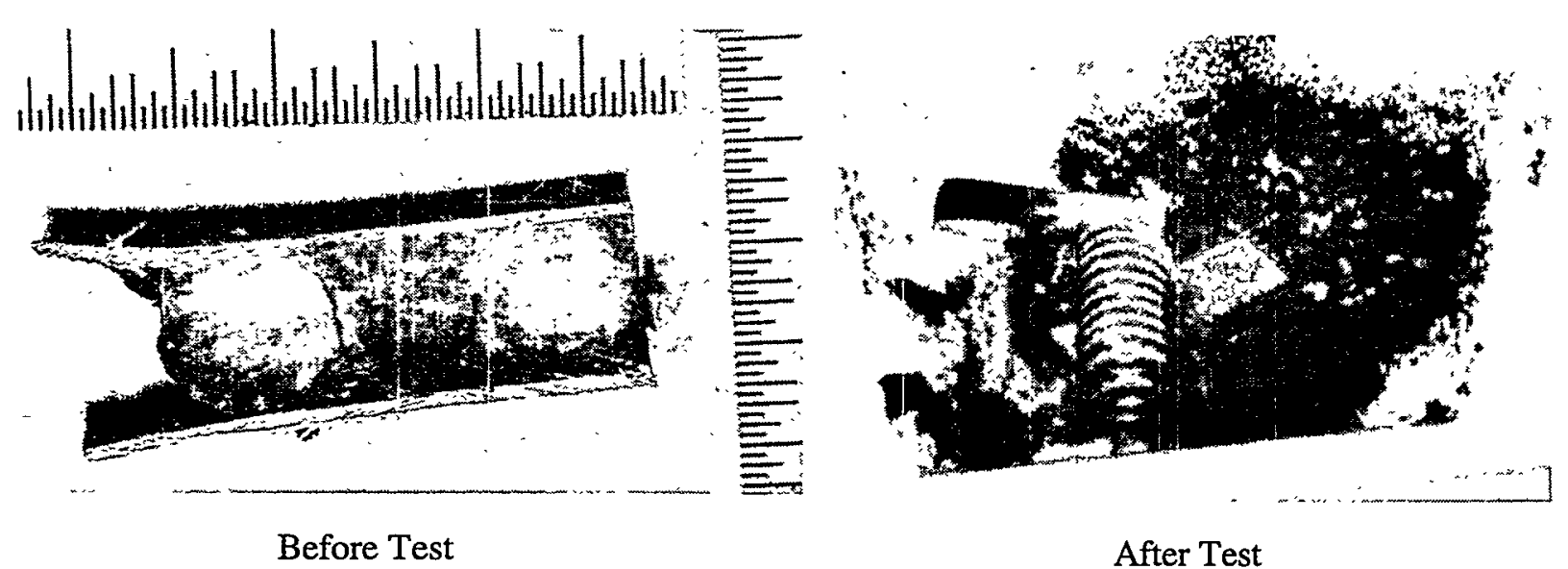

After Test

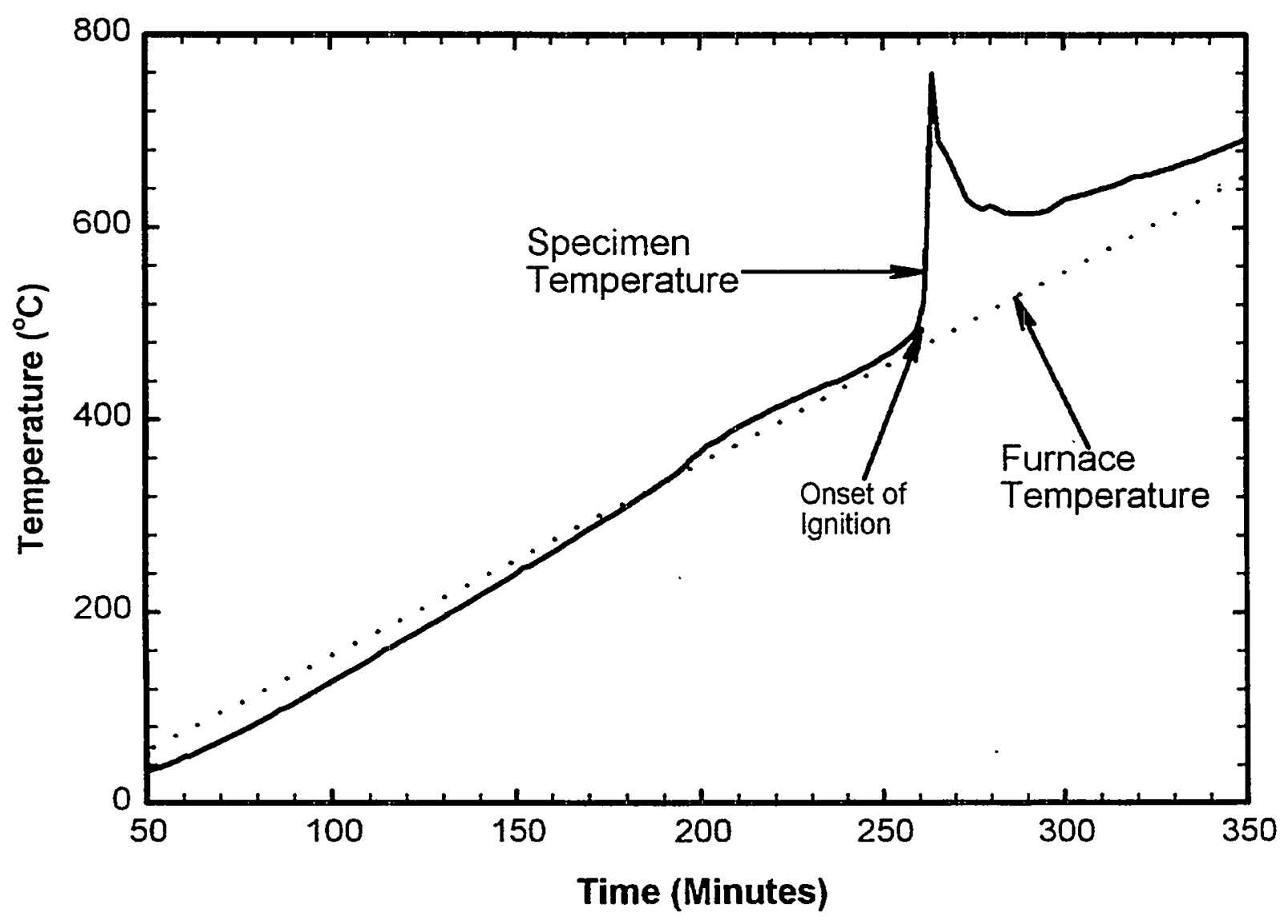

Figure 4.7. Ignition Results of Conditioned, Damaged/Corroded SNF Sample 5-S1A-B1 
after-test photographs of the test samples, which show complete oxidation and rubbleization of the SNF pieces. Generally, the ignition events for these damaged/corroded SNF samples occurred at temperatures lower than those for the undamaged samples in Figures 4.1 and 4.2. The ignition event for Figures 4.3 and 4.4 for as-cut samples 5-S1A-D (Figure 4.3) and 5-S1A-H (Figure 4.4) occurred at temperatures below $300^{\circ} \mathrm{C}$. For the conditioned samples, 5-S1A-I (Figure 4.6) and 5-S1A-B1 (Figure 4.7), ignition events occurred at temperatures below $400^{\circ} \mathrm{C}$ and $500^{\circ} \mathrm{C}$, respectively. The estimated ignition temperatures listed in Table 4.1 for all these runs are discussed in Section 4.3.

In Figure 4.5, the specimen temperature profile does not show a well-defined sudden change in slope. This is a case where the damaged SNF experienced a rapid oxidation event, but the heat generated did not increase the remaining sample temperature to a point of ignition. The after-test photograph shows the rapid oxidation initiated at the damaged/corroded surface of the sample.

The complete set of the burning curves for all 17 ignition tests is shown in Appendix B. Alsa shown are the data for the moisture content and the hydrogen in the offgas stream during these ignition tests. The hydrogen concentration in the offgas stream for the damaged/corroded SNF samples that ignited (Figures B.12 and B.30) were significantly higher than those that showed a rapid oxidation behavior.

\subsection{SNF Specific Area}

The ignition of a solid metallic fuel such as the samples used in these tests is closely related to their surface-area-to-mass ratios $(S=A / M)$. Dimensions of the specimens (Figure 3.6) taken before the ignition test was performed are given in Appendix A for all samples tested.

The specific area of each ignition test sample can be calculated from the specimen dimensions given in Appendix A. The specific areas of the samples cut from the undamaged section of the fuel elements are easily computed from the specimen dimensions and are listed in Table 4.2. For samples cut either from corroded or broken ends of the fuel elements, the specific area is difficult to estimate because of cracks and roughness of the damaged surface. If the sample were cut from the damaged end of the fuel element, the surface area value estimated from the specimen dimensions could be much smaller than that of the actual corroded surface portion of the sample.

Table 4.2. Specific Surface Area of Undamaged SNF

\begin{tabular}{|c|l|c|c|c|c|}
\hline Run & $\begin{array}{c}\text { Sample } \\
\mathbf{W}\end{array}$ & $\begin{array}{c}\text { Surface Area } \\
\left(\mathbf{c m}^{\mathbf{2}}\right)\end{array}$ & $\begin{array}{c}\text { Mass } \\
(\mathbf{g})\end{array}$ & $\begin{array}{c}\text { Specific Area } \\
\left(\mathbf{c m}^{\mathbf{2}} \mathbf{g}\right)\end{array}$ & $\begin{array}{c}\text { Ignition Temp. } \\
(\mathbf{}\end{array}$ \\
\hline 11 & 5-S2-E3A & 3.77 & 14.70 & 0.26 & 640 \\
\hline 12 & 5-S2-E4A & 3.09 & 9.41 & 0.33 & 640 \\
\hline 13 & 5-S2-H & 5.97 & 28.57 & 0.21 & 670 \\
\hline 14 & 5-S2-D & 6.04 & 28.79 & 0.21 & 650 \\
\hline 15 & 5-S2-I & 6.46 & 37.27 & 0.17 & 650 \\
\hline
\end{tabular}




\subsection{SNF Ignition Temperature}

The typical temperature-time trace obtained from the ignition test is called a "burning curve." Ignition was apparent when the slope of the burning curve was observed to increase abruptly (Figure 3.7). The burning curves for all ignition samples tested are given in Appendix B. Some of the SNF burning curves, such as Runs 13 through 15 for Element 4378 and Runs 29 through 33 for Element 4366, do not display a sudden change in their heating rates, making it difficult to ascertain the ignition temperature. For these cases, the temperature ranges where the samples underwent rapid oxidation were estimated. The observed slow change in the sample temperature might partly be due to loose contact of the thermocouple with the sample at the stage of the test when the ignition event started. The other burning curves (Figures 4.3, 4.4, 4.6, 4.7, B.29, and B.31) showed a well-defined sudden change in the slope of the temperature at the point of ignition.

The ignition temperatures for all the burning curves were determined graphically, as indicated in Figure 3.7. However, a second approach was used to improve on the consistency of the ignition point estimate. This approach involved differentiating the temperature-time curves for both sample and furnace to determine the maximum heating rates; the ignition temperature or the temperature for the onset of rapid oxidation may be determined by comparing the maximum heating rate of the sample to that of the furnace. If the maximum heating rate of the sample is much larger than that of the furnace, the ignition point is readily determined; otherwise, the heating rate comparison provides information for the onset of rapid oxidation. However, with this method, the derivatives of a few points subject to normal data scatter may be too erratic; if more points are used to reduce data error, then the result is likely to differ little from the entire burning curve, which is fairly straight. Because of this difficulty, a temperature range has been estimated for the onset of rapid oxidation for samples tested in Runs 29 through 33.

The ignition temperatures of Element 4378 samples are relatively well defined; however, most of the samples cut from Element 4366 do not show distinct inflection points in their burning curves. Thus, the ignition temperatures were not clearly defined for these tests, as seen in Figures B.21, B.23, B.26, and B.28 in Appendix B (Runs 29, 30, 32, and 33). The ignition temperatures of these specimens are to be considered as points of rapid oxidation and were estimated to be in the range of $400^{\circ} \mathrm{C}$ to $500^{\circ} \mathrm{C}$. As Table 4.1 shows, the test results indicate that the conditioning process does not increase the ignition/rapid oxidation temperature for the broken fuel; the conditioned samples of Run 36 and Run 39 even ignited at temperatures lower than the as-cut samples. The results of the ignition tests are summarized below.

- The ignition temperature of undamaged bulk material is much higher than that of damaged material and is in agreement with the temperature predicted by the theory of burning curve ignition for unirradiated, undamaged uranium.

- The corroded K-West SNF ignites at a temperature as low as $277^{\circ} \mathrm{C}$ because of the corroded, rough surface that can increase the specific area (Figure 4.8) and because uranium hydride inclusions were present.

- Ignition of the corroded SNF samples was initiated at the corroded surfaces. 
- Conditioning increases the ignition temperature of corroded $\mathrm{SNF}$ by $130^{\circ} \mathrm{C}$ to $200^{\circ} \mathrm{C}$, as shown by testing performed on the four specimens in Runs 17, 19,22, and 24. Although they were not identical, the specimens were cut from the same corroded end of Element 4378 , and their surface features appear to be similar.

- Results of Run 26 (Figure B.19) provide evidence that drying without the oxidation step can affect the pyrophoric potential for uranium fuel. The specimen was dried at a high temperature in vacuum but was not oxidized; it ignited at a temperature much lower than the conditioned samples.

- The ignition temperature of broken fuel is lower than that of undamaged fuel but higher than that of corroded fuel. The broken or "sheared" surfaces of the samples are not as rough as the corroded surfaces (Figure 3.1). Specific area is the key factor for this difference, although the unknown influence of the hydride cannot be discounted.

- The ignition temperatures of a few samples sectioned from the broken fuel element and tested in Runs 29, 30,32, and 33 are not clearly defined; as a result, the effects of conditioning on these samples cannot be determined with confidence.

- In some instances, pyrophoric properties of broken fuel may remain despite conditioning. In Run 36, which has a well-defined ignition temperature, the conditioned specimen ignited at a temperature lower than that of as-cut specimens and released a large amount of hydrogen at ignition. The hydrogen release shows that conditioning did little to decompose hydrides in occluded areas of this sample.

The possibility that the ignition temperatures of the conditioned specimens were higher than those of the unconditioned specimens (suggesting that conditioning did actually lead to the increase in ignition temperature for the conditioned specimens) can be shown by comparing the ignition data for the damaged/corroded SNF samples with well-defined ignition events. Of the two unconditioned specimens, 5-S1A-D (Figure 4.3) ignited at about $278^{\circ} \mathrm{C}$ and 5-S1A-H (Figure 4.4) ignited at about $277^{\circ} \mathrm{C}$. These ignition temperatures are lower than those for conditioned samples 5-S1A-I (Figure 4.6) and 5-S1A-B1 (Figure 4.7) that ignited at $310^{\circ} \mathrm{C}$ and $450^{\circ} \mathrm{C}$, respectively, thus indicating the proposed conditioning process is capable of raising ignition temperature. From the ignition temperature data listed in Table 4.1, the effects of conditioning on fuel ignition are summarized in Table 4.3.

Table 4.3. Effects of Conditioning on Fuel Ignition Temperatures

\begin{tabular}{|c|c|c|c|}
\hline Fuel & State & $\begin{array}{c}\text { Bulk Material } \\
\left(\mathrm{T}_{\mathrm{i}},{ }^{\circ} \mathrm{C}\right)\end{array}$ & $\begin{array}{l}\text { Corroded/Broken } \\
\text { Material }\left(\mathrm{T}_{\mathrm{i}},{ }^{\circ} \mathrm{C}\right)\end{array}$ \\
\hline \multirow{2}{*}{$\begin{array}{l}\text { Element } 4378 \\
\text { (Corroded) }\end{array}$} & Unconditioned & 640 & 277 \\
\hline & Conditioned & $650-670$ & $400-485$ \\
\hline \multirow{2}{*}{$\begin{array}{l}\text { Element } 4366 \\
\text { (Broken) }\end{array}$} & Unconditioned & -- & $400-500$ \\
\hline & Conditioned & -- & $400-500^{(a)}$ \\
\hline
\end{tabular}




\subsection{Hydrogen and Moisture in the Offgas}

Results of the hydrogen release detected by the GC and moisture traces by the moisture probe in the offgas stream are given in Appendix B. The hydrogen data indicate there was a hydrogen release from the sample when the sample heating rate exceeded the furnace heating rate. There are two main sources of hydrogen; the first being the product of water reaction with the uranium and the second originating from probable thermal decomposition of uranium hydride inclusions in the sample (Figure 4.8). Since the observed hydrogen release occurred before, at, or after ignition, and the quantity of hydrogen release in each test varies significantly, most of the hydrogen may have resulted from a moisture reaction with the SNF sample. The level of moisture concentration in the gas stream during the test was uncontrolled and was dependent on the in-leakage of the atmospheric air in the furnace. Most of the hydrogen released by thermal decomposition of uranium hydride may have reacted with excess oxygen in the system to produce water and, hence, would not be detected. If hydrogen from the water reaction was the main source, then an increase in its concentration in the gas stream may be the signature for increased reactivity of the sample. This may explain the observed high concentration of hydrogen during the ignition and/or rapid oxidation points of these tests.

\subsection{Metallography}

Because the samples were tested with the cladding intact, it was important the cladding not be separated so that the total reactive metal surface remain unchanged during the drying and conditioning. The bonding between cladding and fuel in the conditioned sample was examined metallographically as shown in Figure 4.9. The boundary remained sound, and no material degradation or porosity is visible from the micrograph. Metallography was also performed on the conditioned specimens to examine the oxide film (Figure 3.4) and uranium hydride (Figure 4.10). The oxide film formed by the oxidation in $2 \%$ oxygen at $250^{\circ} \mathrm{C}$ during the conditioning process does not appear to be continuous or uniform; in some areas the film spalled from the substrate (Abrefah et al. 1996). As to hydride inclusions, the micrograph shows that some of the dark structures around the carbide precipitates could be either hydride phase or voids. The hydride in the fuel matrix was generated through the reaction of uranium with hydrogen during storage. Evidently, it was not removed completely during the drying process. Information on the quantitative reduction of hydride by the drying and conditioning process is not available from these limited examinations. 

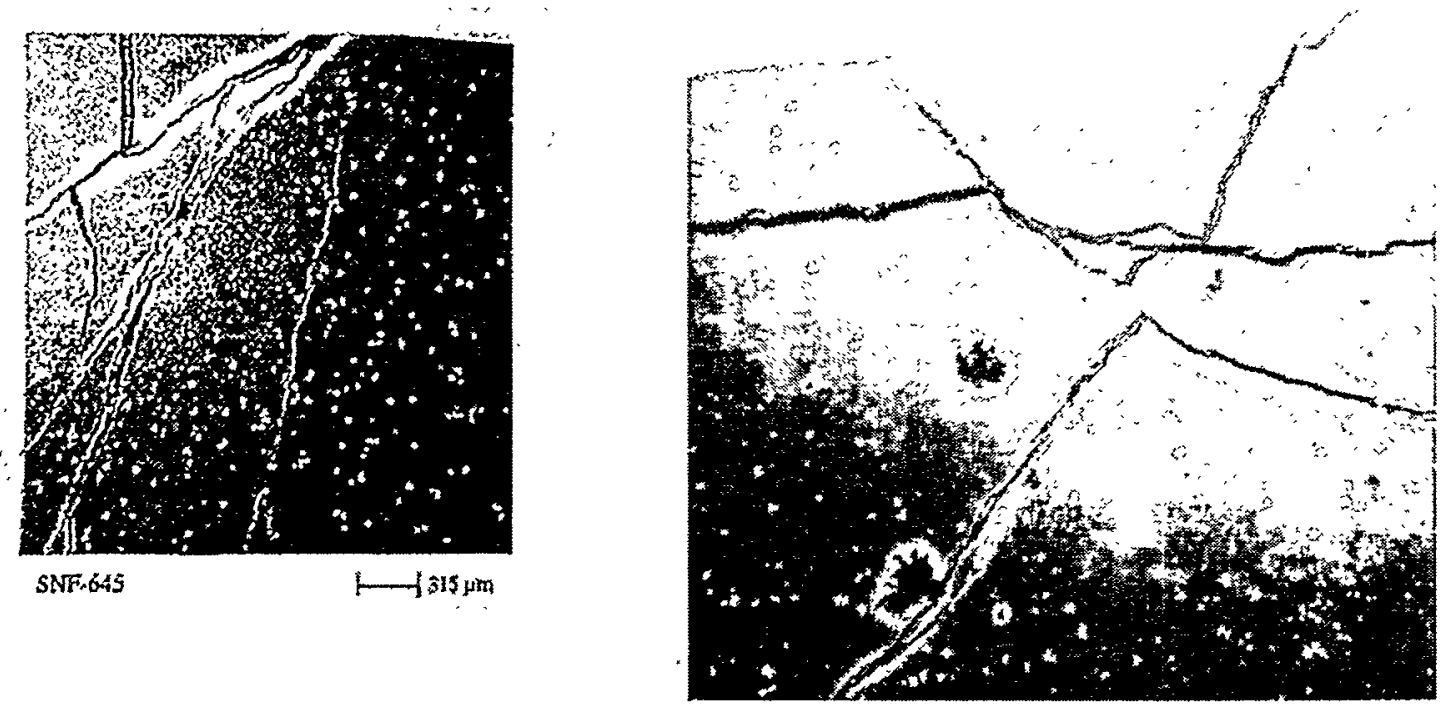

Figure 4.8. Uranium Hydride Inclusions in the Damaged/Corroded Region of SNF Element 4378

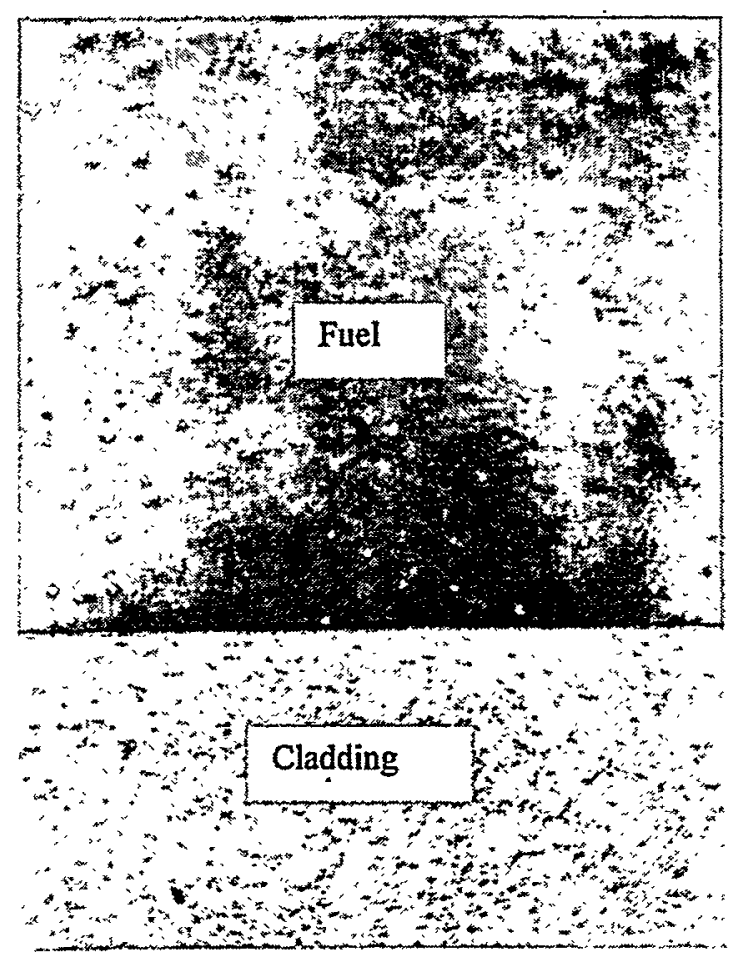

Figure 4.9. Inner Cladding/Fuel Boundary of Polished, Conditioned Specimen SFEC5,4378-S2-B in the Longitudinal Plane; 50X 


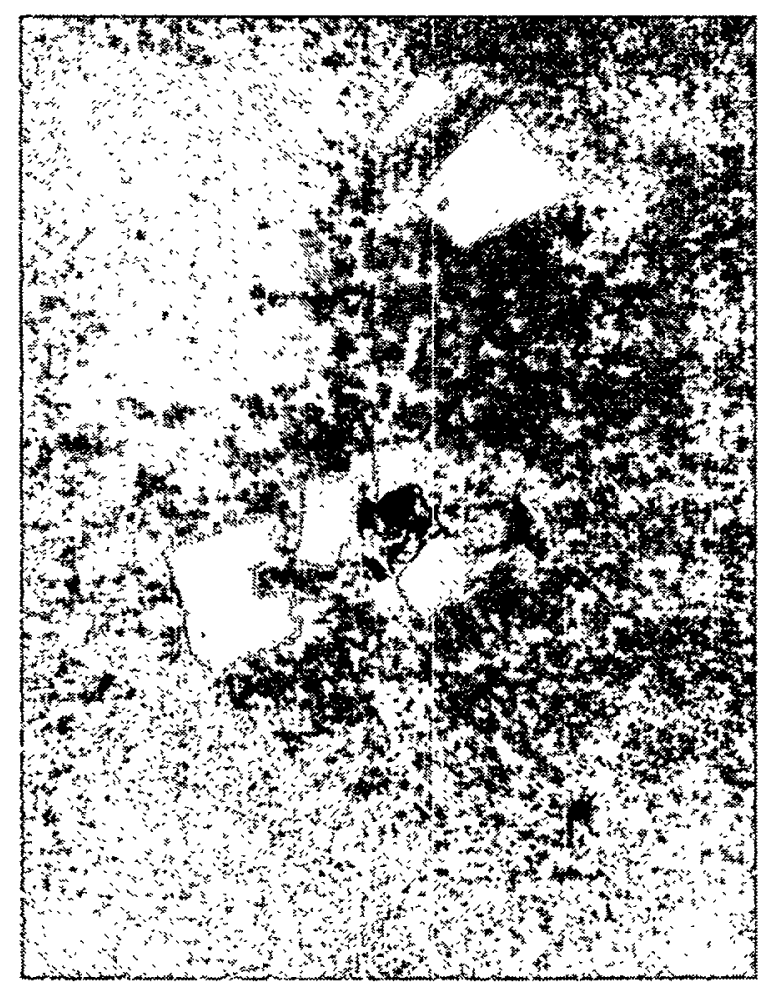

Figure 4.10. Micrograph of Conditioned Specimen SFEC5,4378-S2-J1 in the Transverse Plane Showing Probable Uranium Hydride Phase and Uranium Carbide Precipitates 


\subsection{Discussion}

Ignition tests were performed to determine the pyrophoric behavior of the damaged/corroded $\mathrm{N}$-Reactor fuel elements stored in the K-Basins. The results of these tests will be used in support of a proposal that will prevent potential ignition events during the handling and conditioning of damaged/ corroded uranium fuels. The ignition behaviors of 17 specimens cut from two K-West fuel elements were determined and the resulting data analyzed below in terms of a balance of heat losses and heat generated by oxidation of the metal.

\subsection{Ignition Behavior of SNF}

Ignition analysis as seen in Equation (2.5) shows the ignition temperature of metallic uranium is affected by surface areas, oxidation rates, and oxide mass on the metal surface. If the oxidation conditions are maintained for different ignition tests, the specific area (S) becomes the most important variable in the metal ignition temperature.

The specific areas of the undamaged samples of Element 4378 were estimated to be in the range of $0.17 \mathrm{~cm}^{2}$ to $0.33 \mathrm{~cm}^{2} / \mathrm{g}$ (Table 4.2), and the precise ignition temperatures found to be between $640^{\circ} \mathrm{C}$ and $670^{\circ} \mathrm{C}$. The results for the undamaged SNF samples are represented by solid triangles in Figure 5.1 and are comparable to the data reported in Baker et al. (1966). The good agreement of the undamaged SNF ignition temperature data with Baker et al. (1966) supports the assertion that even for cases when the burning curves for the $\mathrm{N}$-Reactor samples did not show the dramatic temperature increase, the estimated ignition temperature is a very good measurement. Effects of pre-oxidation are investigated by conditioning the sample through the process noted in Section 3.1: high-temperature drying plus exposure to $2 \%$ oxygen at $250^{\circ} \mathrm{C}$ for 11 hours. As shown in Table 4.2 , conditioning changes the ignition temperature of samples cut from bulk material insignificantly. Although oxide layers can passivate the hydrides on the metal surface, they do little to substantially change the pyrophoric behavior of the "undamaged" large samples. On the other hand, damaged fuel provides a larger surface area and therefore has a higher potential to ignite.

The specific area of corroded sample SFEC5,4378-S1A-D is difficult to estimate; a portion of the corroded sample has cracks or protrusions with very large $S$ values, as shown in Figures 4.3, 4.6, and 4.7. Once ignition starts in these areas, the whole fuel sample may burn. From Figure 5.1, the specific area in these corroded portions should be larger than $100 \mathrm{~cm}^{2} / \mathrm{g}$ (350 times larger than those of the intact/ undamaged specimen) for fuel fragments to ignite at $278^{\circ} \mathrm{C}$. The large $\mathrm{S}$ values in the corroded sample may be decreased by conditioning, resulting in a higher ignition temperature. Tests comparing the conditioned with unconditioned corroded samples of Element 4378 proved that conditioning can increase the ignition temperature $130^{\circ} \mathrm{C}$ to $200^{\circ} \mathrm{C}$ for corroded fuel.

The potential for the broken fuel to ignite was found to be lower than the corroded fuel mainly because it has a less-irregular surface where hydride is formed. With ignition temperatures in a range of $400^{\circ} \mathrm{C}$ to $500^{\circ} \mathrm{C}$, the $\mathrm{S}$ values should be in the range of 1.5 to $4 \mathrm{~cm}^{2} / \mathrm{g}$ (or fragment sizes on the order of 


\section{Temperature (K)}

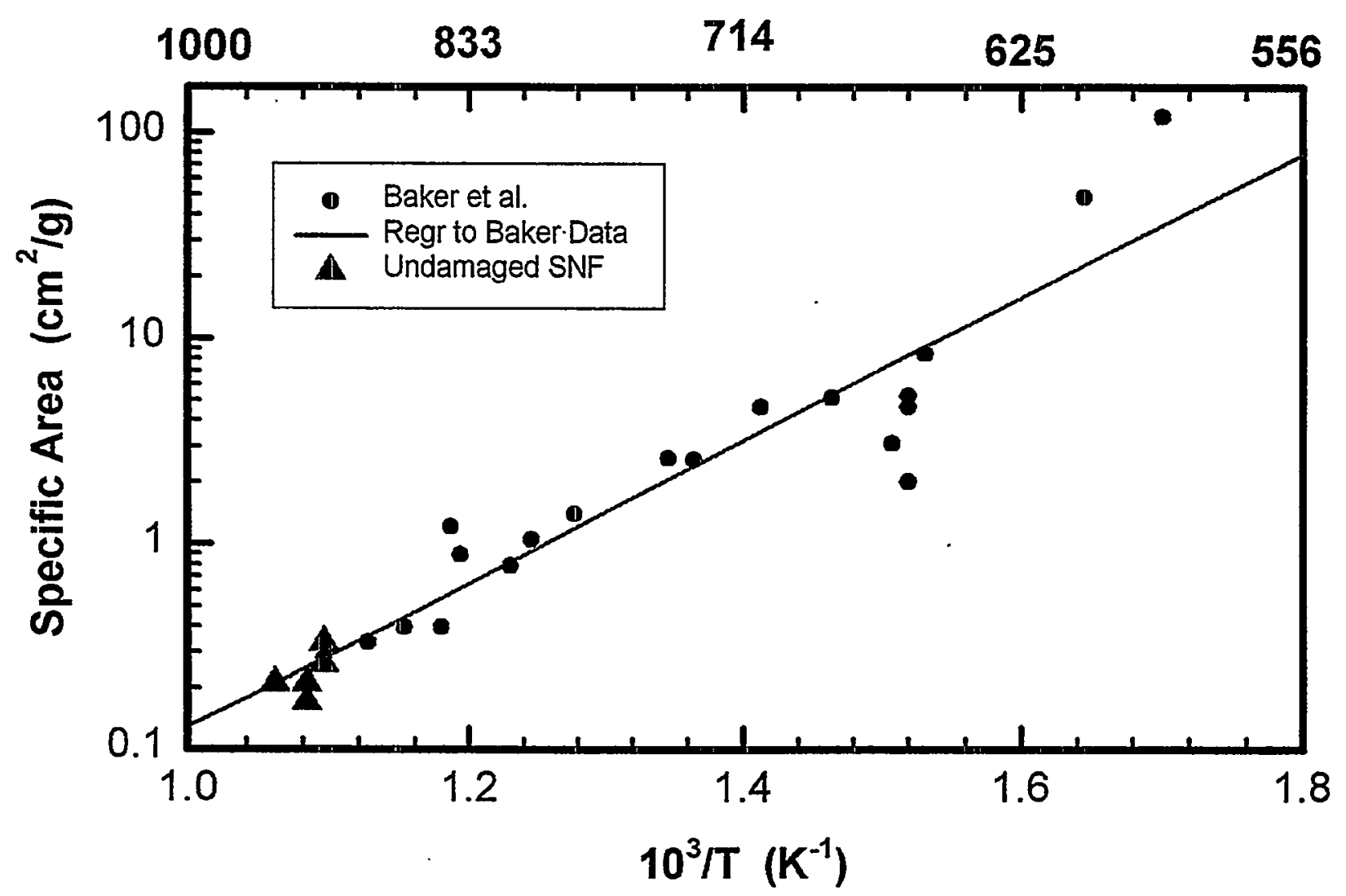

Figure 5.1. Dependence of Uranium Ignition Temperature on Specific Area; Comparison of Historic Data (Baker et al. 1966) and Results of Current SNF Tests

about $0.2 \mathrm{~cm}$ ) based on Figure 5.1. Hydride is unstable in contact with water and oxygen. It exists only in occluded areas in the metal or oxide; thus, the broken fuel does not have as much hydride for combustion. This explanation is supported by the ignition tests showing a lower hydrogen release from Element 4366 (broken fuel) than from Element 4378 (corroded fuel).

A few samples cut from Element 4366 do not show a sudden change in slope in their burning curves. The ignition temperatures of these samples are difficult to determine, as mentioned previously. With a large uncertainty in ignition temperature, it is difficult to conclude that conditioning benefits the broken fuel element, Element 4366. Results of the estimated ignition temperature for samples cut from Element 4366 indicate the ignition temperature is slightly lower than that of bulk material and conditioning does little to increase the ignition temperature.

Contrary to what was expected, the as-cut sample in the test on Run 37 (taken from broken Element 4366) ignited at a higher temperature than the conditioned Run 39 sample, which was taken from a location directly adjacent to the location of the Run 37 sample (see Table 4.1). The conditioning 
process is expected to decompose uranium hydride and oxidize small fuel fragments, which are the contributors to high specific area; after conditioning, the specific area of the sample should be reduced and the ignition temperature should increase. However, the specimen tested in Run 39 did not perform as expected; the possible explanation is that after the Run 39 sample was conditioned, there were still more damaged surfaces. with larger specific areas or there were some hydride inclusions left behind.

\subsection{Application of Ignition Test Results}

The furnace test data provide useful information to identify safety issues on the potential for K-Basin SNF combustion during transportation or staging. However, the thermal ignition temperature measured in the test furnace should be used cautiously because the heat environment in the furnace is different from the MCO environment. The heat transfer process in the MCO is more complicated; it varies with the fuel element configuration in the container and the storage modes for the fuel. Initiation of ignition essentially depends on specific area, but the ignition temperature of multi-uranium pieces in an actual fuel container may not be certain. Previous experiments by Baker et al. (1966) have shown that the ignition temperatures of foil stacks are considerably lower than those of individual foils with the same specific area. A single foil will lose heat by radiation and convection from both faces, but two foils stacked together have relatively fewer surfaces available for heat loss than those for reaction (i.e., a larger effective specific area) and therefore ignite at a lower temperature. In the same experiments, an ignition test was performed on a sample of $0.25 \times 10 \times 10 \mathrm{~mm}$ foil, which was placed on top of a uranium cube $8.5 \mathrm{~mm}$ across. The foil ignited at the same temperature of $400^{\circ} \mathrm{C}$ as if it were alone, then burned the 25-times larger cube. The ignition temperature of a cube this size is $650^{\circ} \mathrm{C}$; apparently, it could not dissipate the heat generated by the ignition of the foil and ignited at a much lower temperature. A large fuel piece has a large capacity to conduct the surface-burning heat away and resists ignition on its own if the fire caused by the small fuel fragments is not sustainable.

The corroded fuel was shown to ignite at temperatures lower than the conditioning temperatures; as a safety precaution, the fuel must be dried and conditioned in a vacuum. As the fuel is heated to $300^{\circ} \mathrm{C}$ for conditioning in an $\mathrm{MCO}$, it becomes vulnerable to ignition if air is introduced accidentally.

The justification for postulating that conditioning increases the ignition temperature of corroded fuel is based on the following thermal ignition test results:

- The corroded surface profiles of the unconditioned and conditioned specimens that were cut from the same end of Element 4378 are similar, as shown in Figures 4.3 through 4.7; the initial ignition temperatures of these respective specimens should be and were about the same. Therefore, the increase in ignition temperature for the conditioned specimens as compared to the unconditioned specimens is attributed to the conditioning process. 
- Incomplete conditioning increases ignition temperature only a fraction of the ignition temperature increase that results from complete conditioning. Run 26 (SFEC5,4378-S1A-I) provides evidence for the effects of conditioning on ignition behavior. The specimen was dried in vacuum at a high temperature but was not passivated; its ignition temperature increased by $30^{\circ} \mathrm{C}$, while the conditioned specimens ignited at a temperature $150^{\circ} \mathrm{C}$ higher than the pre-conditioned temperature.

- Conditioning is shown to reduce pyrophoric potential for the fuel with rough surfaces more than it does for fuel with smooth surfaces. In the conditioning process, all exposed surfaces oxidize at the same rate per unit area and to the same depth for a given period of oxidation time; small fuel fragments would be oxidized completely, while massive pieces would have only a thin oxide layer. Because the corroded fuel has more fragments with large specific areas as compared to the broken fuel, the specific area of the corroded fuel can be reduced more efficiently by oxidation, owing to its smaller size. As the specific area ( $\mathrm{A} / \mathrm{M})$ decreases during the conditioning, the ignition temperature increases. For this reason, conditioning increases the ignition temperature of corroded fuel much more significantly than that of the broken fuel or the undamaged fuel, as seen in Table 4.2. Without conditioning, the specific area of specimens tested in Runs 22 and 24 would not be reduced and the ignition temperature of the specimens would not increase from $300^{\circ} \mathrm{C}$ to $400^{\circ} \mathrm{C}$ or higher.

Thus, the increase in ignition temperature of conditioned specimens cut from corroded fuel is judged to be valid. Uranium corrosion and water radiolysis generate hydrogen, which then forms uranium hydride. Test results have shown that the drying and conditioning process is effective in removing water, decomposing hydride, and oxidizing metallic surfaces to reduce the potential for pyrophoric events. 


\subsection{Conclusions}

Testing was conducted to determine the ignition temperature of actual $\mathrm{K}$-West Basin fuel and the effects of conditioning on fuel combustion behavior. Some uncertainties still exist as to the extent of hydriding, fuel damage, and the reactive metal surfaces. Results of the tests led to the following observations:

- Damaged/corroded K-West SNF samples with uranium fragments and/or uranium hydride inclusions provide large surface areas and, therefore, have a higher potential to ignite. The lowest ignition temperature determined for the damaged/corroded SNF was $277^{\circ} \mathrm{C}$.

- Samples sectioned from the damaged/corroded SNF element exhibited well-defined ignition temperatures, and the initiation of the ignition event was at the corroded surface.

- The IPS conditioning step decreased the pyrophoricity of samples taken from the damaged/corroded SNF element (SFEC5,4378), but had no measurable effect on the ignition characteristics of samples taken from the broken and less corroded SNF element (SFEC10,4366). The ineffective conditioning on the broken SNF samples may be due to an inability to decompose hydrides in occluded areas and/or limited access of oxygen to higher-surface-area uranium particulates.

- Results obtained from unconditioned and conditioned samples of corroded fuel lend support that the fuel conditioning process may reduce the pyrophoric potential of the $\mathrm{K}$-West fuel.

- The data indicated that the extent of damage/corrosion to the SNF sample may be less important in inferring the pyrophoric potential than the generation of highly reactive particulates (metallic uranium and uranium hydride) and their distribution in the sample matrix.

These observations support the conclusion that degradation of the metallic uranium cores has increased the pyrophoricity characteristics of the N-Reactor SNF stored in the K-Basins. 


\subsection{References}

Abrefah, J., W. Gray, G. Ketner, S. Marschman, T. Pyecha, and T. Thornton. 1994. Characterization Plan for Hanford Spent Nuclear Fuel. PNNL-10210, Rev. 0, Pacific Northwest National Laboratory, Richland, Washington.

Abrefah, J., W. Gray, G. Ketner, S. Marschman, T. Pyecha, and T. Thornton. 1996. K-Basin Spent Nuclear Fuel Characterization Data Report II. PNNL-10944, Pacific Northwest National Laboratory, Richland, Washington.

Baker L., and J. Bingle. 1966. "The Kinetics of Oxidation of Uranium Between 300 and $625^{\circ} \mathrm{C}$." Journal of Nuclear Materials 20:11.

Baker, L., J. Schnizlein, and J. Bingle. 1966. "The Ignition of Uranium." Journal of Nuclear Materials 20:22.

Huang, F. H. 1996. "Container Materials in Environments of Corroded Spent Nuclear Fuel." Journal of Nuclear Materials 231:74.

Independent Technical Assessment (ITA). 1994. Dry Storage of N Reactor Fuel, Volumes 1 and 2. MAC Technical Services Company, Richland, Washington.

Lawrence, L. A. 1995. "Data Quality Objectives for the Initial Fuel Conditioning Examinations." Westinghouse Hanford Company, Richland, Washington.

Lawrence, L. A., T. A. Thornton, and J. Abrefah. 1995. "Data Quality Objectives for the Initial K West Fuel Examinations." Westinghouse Hanford Company, Richland, Washington.

Mouradian, E. M., and L. Baker. 1963. "Burning Temperatures of Uranium and Zirconium in Air." Nuclear Science and Engineering 15:388.

Musgrave, L. E. 1972. “A Theory of Burning Curve Ignition of Nuclear Metals." Journal of Nuclear Materials 43:155.

Smith, R. B. 1956. The Fire Properties of Metallic Uranium. AEC-TID-8011, Atomic Energy Commission.

Tetenbaum, M., L. Mishler, and J. Schnizlein. 1962. "Uranium Powder Ignition Studies." Nuclear Science and Engineering 14:230.

Westinghouse Hanford Company (WHC). 1995. Integrated Process Strategy for K Basins Spent Nuclear Fuel. WHC-SD-SNF-SP-005, Rev. 0, Richland, Washington. 


\section{Appendix A}

\section{Specimen Dimensions}




\section{Appendix A}

\section{Specimen Dimensions}

Table A.1. Specimen Dimensions (in mm) per Figure 3.6

\begin{tabular}{|c|c|c|c|c|c|c|c|}
\hline \multirow[b]{2}{*}{ Specimen ID } & \multicolumn{2}{|c|}{ Length } & \multicolumn{2}{|c|}{ Inner Chord } & \multicolumn{2}{|c|}{ Outer Chord } & \multirow[b]{2}{*}{ Thickness } \\
\hline & $\mathbf{Z}_{\mathbf{a}}$ & $\mathbf{Z}_{\mathrm{b}}$ & $\mathbf{X}_{12}$ & $\mathbf{X}_{1 b}$ & $\mathbf{X}_{2 \mathrm{a}}$ & $\mathrm{X}_{2 \mathrm{~b}}$ & \\
\hline SFEC 5,4378-S2-E3A & 11.7 & 11.45 & 7.85 & 7.05 & 9.25 & 8.95 & 9.5 \\
\hline SFEC5,4378-S2-E4A & 10.7 & 10.7 & 4.3 & 3.85 & 7.1 & 7.0 & 9.5 \\
\hline SFEC5,4378-S2-H & 24.15 & 24.15 & 5.5 & 6.05 & 8.75 & 8.85 & 9.5 \\
\hline SFEC5,4378-S2-D & 25.25 & 25.25 & 5.25 & 6.55 & 8.05 & 8.95 & 9.3 \\
\hline SFEC5,4378-S2-I & 24.5 & 24.9 & 7.4 & 7.9 & 11.4 & 11.2 & 9.45 \\
\hline SFEC5,4378-S1A-D & 29.05 & 23.75 & 6.6 & 6.45 & 10.35 & 9.75 & 9.0 \\
\hline SFEC5,4378-S1A-H & 26.75 & 27.3 & 8.55 & 8.55 & 12.05 & 11.85 & 9.55 \\
\hline SFEC5,4378-S1A-G & 29.65 & 22.75 & 5.65 & 5.9 & 9.55 & 9.6 & 9.7 \\
\hline SFEC5,4378-S1A-B1 & 23.5 & 15.5 & 6.6 & 6.55 & 10.05 & 10.0 & 9.1 \\
\hline SFEC5,4378-S1A-I & 42.0 & 46.5 & 5.95 & 6.15 & 10.15 & 9.7 & 10.0 \\
\hline SFEC10,4366-S1-D & 17.95 & 17.95 & 6.85 & 8.7 & 7.9 & $\overline{10.75}$ & 7.75 \\
\hline SFEC10,4366-S2-D & 12.35 & 12.4 & 9.95 & 15.0 & 12.25 & 18.0 & 7.85 \\
\hline SFEC10,4366-S3-G & 38.25 & 37.25 & 8.25 & 8.1 & 10.0 & 10.0 & 8.0 \\
\hline SFEC10,4366-S1-A & 17.7 & 17.5 & 7.55 & 8.3 & 10.25 & 10.6 & 8.25 \\
\hline SFEC10,4366-S2-A & 12.95 & 13.15 & 4.75 & 7.25 & 8.35 & 10.65 & 8.1 \\
\hline SFEC10,4366-S3-E1 & 29.0 & 22.9 & $\overline{9.4}$ & 7.5 & 10.5 & 9.7 & 9.05 \\
\hline SFEC10,4366-S3-H & 36.25 & 31.35 & 7.5 & 8.0 & 10.0 & 11.0 & 8.0 \\
\hline
\end{tabular}




\section{Appendix B}

\section{Ignition Test Results}




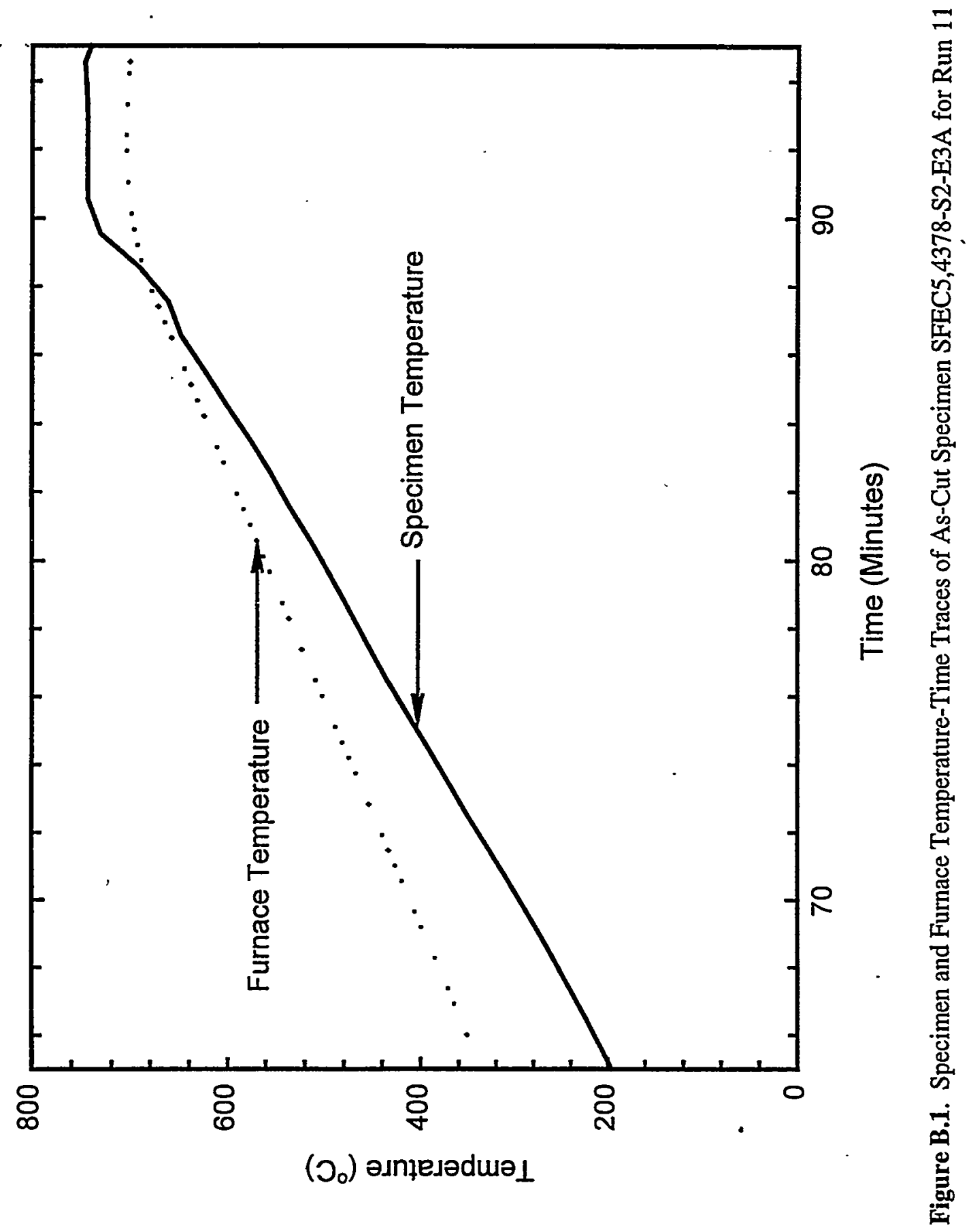

B. 1 


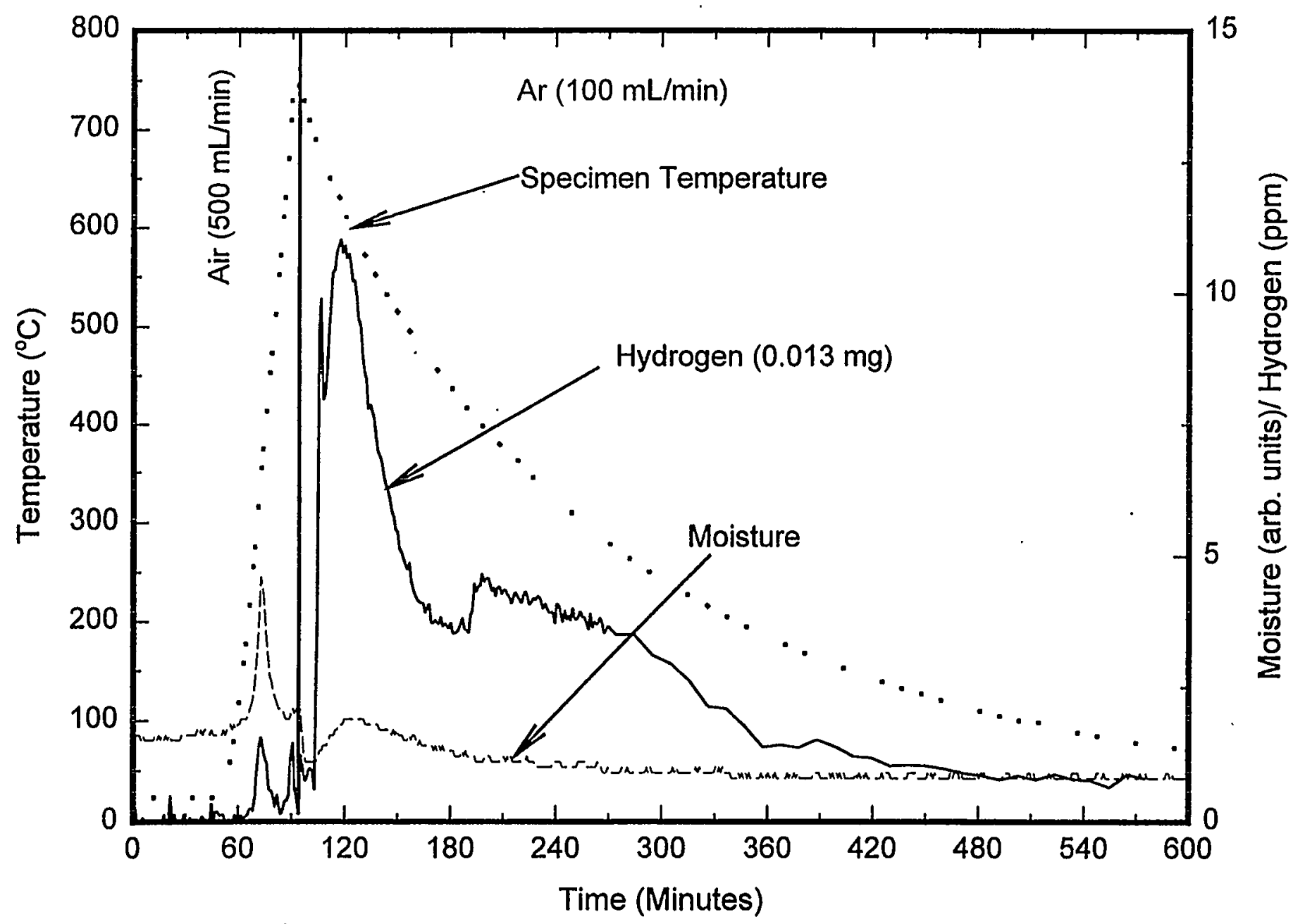

Figure B.2. Ignition Test Results of As-Cut Specimen SFEC5,4378-S2-E3A for Run 11 


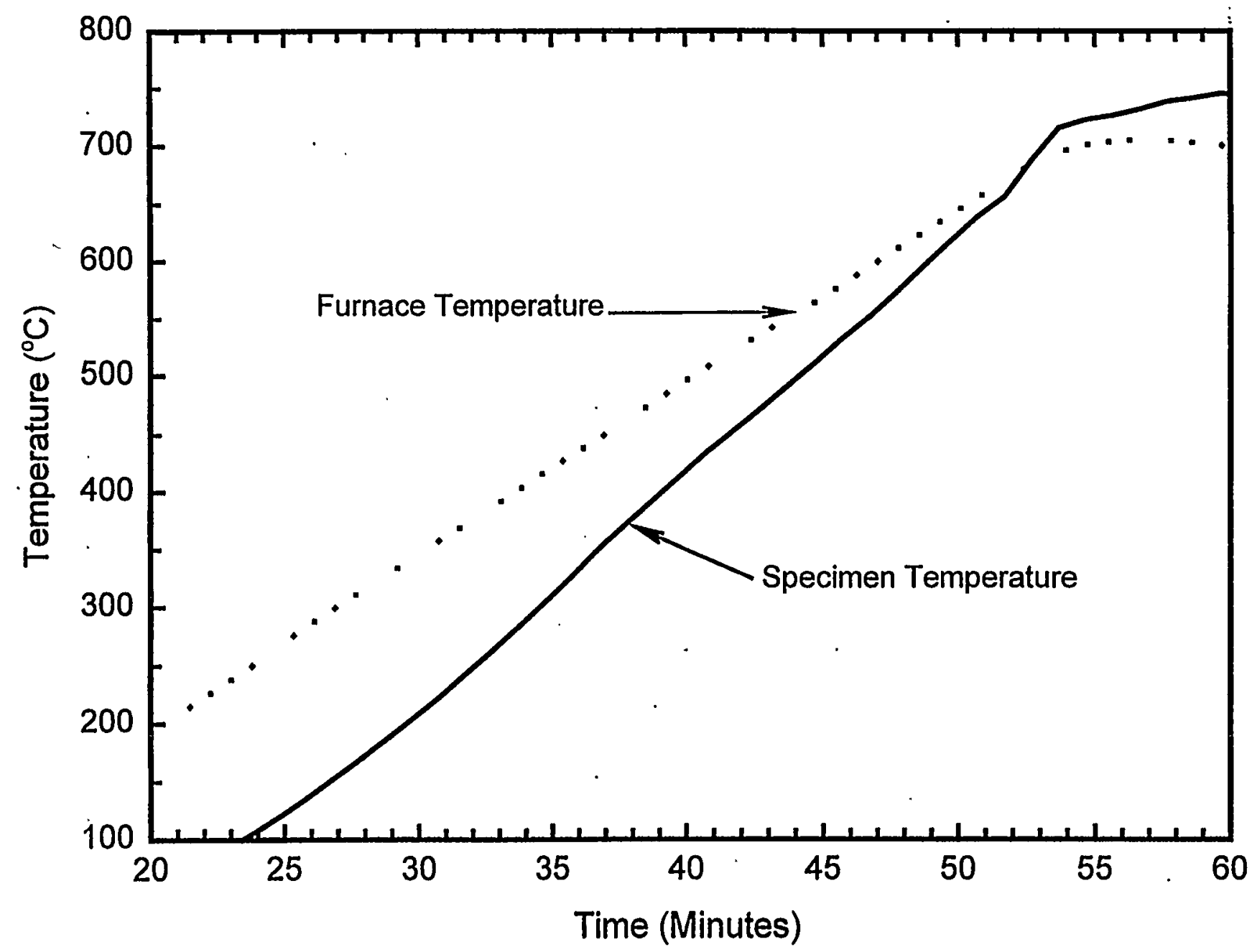

Figure B.3. Specimen and Furnace Temperature-Time Traces of As-Cut Specimen SFEC5,4378-S2-E4A for Run 12 


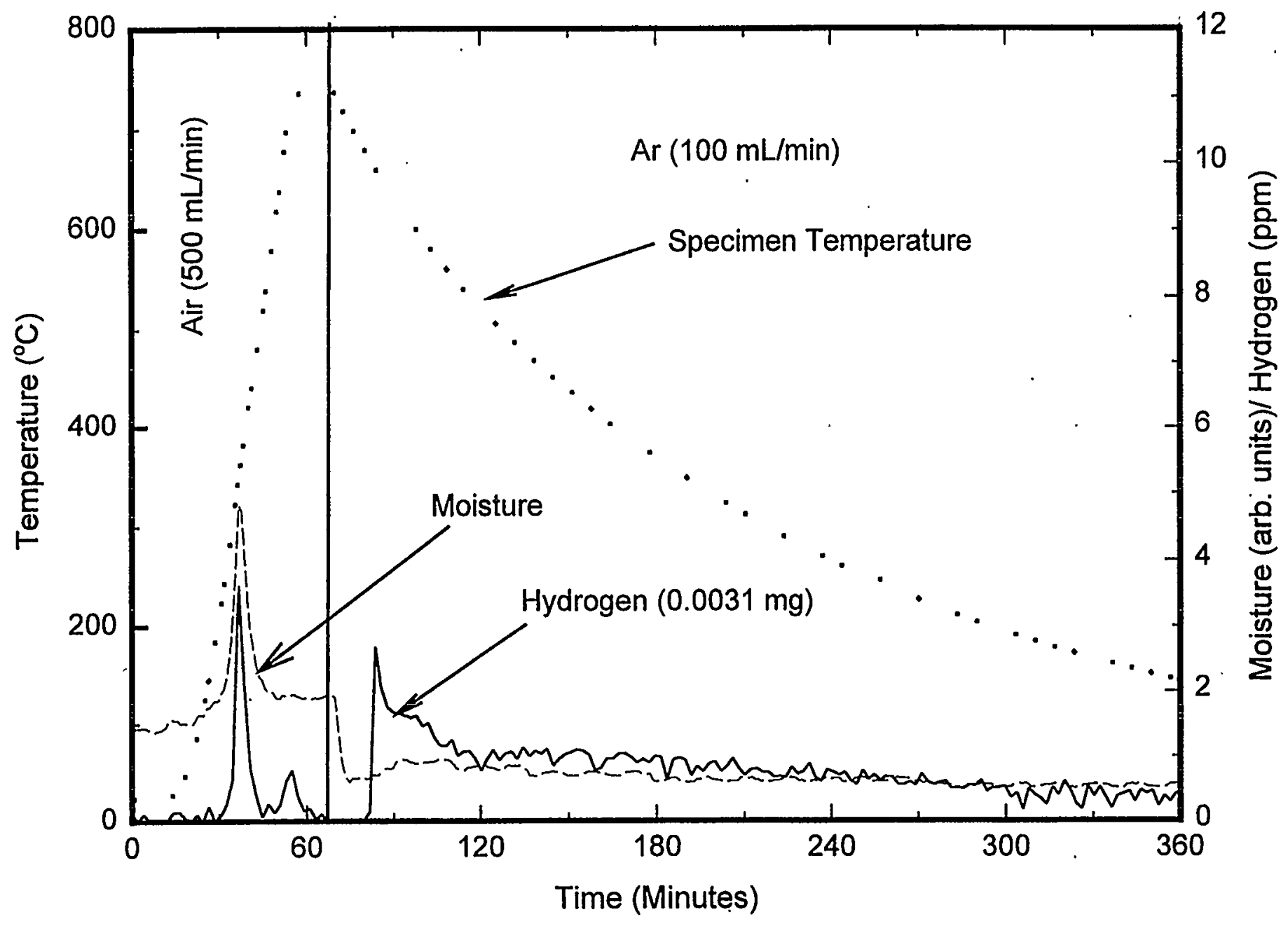

Figure B.4. Ignition Test Results of As-Cut Specimen SFEC5,4378-S2-E4A for Run 12. 


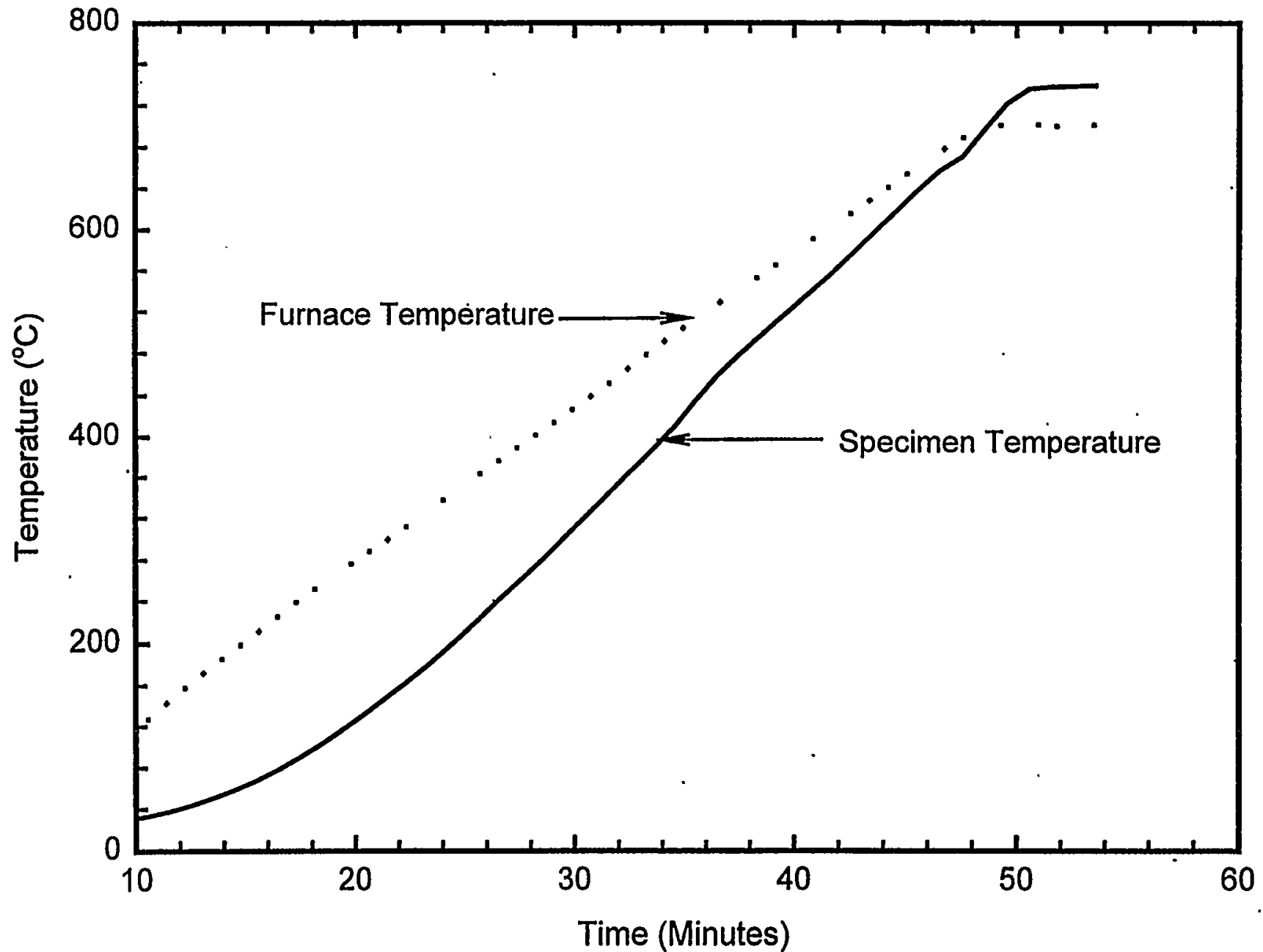

Figure B.5. Specimen and Furnace Temperature-Time Traces of Conditioned Specimen SFEC5,4378-S2-H for Run 13 


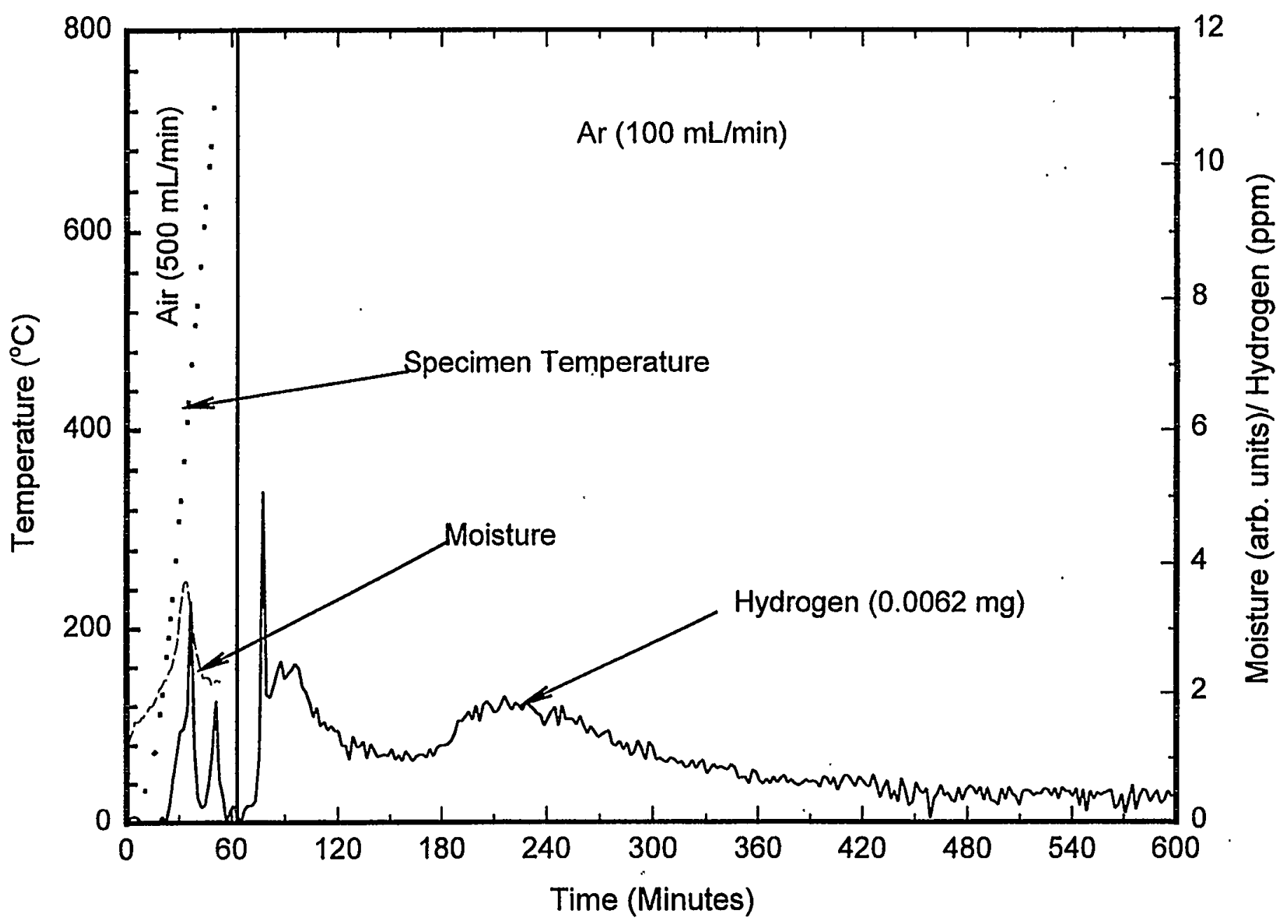

Figure B.6. Ignition Test Results of Conditioned Specimen SFEC5,4378-S2-H for Run 13 


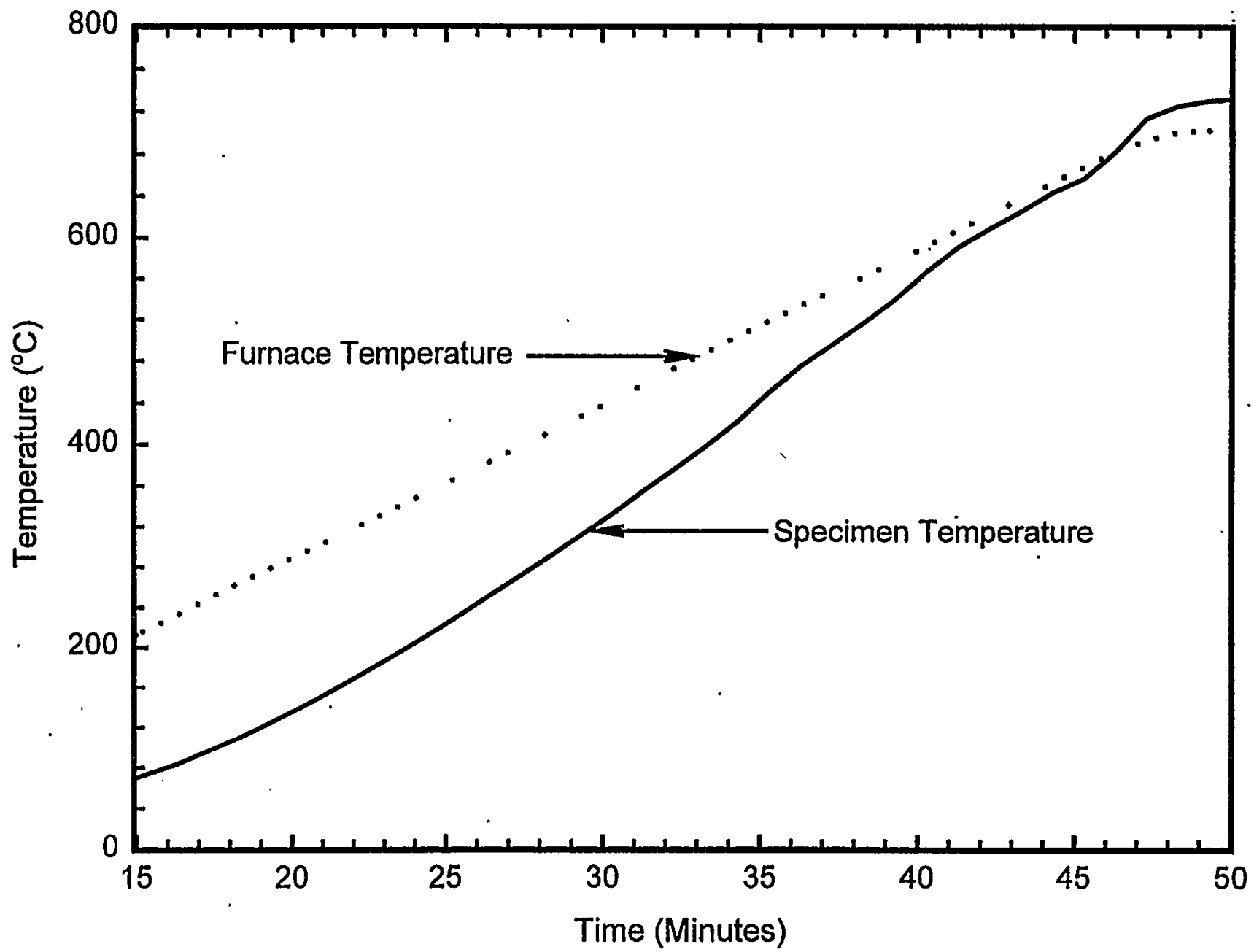

Figure B.7. Specimen and Furnace Temperature-Time Traces of Conditioned Specimen SFEC5,4378-S2-D for Run 14 


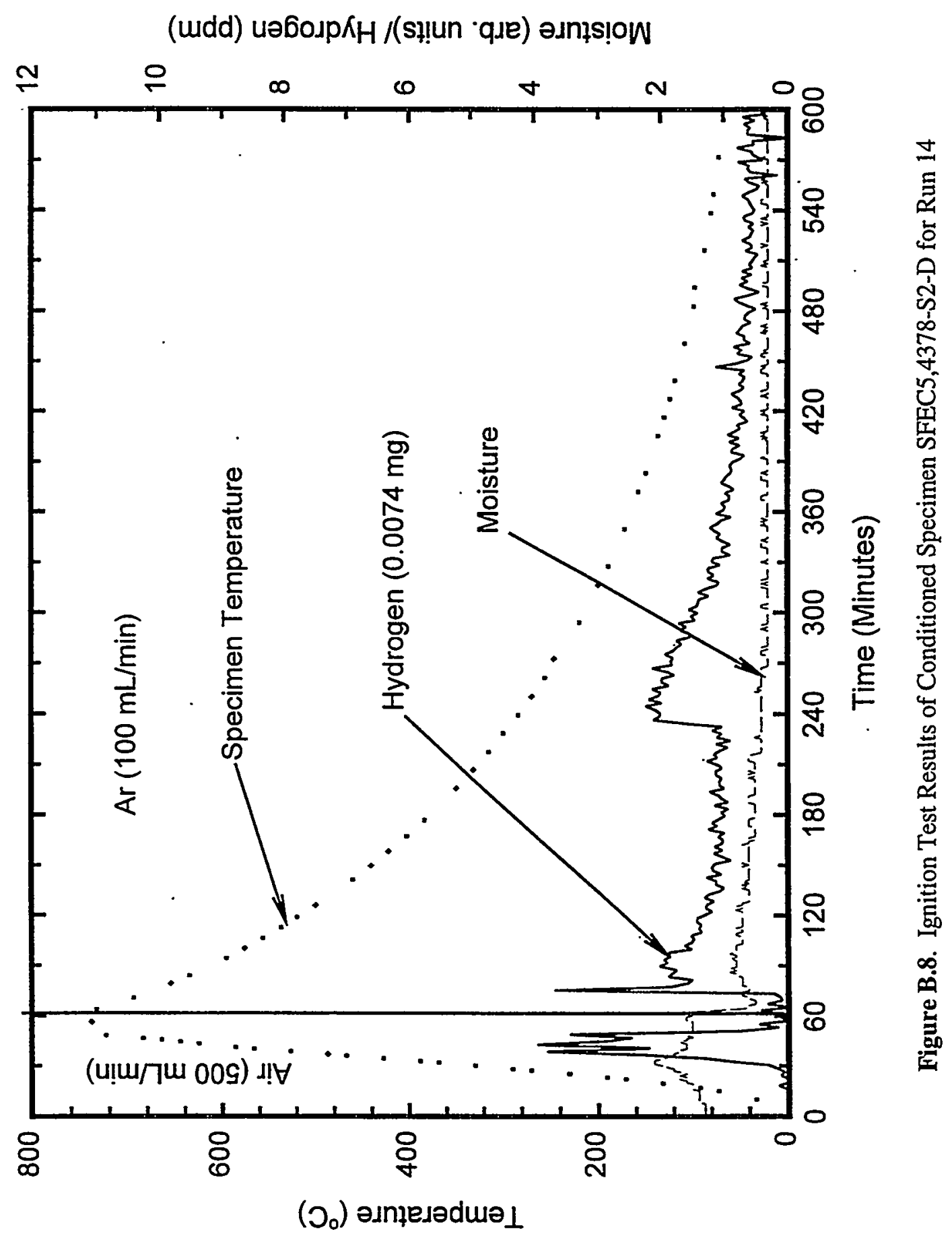




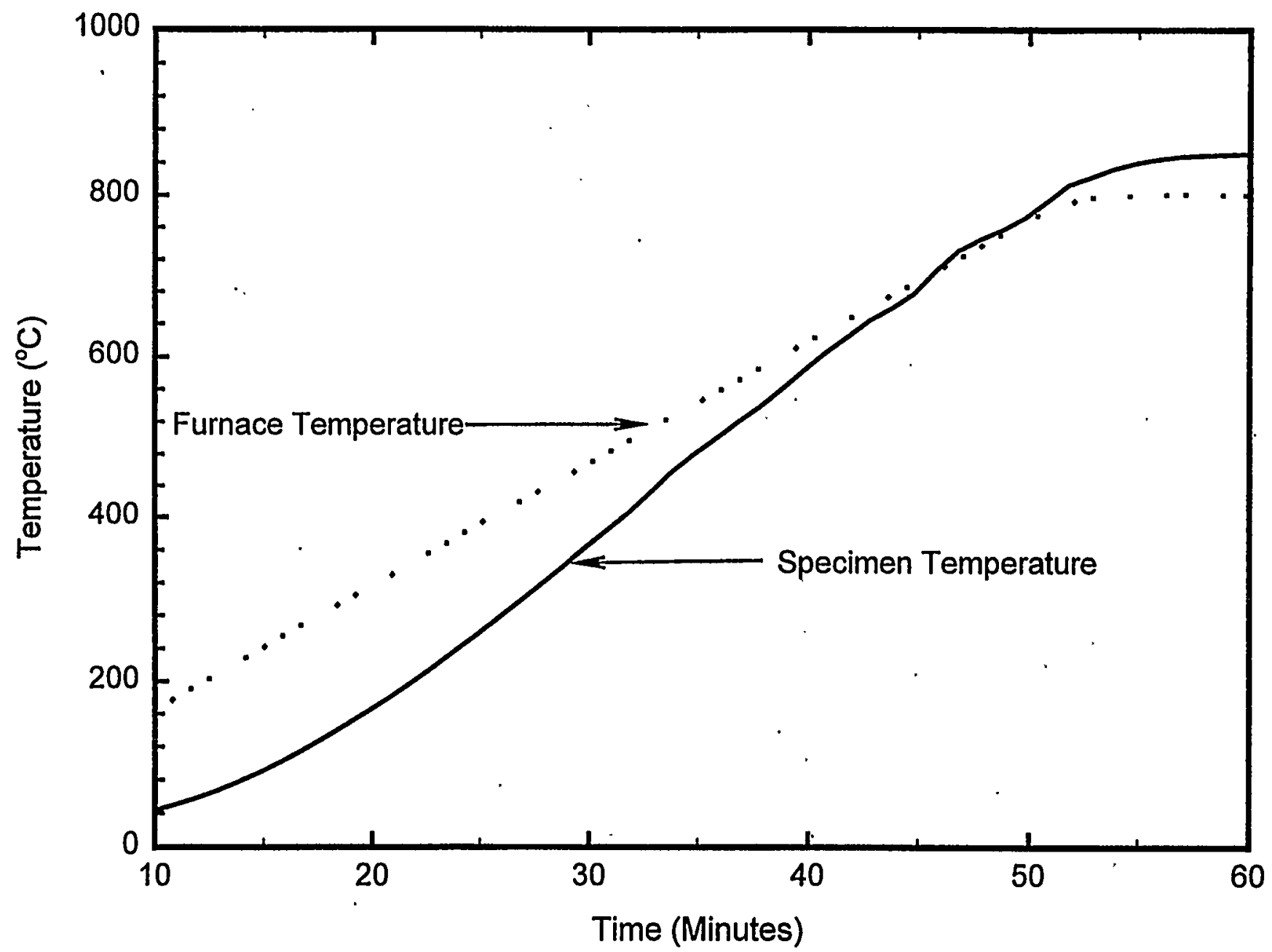

Figure B.9. Specimen and Furnace Temperature-Time Traces of Conditioned Specimen SFEC5,4378-S2-I for Run 15 


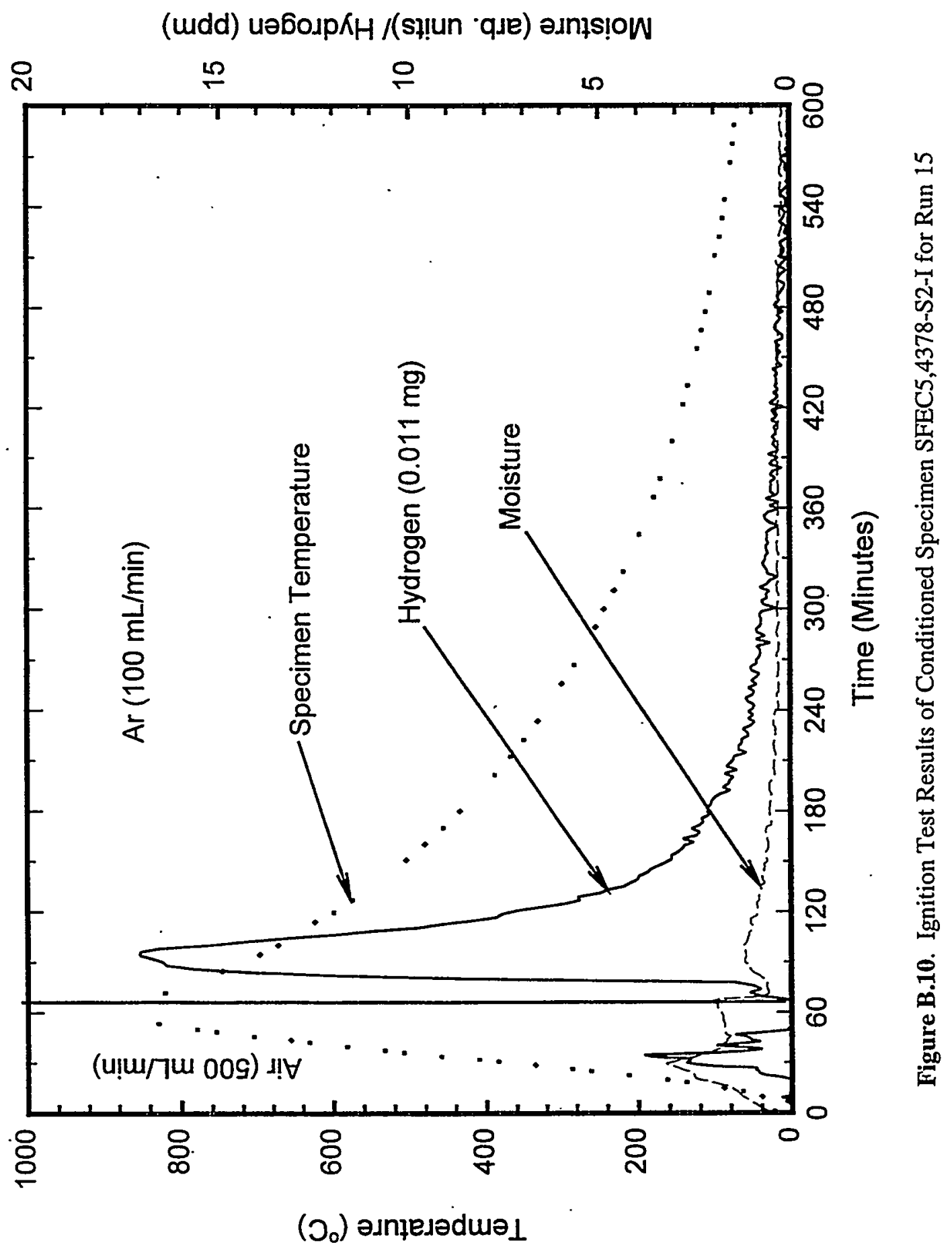

B.10 


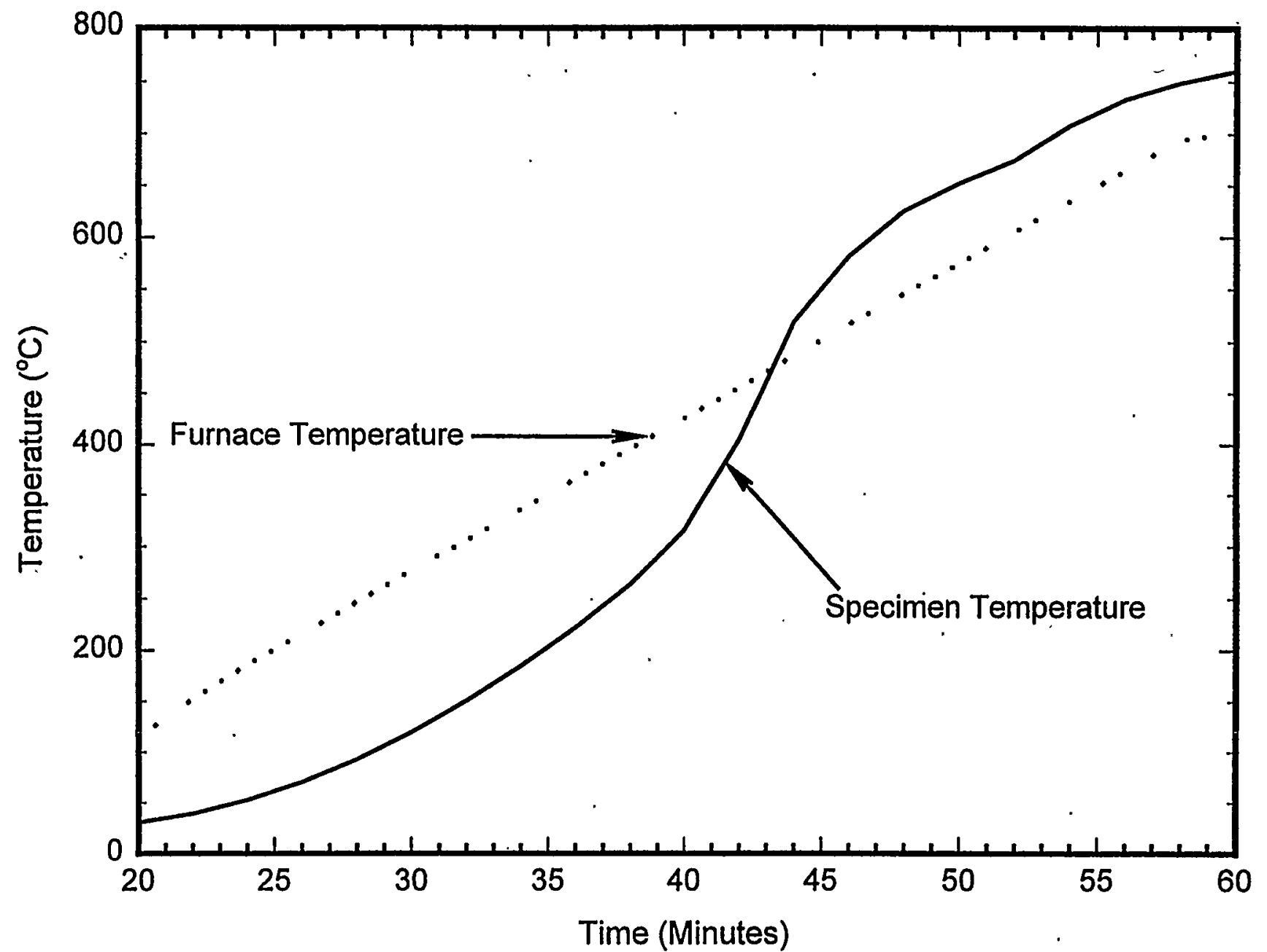

Figure B.11. Specimen and Furnace Temperature-Time Traces of As-Cut Specimen SFEC5,4378-S1A-D for Run 17 


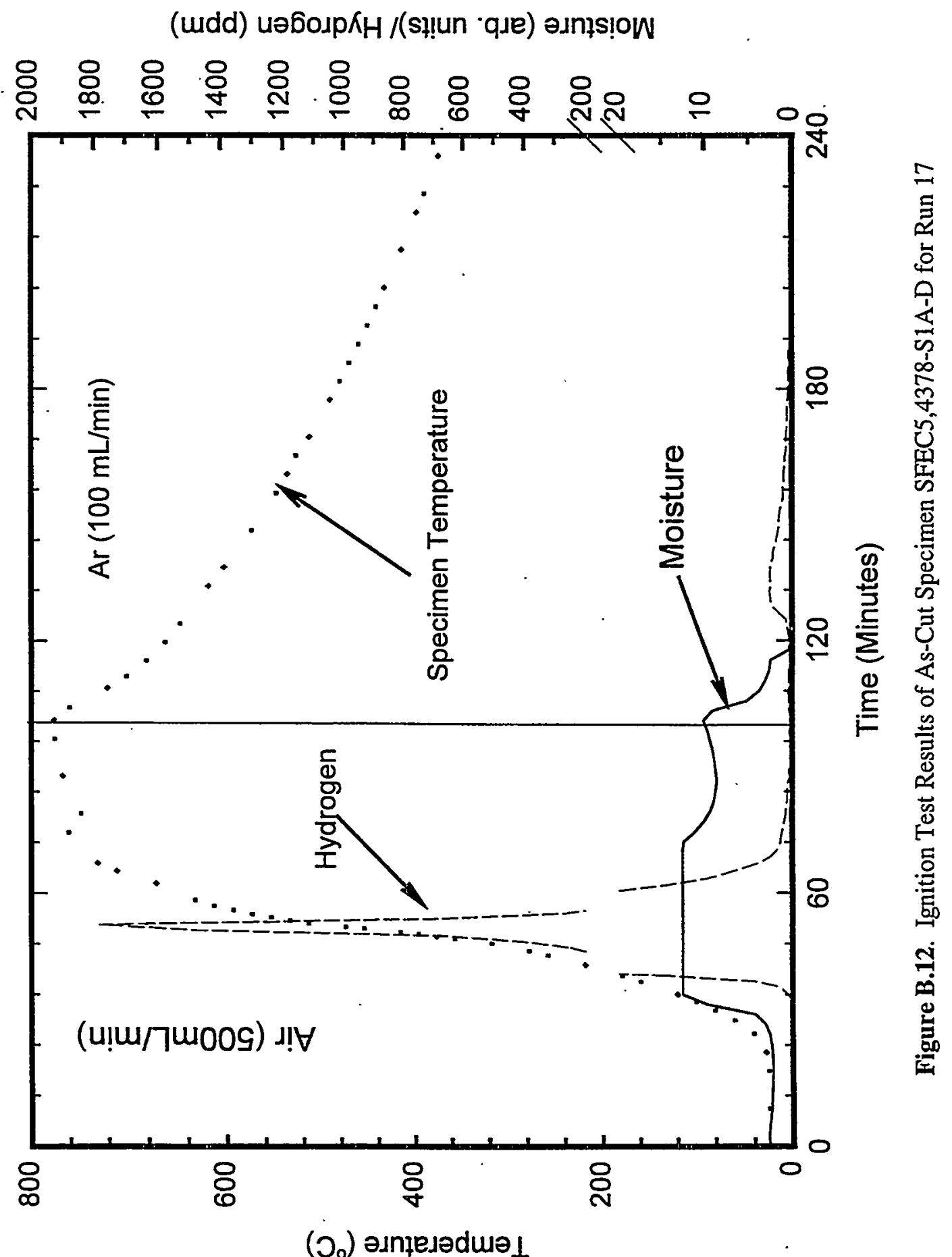

B. 12 


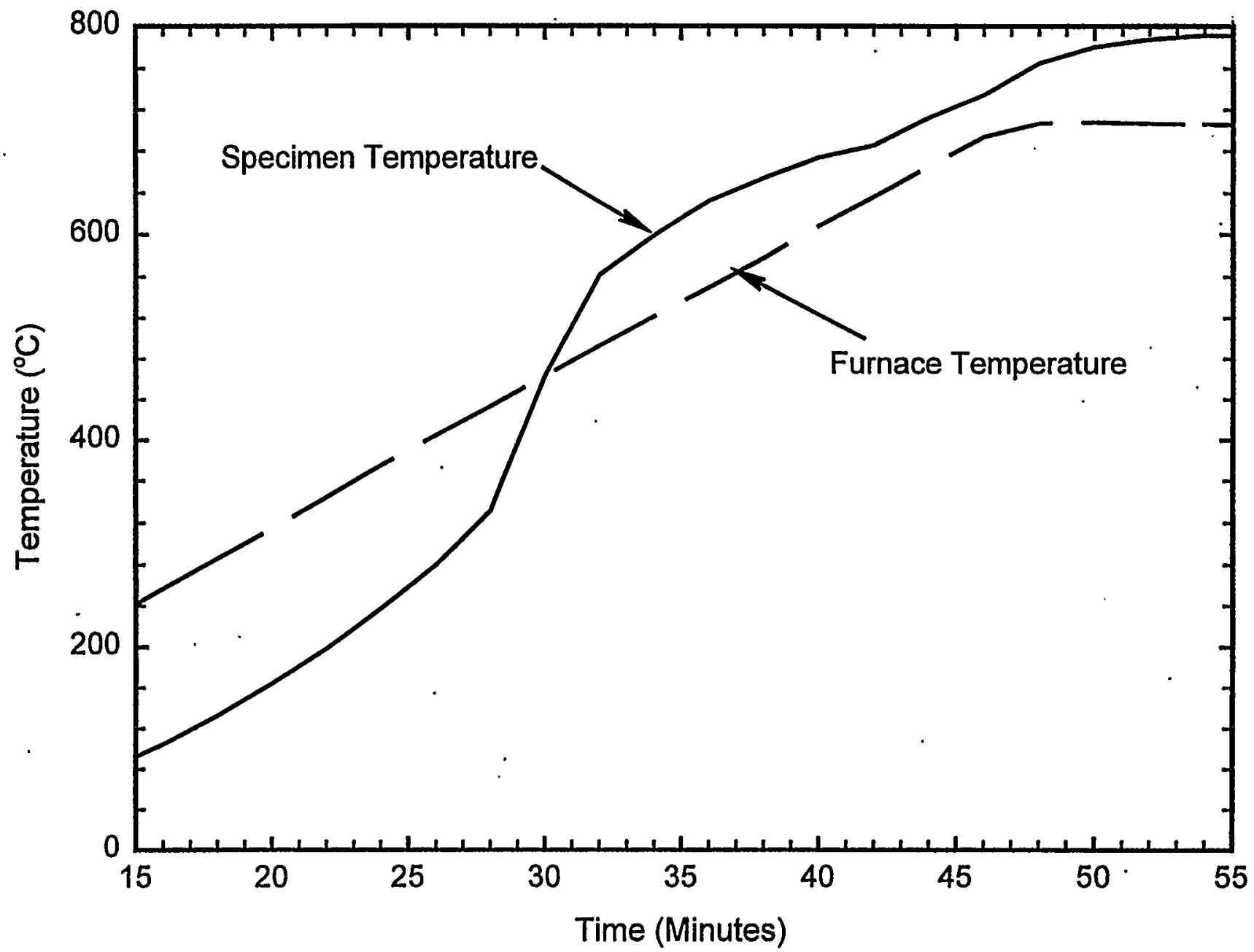

Figure B.13. Specimen and Furnace Temperature-Time Traces of As-Cut Specimen SFEC5,4378-S1A-H for Run 19 


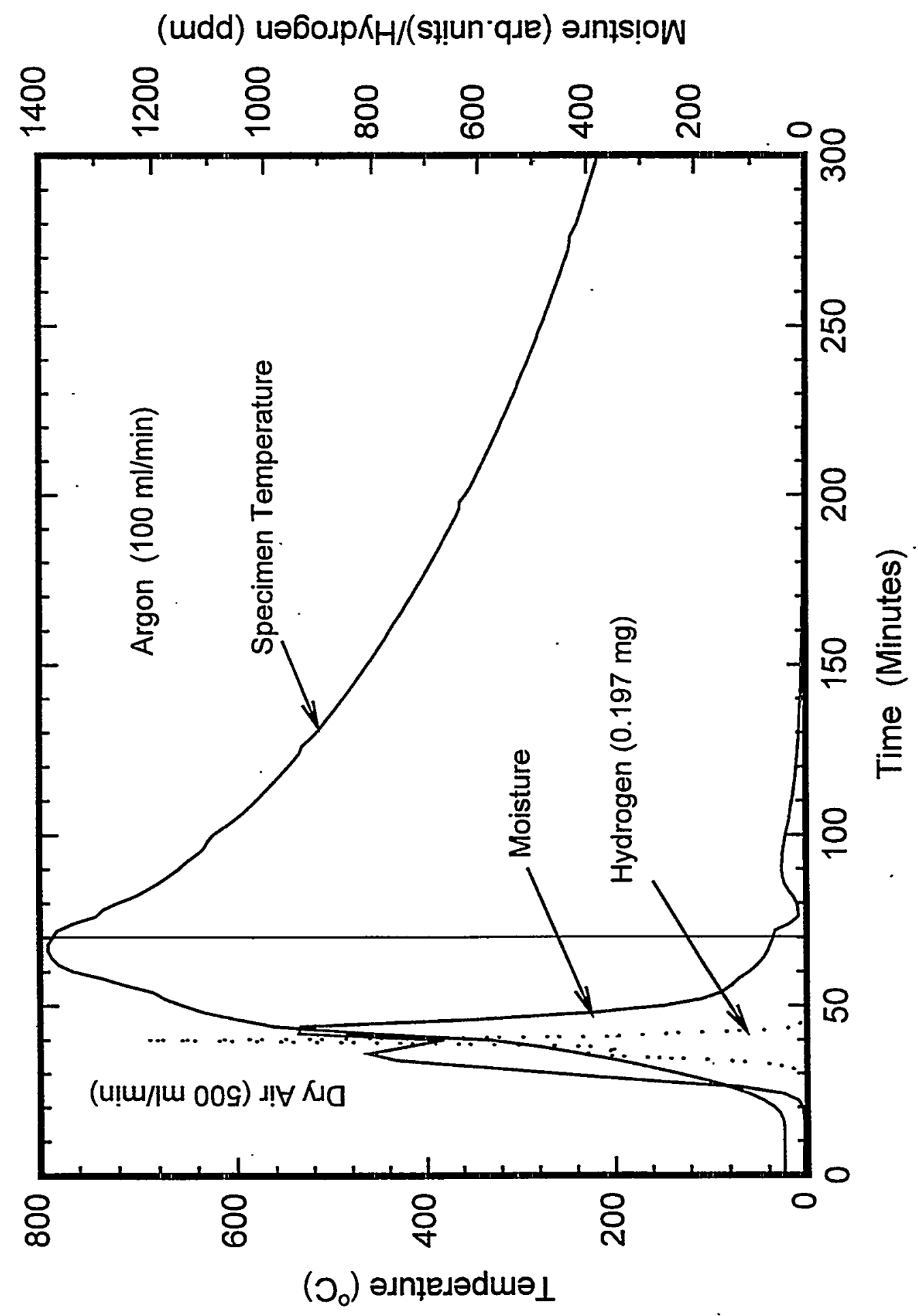

B. 14 


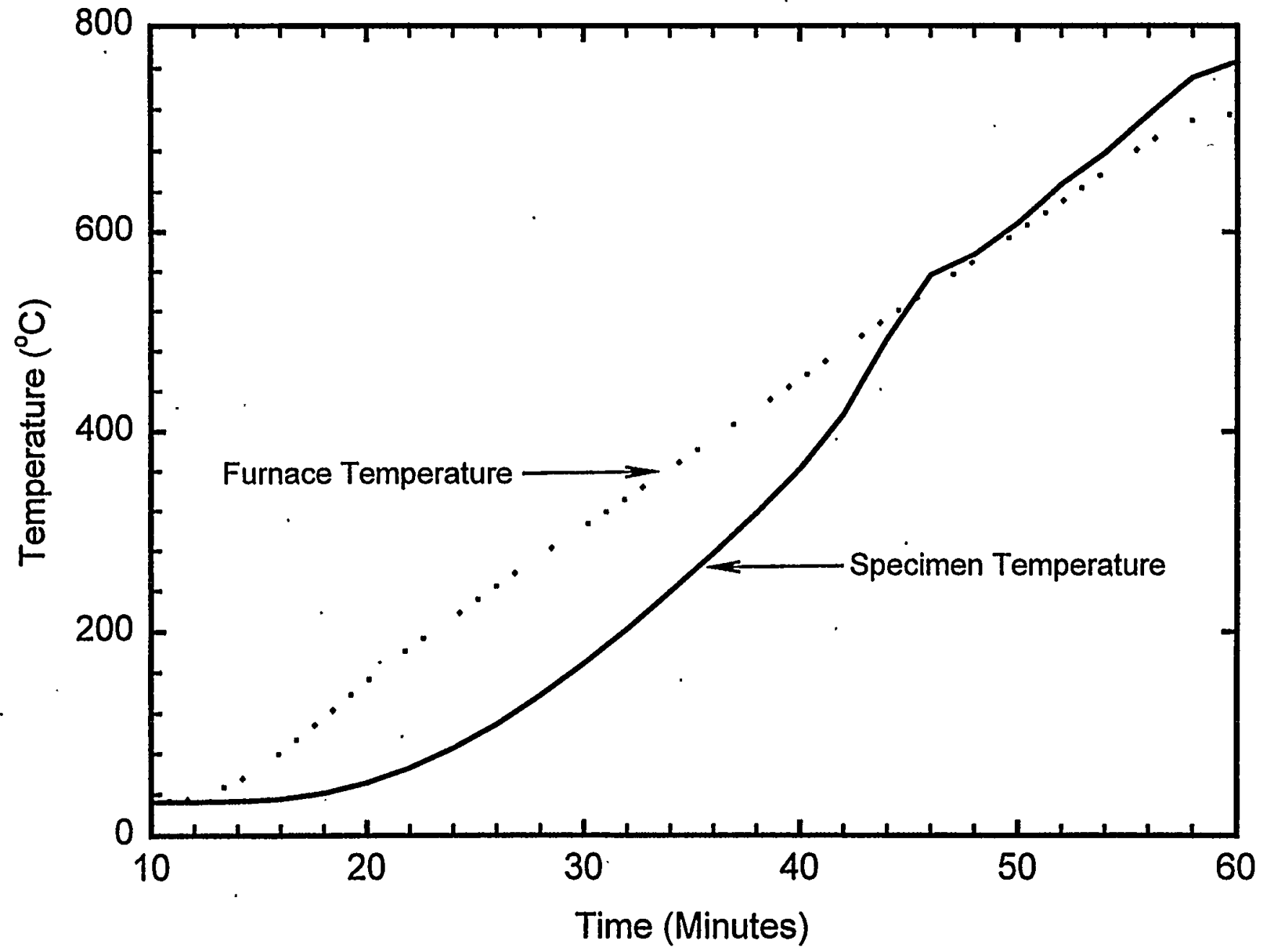

Figure B.15. Specimen and Furnace Temperature-Time Traces of Conditioned Specimen SFEC5,4378-S1A-G for Run 22 


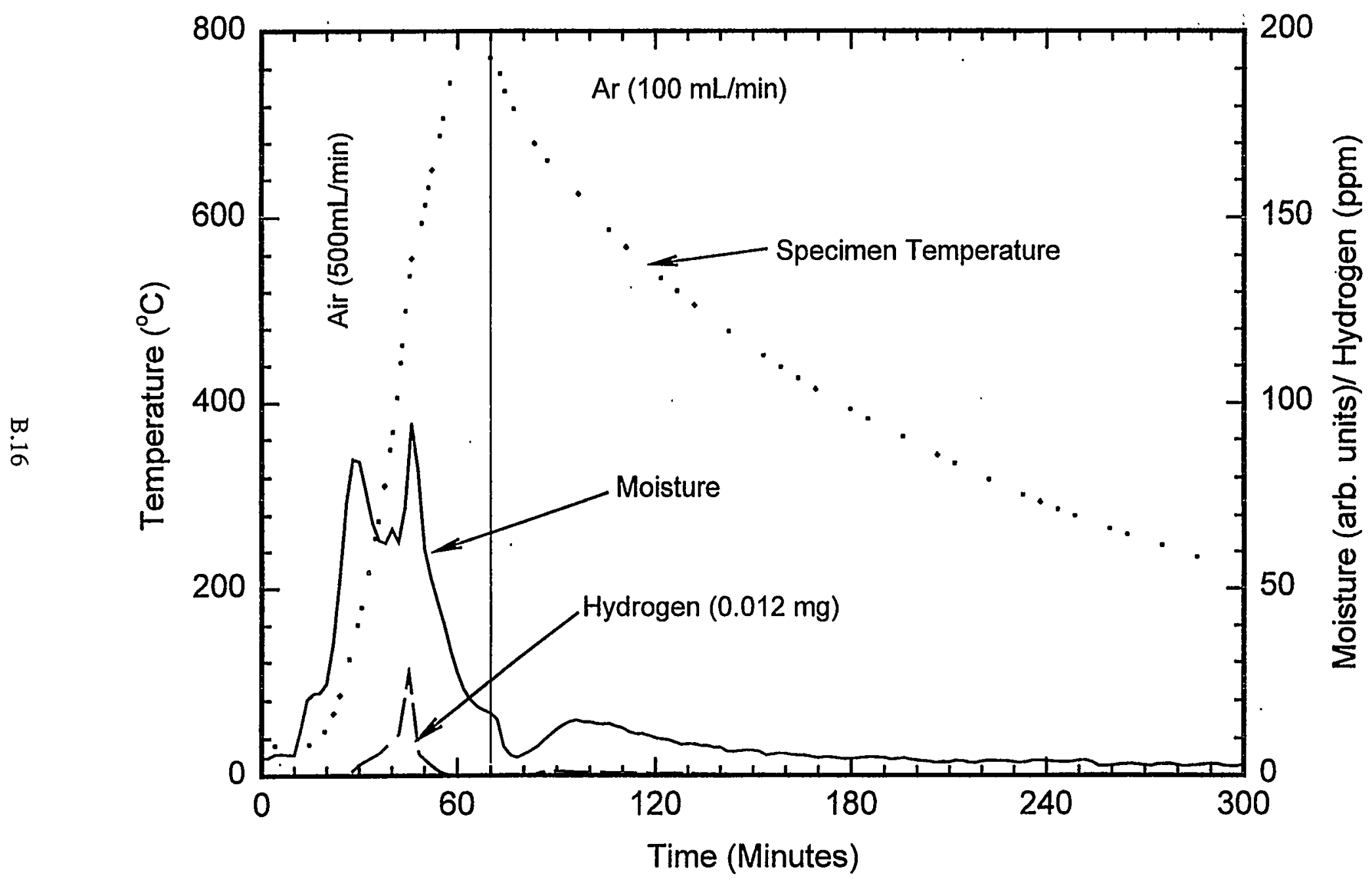

Figure B.16. Ignition Test Results of Conditioned Specimen SFEC5,4378-S1A-G for Run 22 


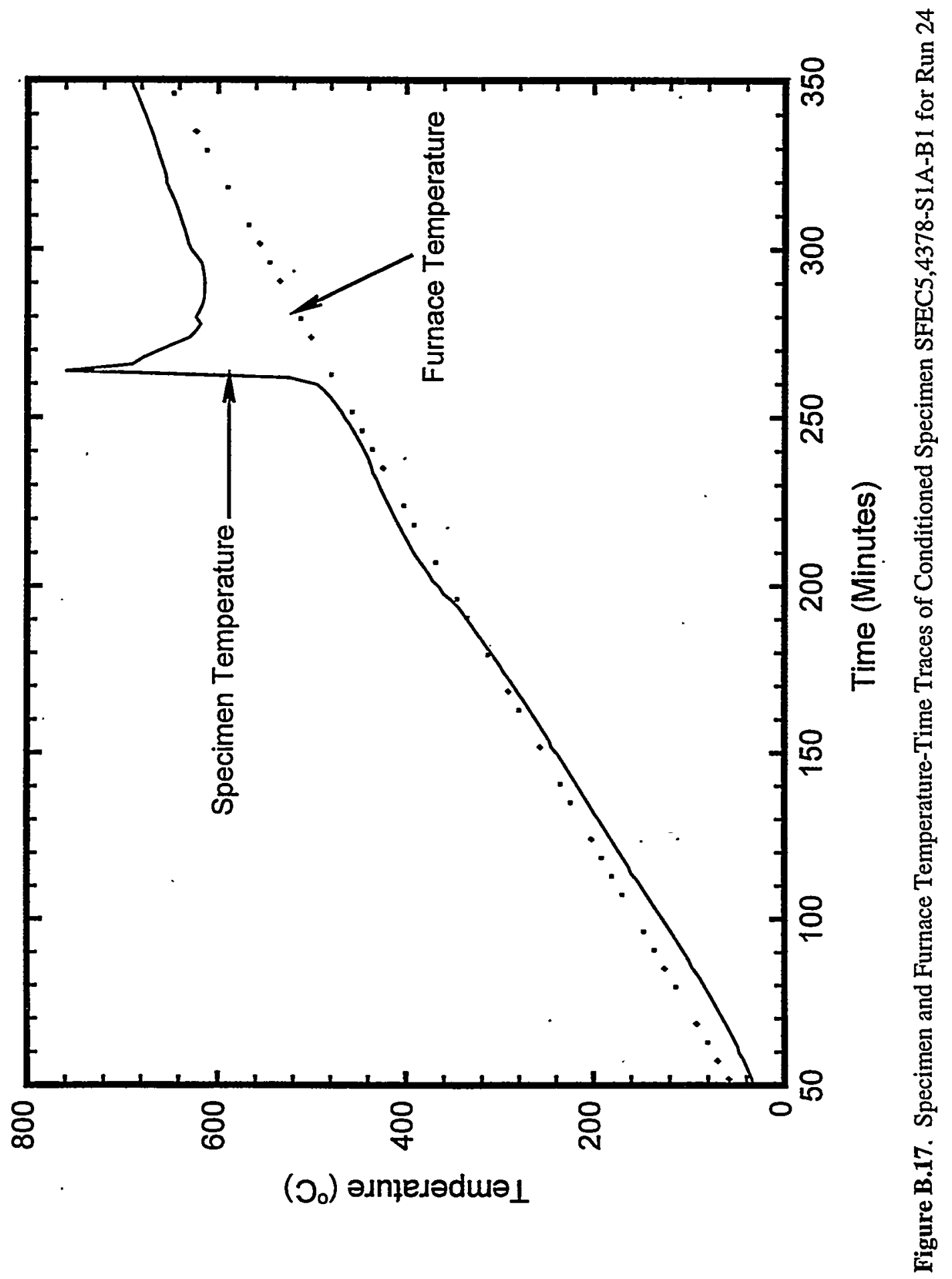

B. 17 


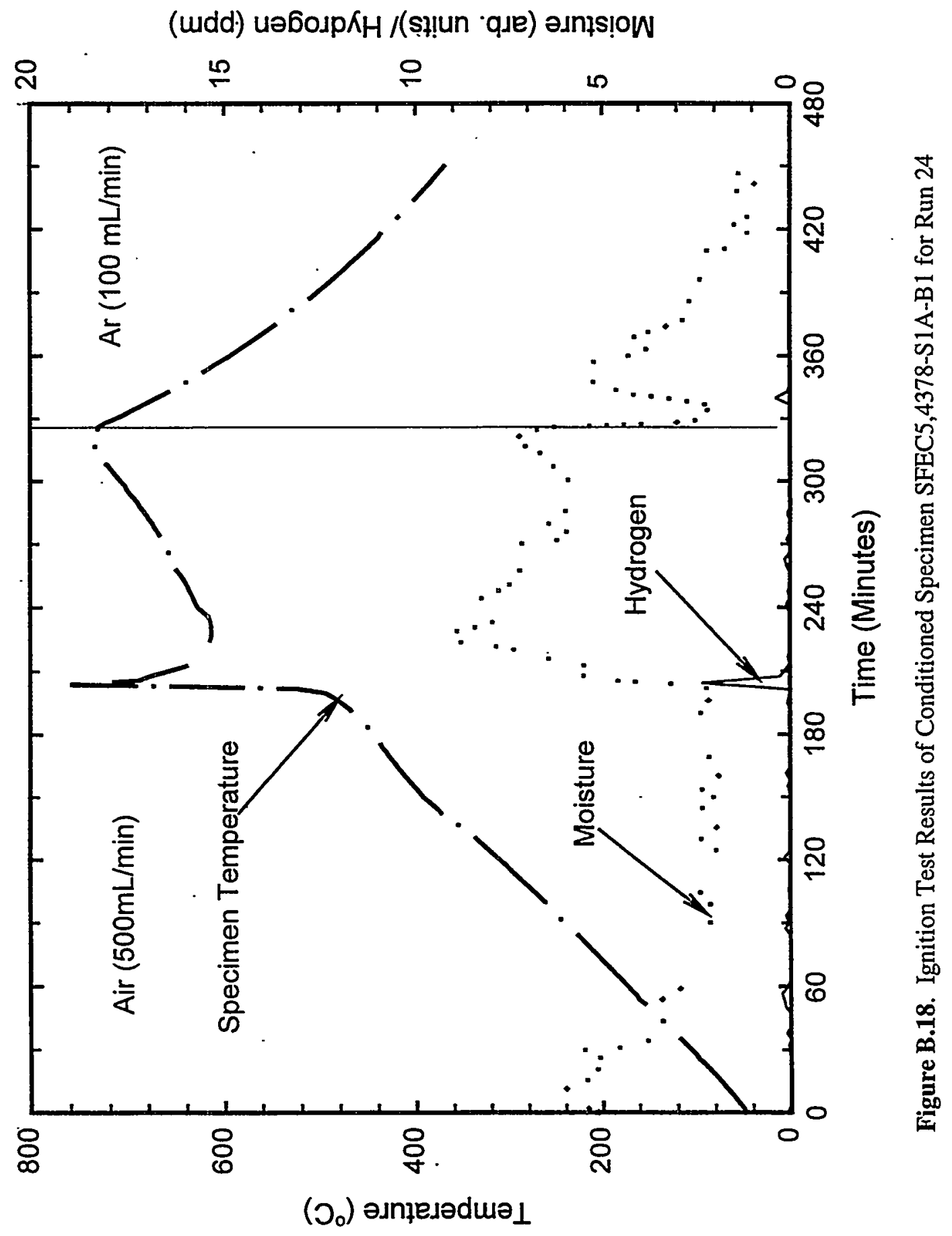

B. 18 


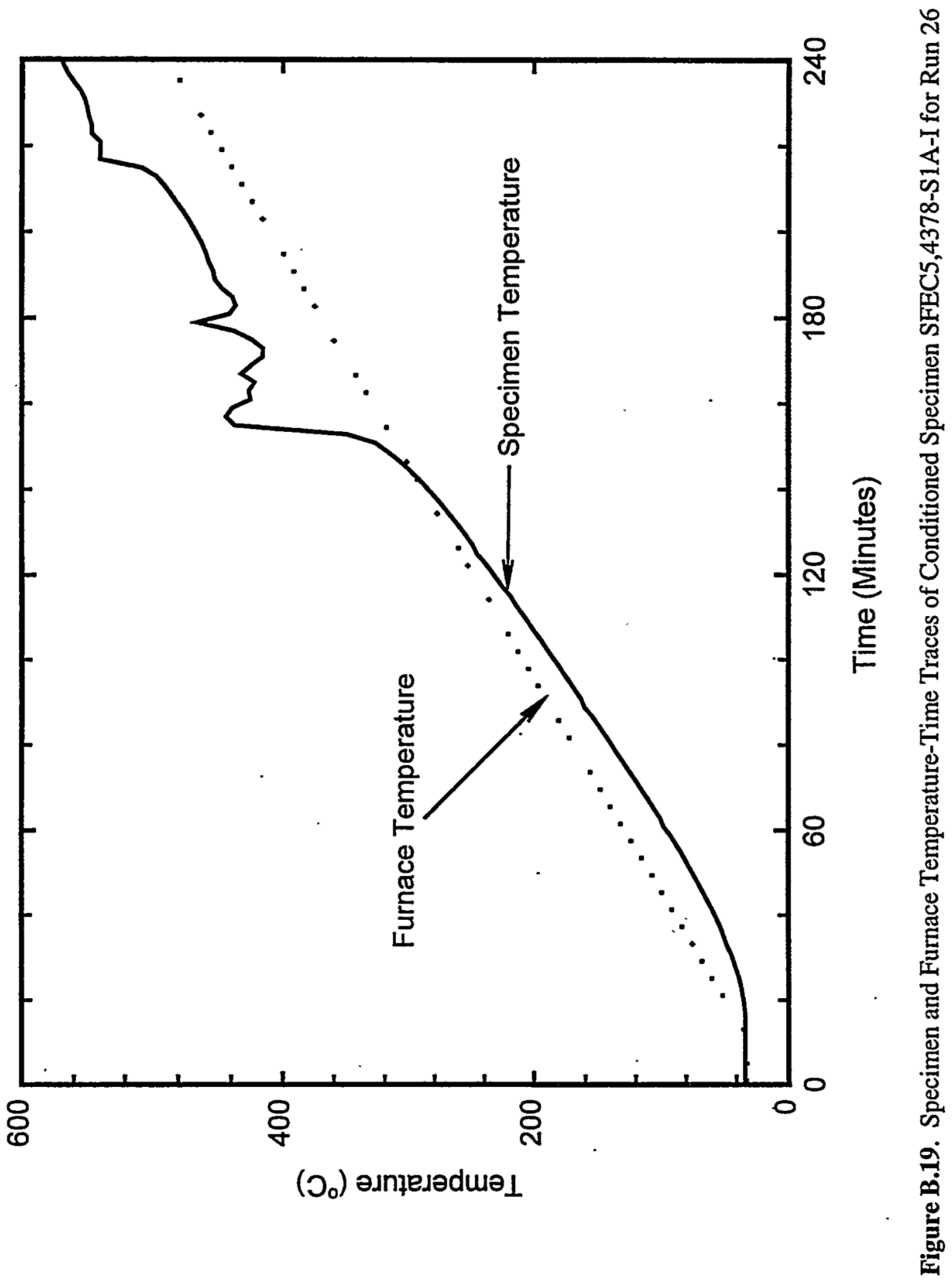




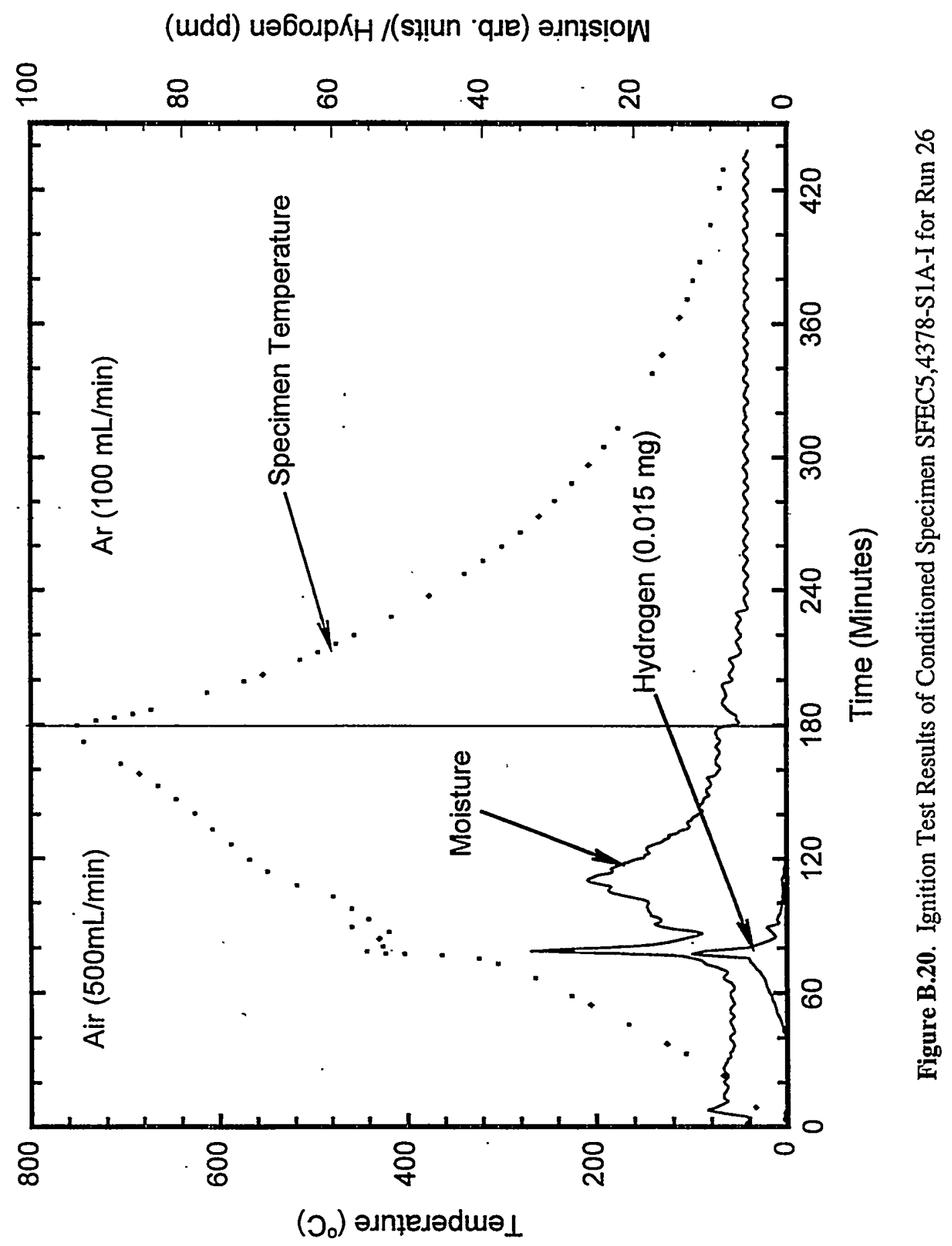




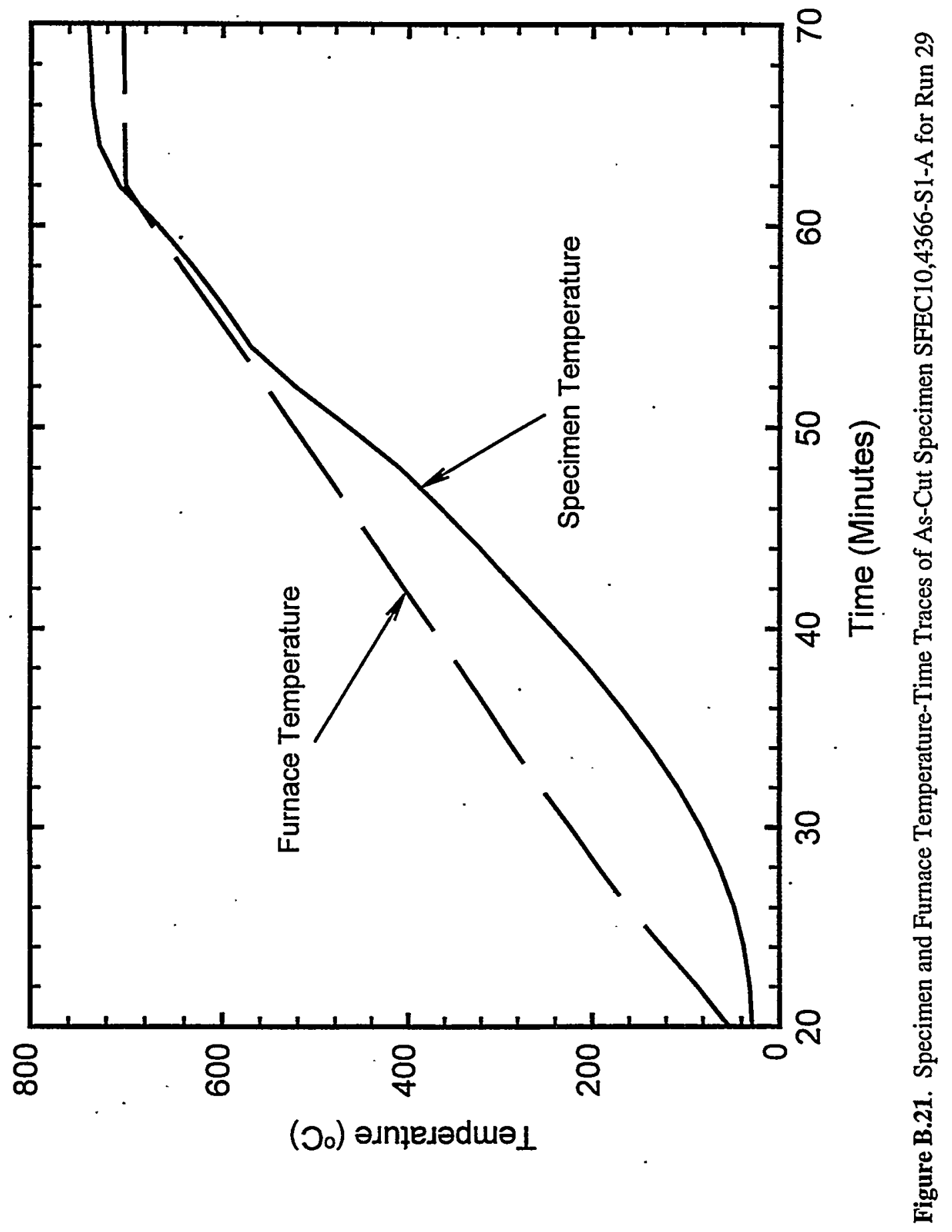

B. 21 


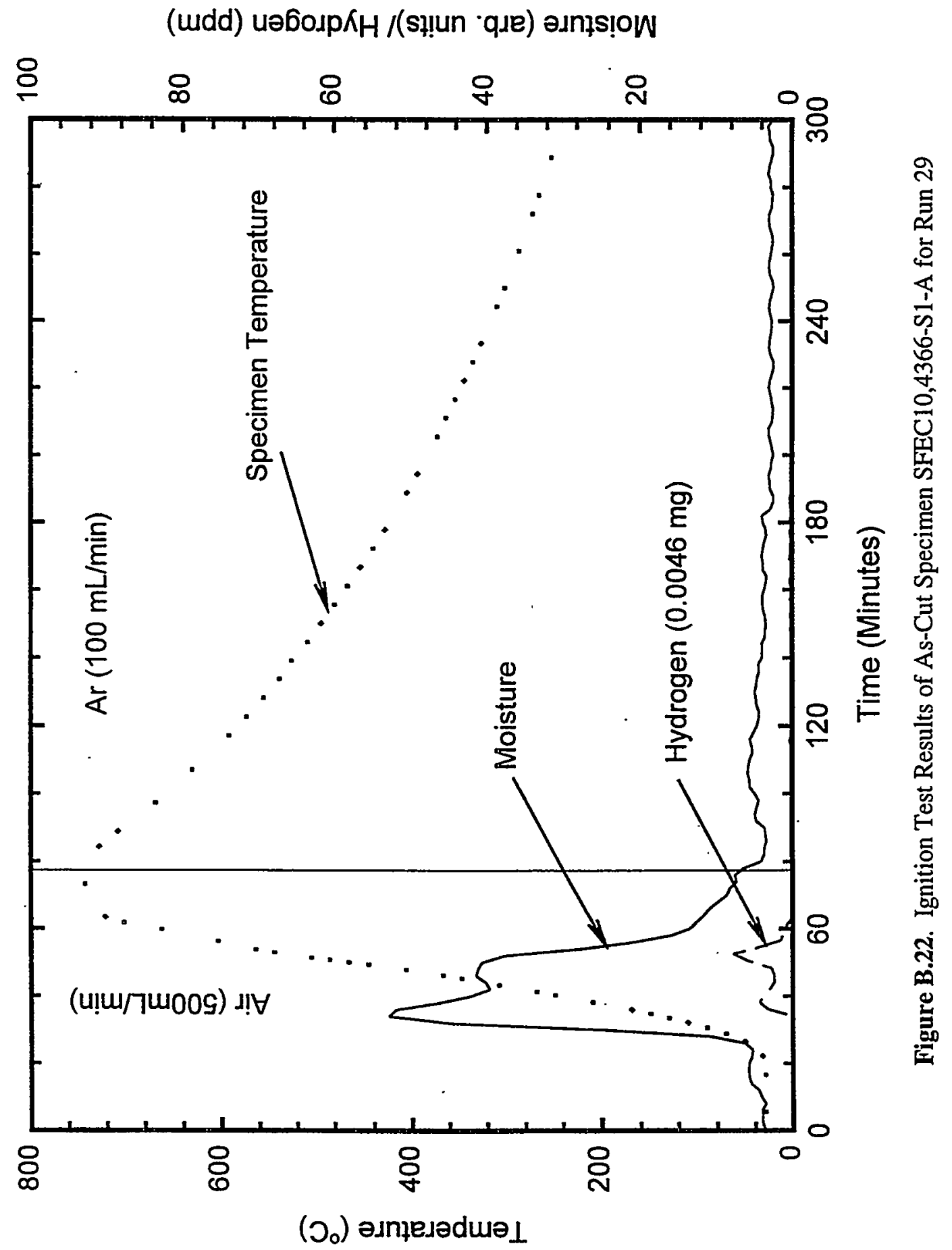

B. 22 


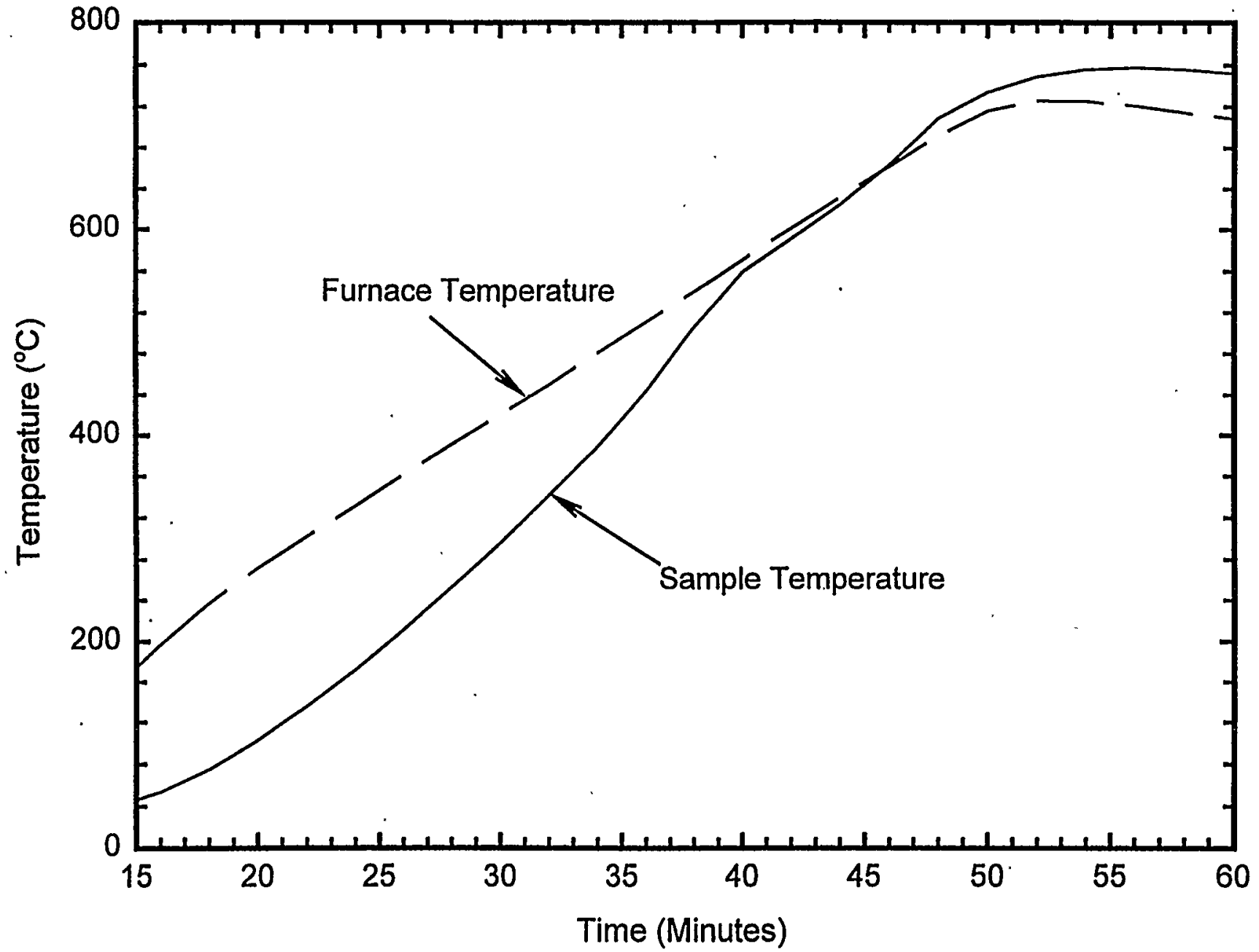

Figure B.23. Specimen and Furnace Temperature-Time Traces of As-Cut Specimen SFEC10,4366-S1-D for Run 30 


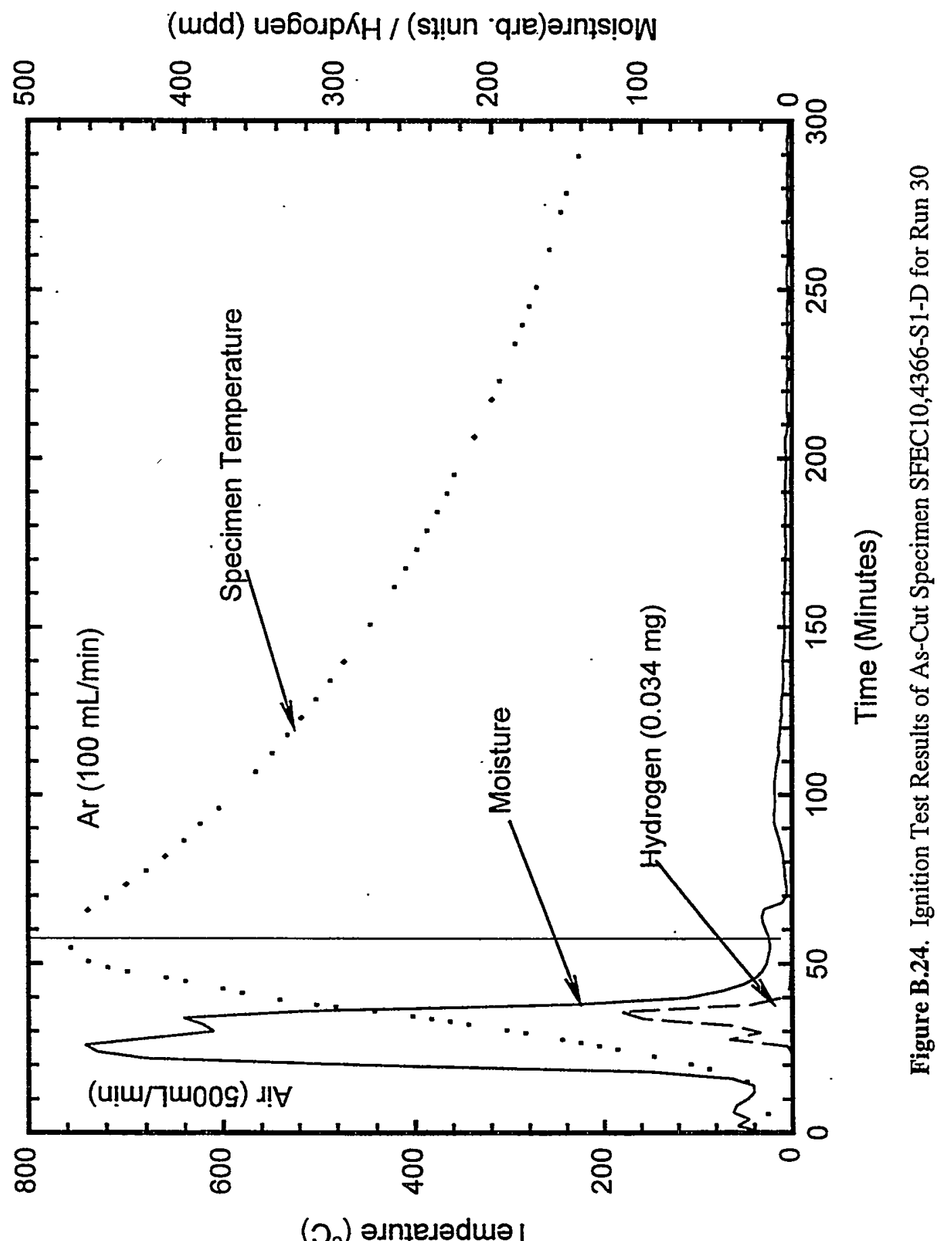




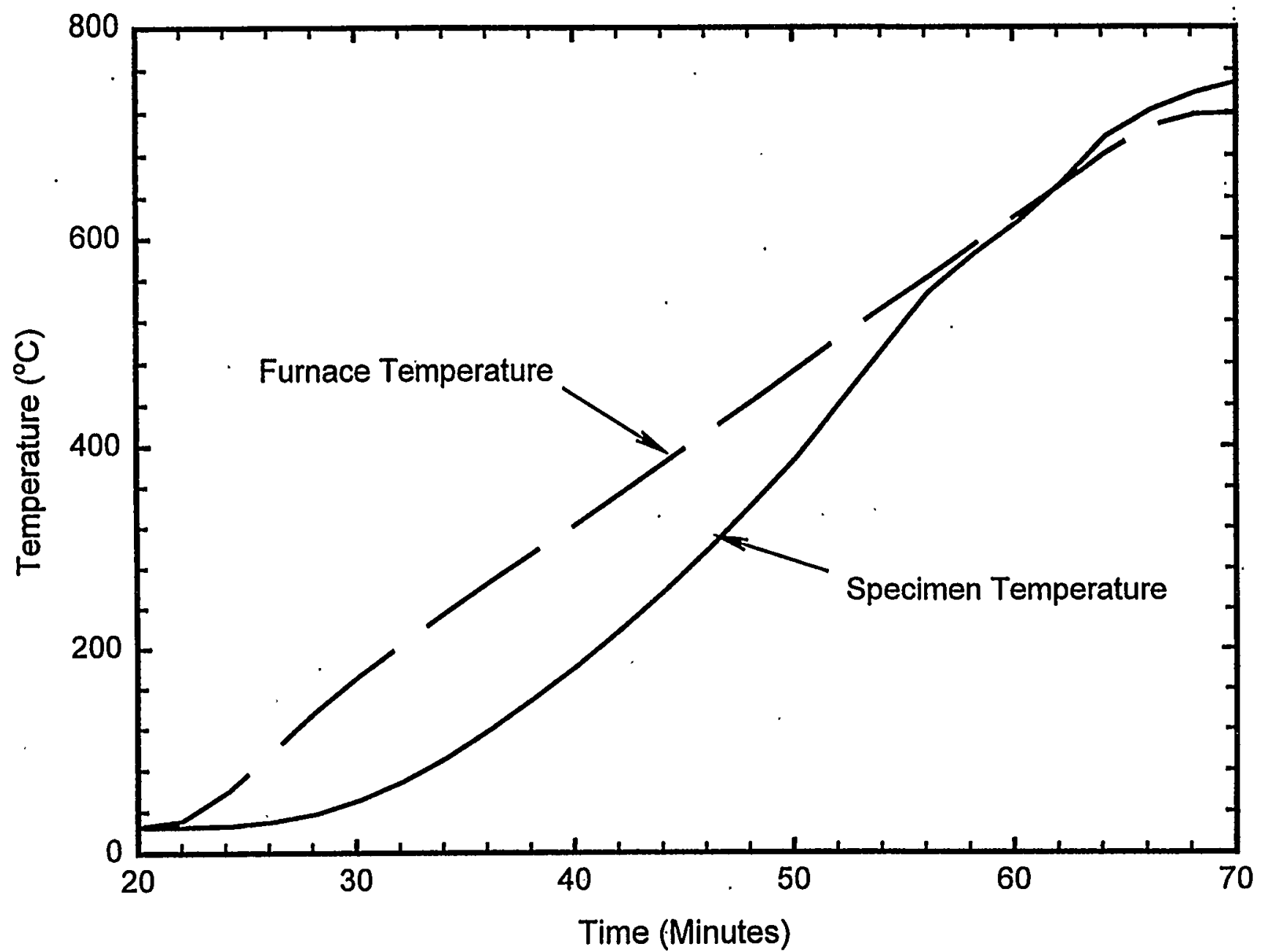

Figure B.25. Specimen and Furnace Temperature-Time Traces of As-Cut Specimen SFEC10,4366-S2-D for Run 32 


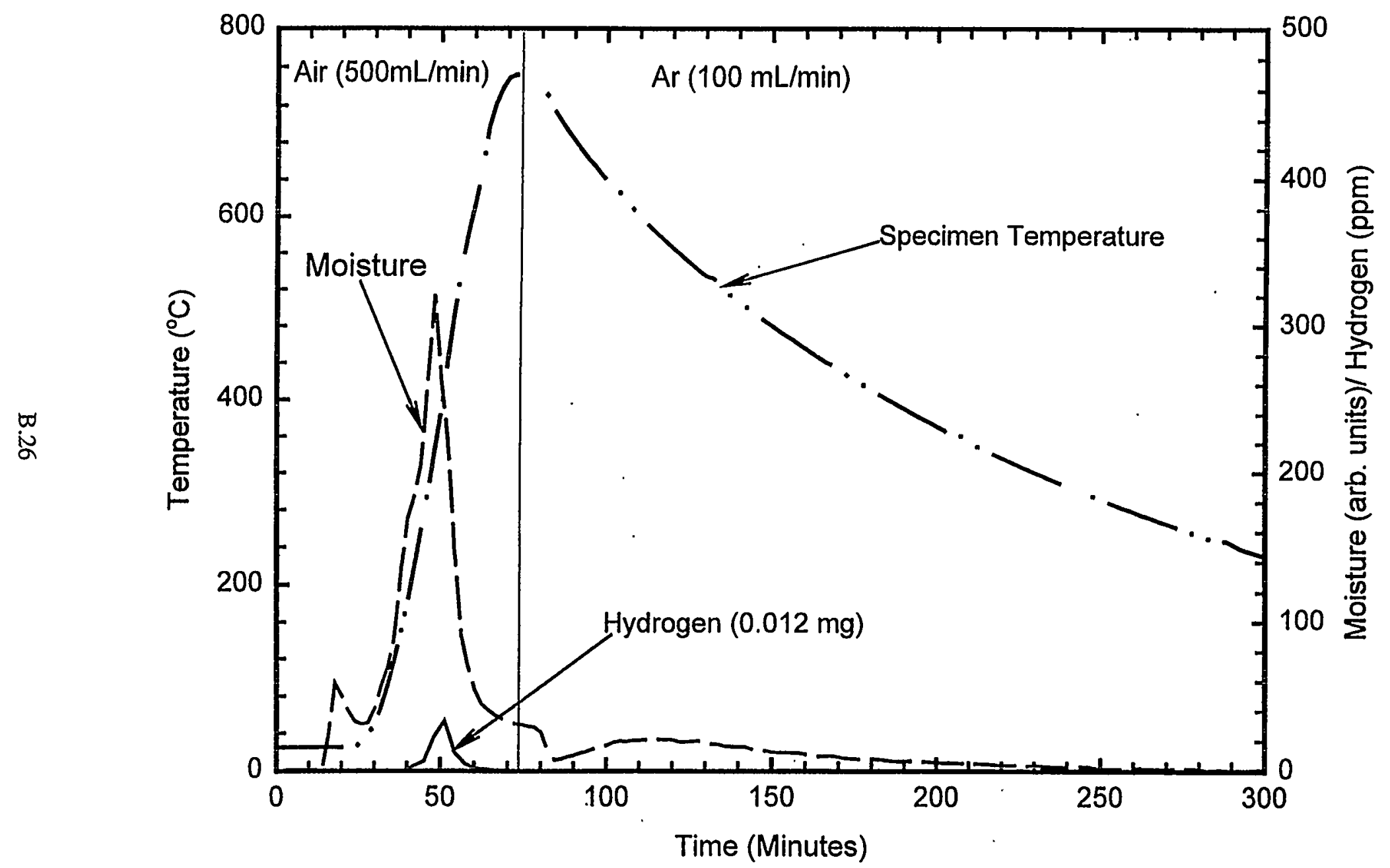

Figure B.26. Ignition Test Results of As-Cut Specimen SFEC10,4366-S2-D for Run 32 


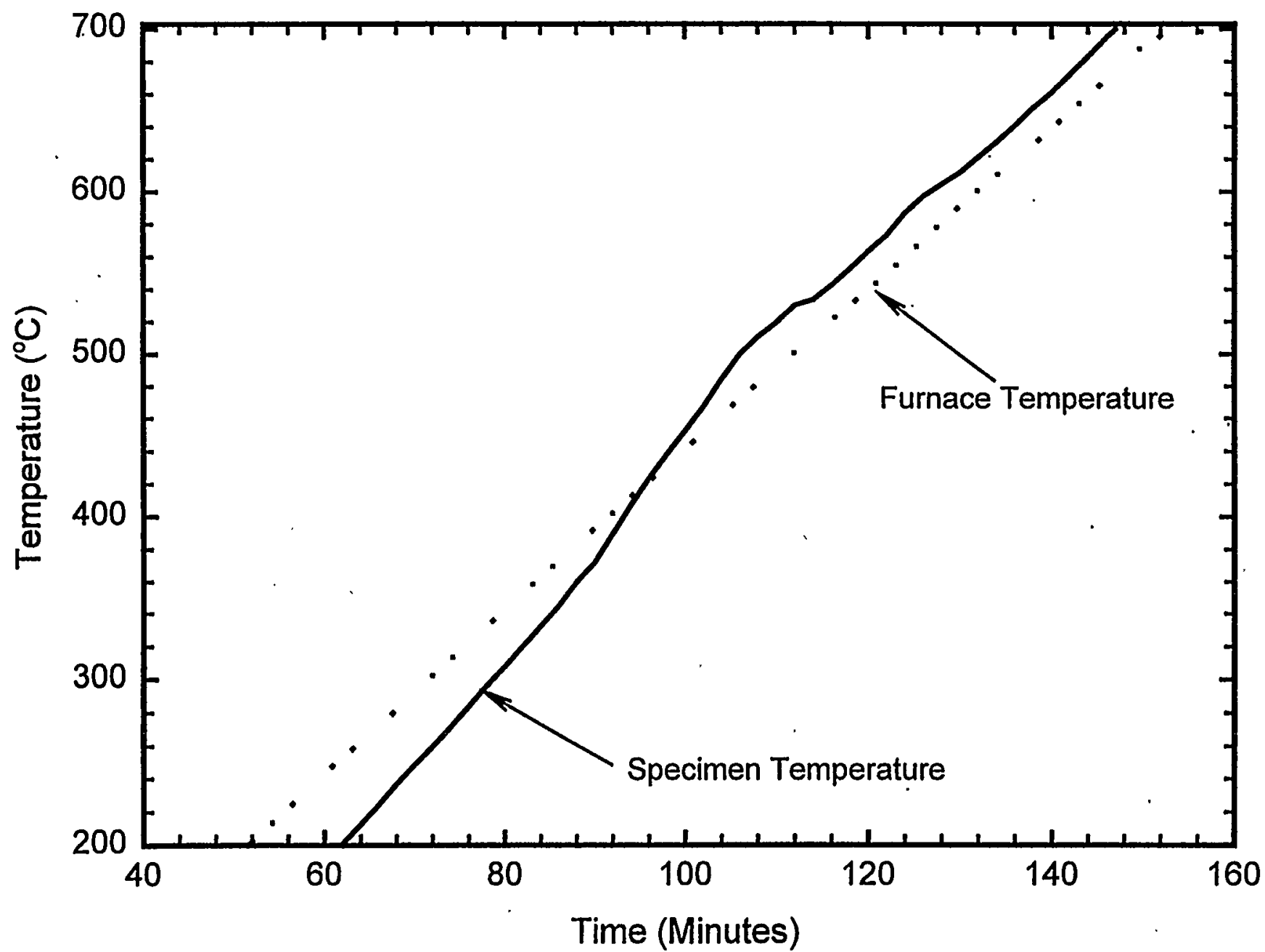

Figure B.27. Specimen and Furnace Temperature-Time Traces of Conditioned Specimen SFEC10,4366-S2-A for Run 33 


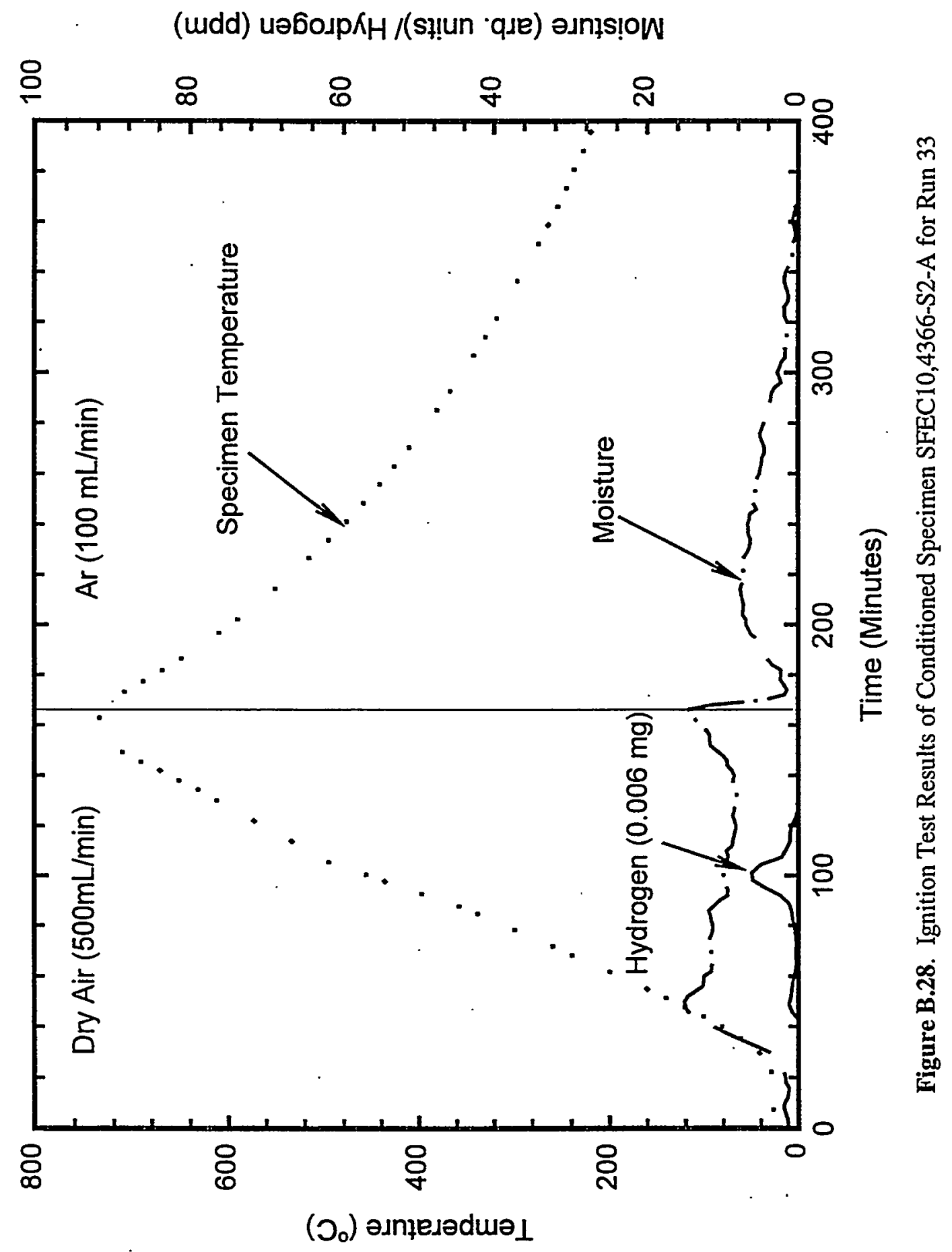




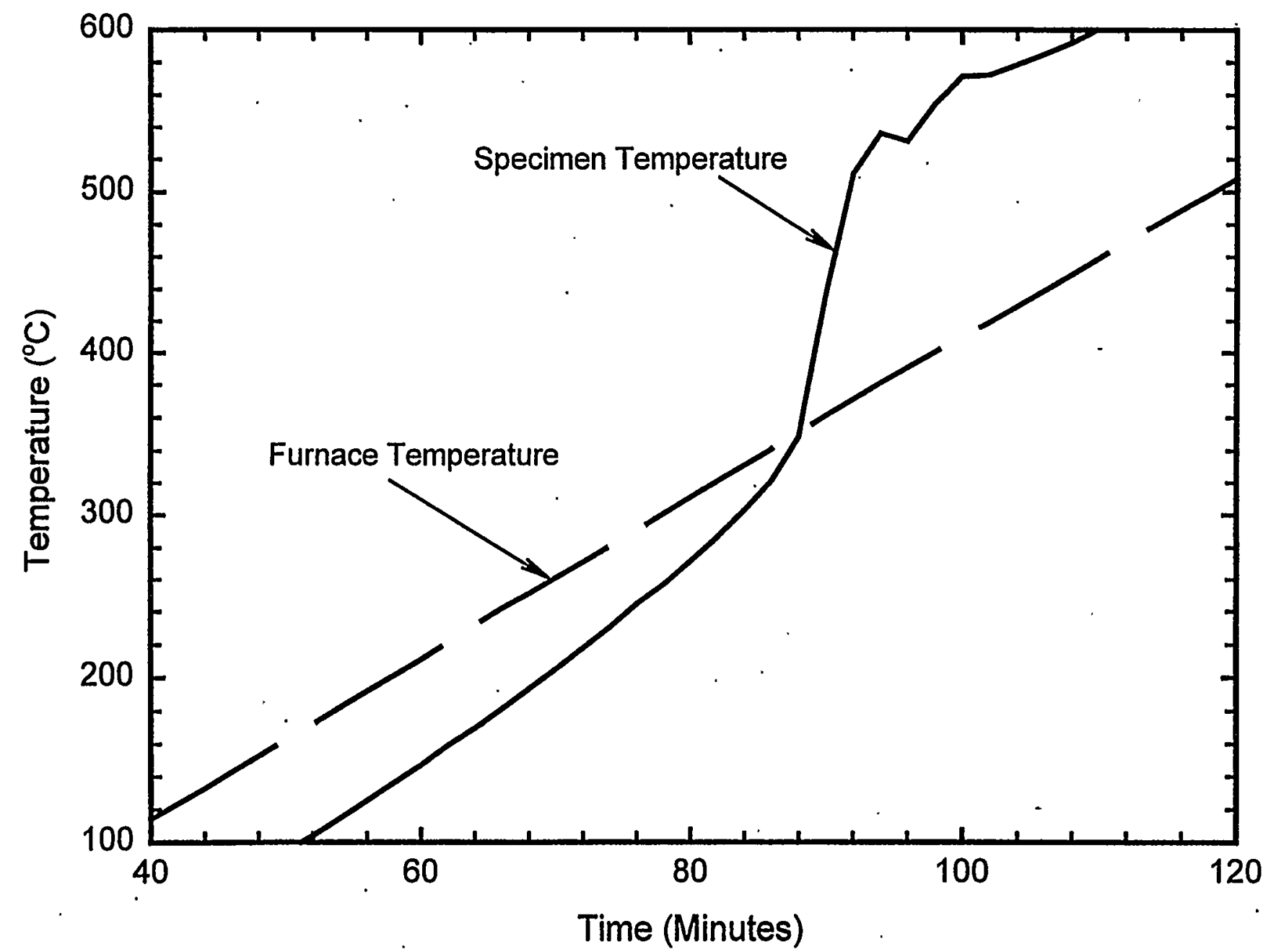

Figure B.29. Specimen and Furnace Temperature-Time Traces of Conditioned Specimen SFEC10,4366-S3-E1 for Run 36 


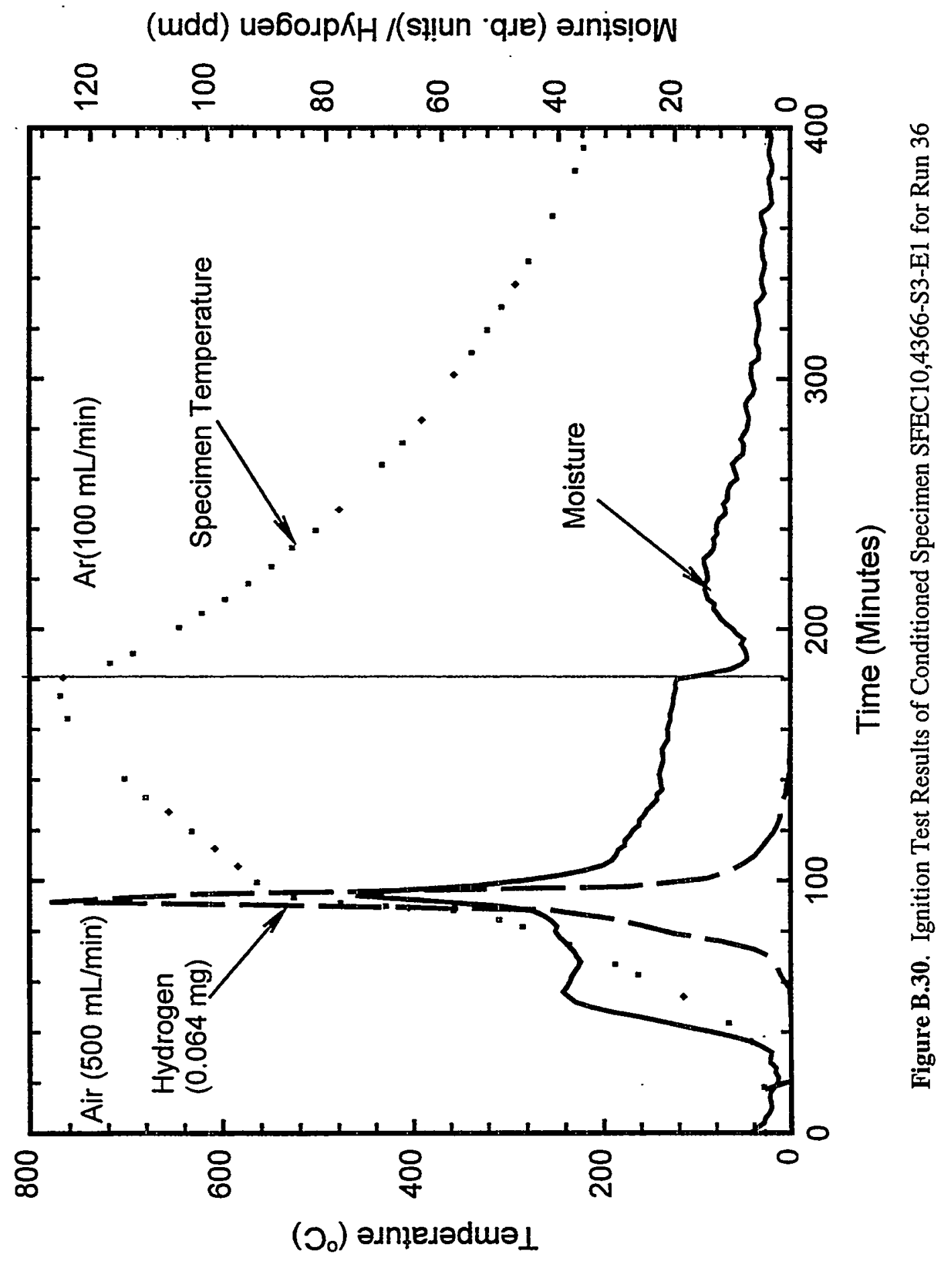




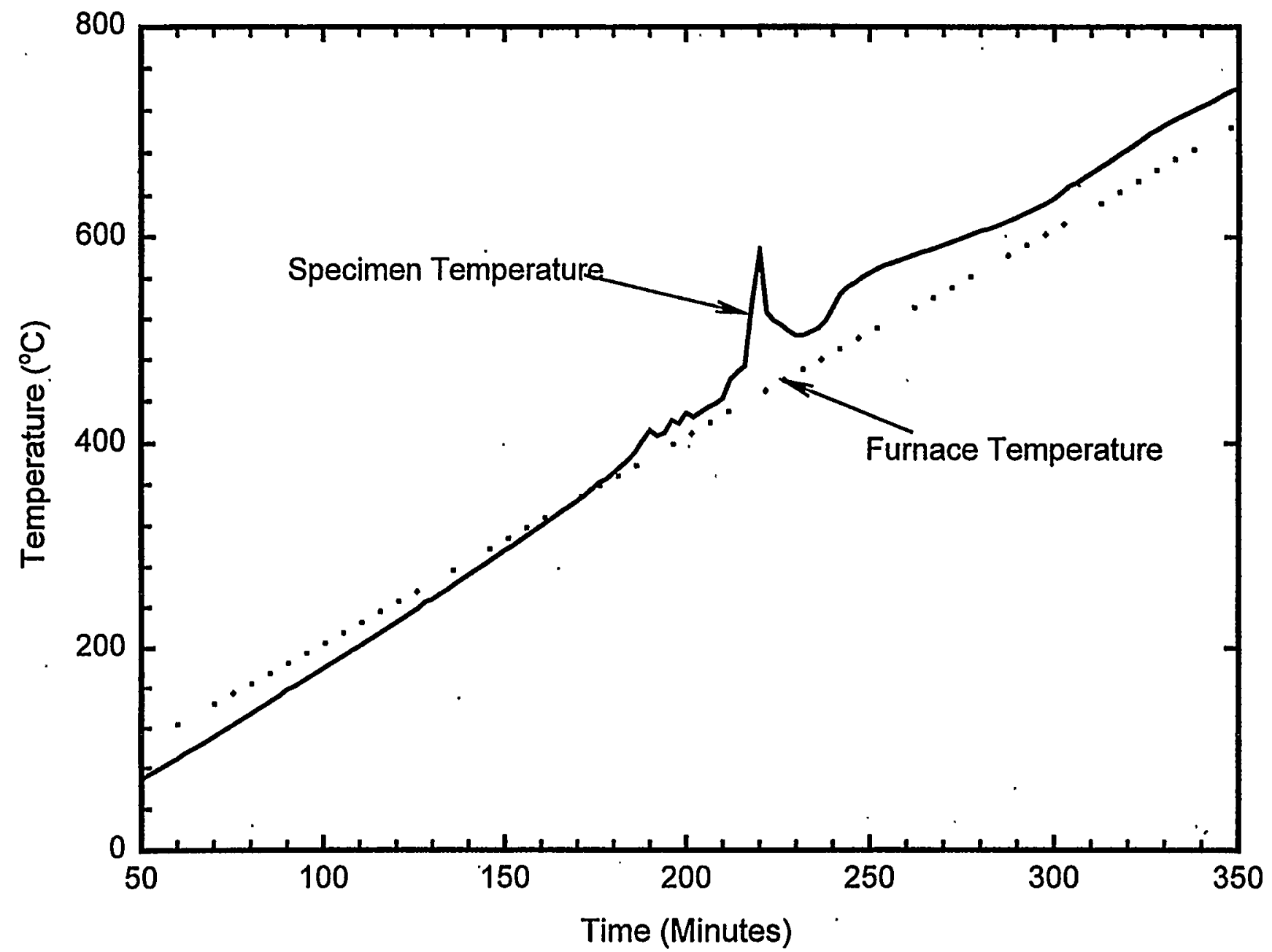

Figure B.31. Specimen and Furnace Temperature-Time Traces of Conditioned Specimen SFEC10,4366-S3-G for Run 37 


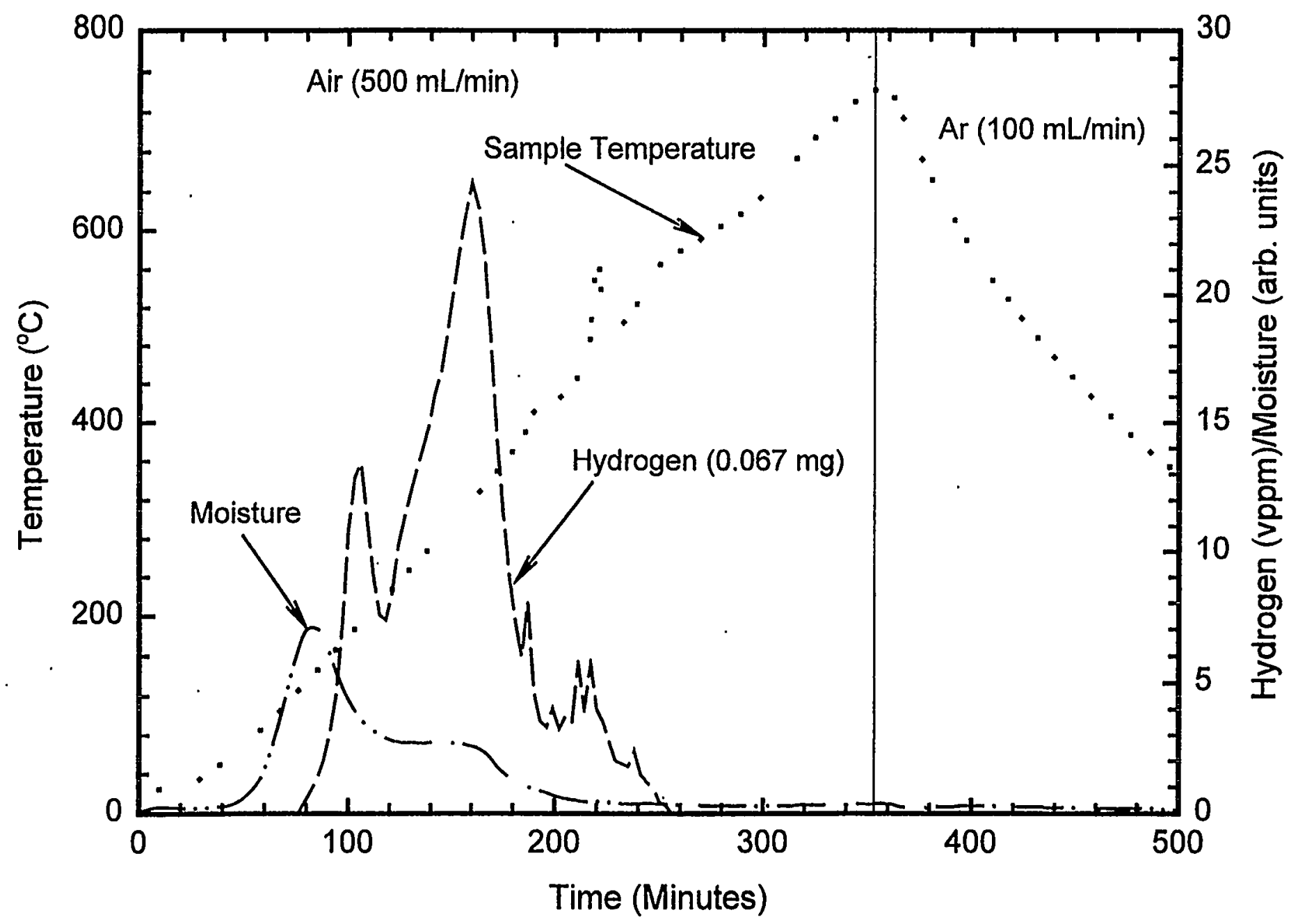

Figure B.32. Ignition Test Results of Conditioned Specimen SFEC10,4366-S3-G for Run 37 


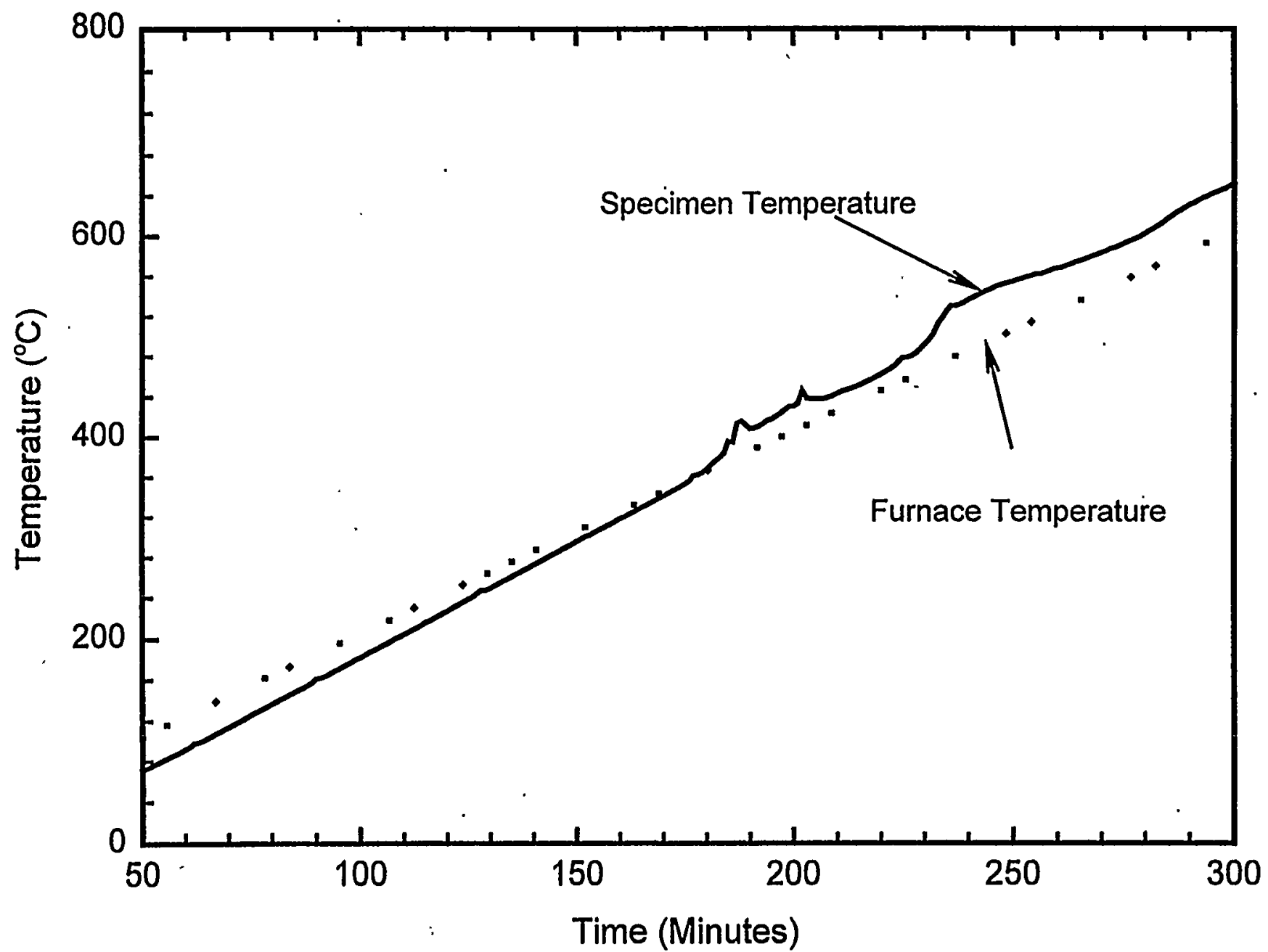

Figure B.33. Specimen and Furnace Temperature-Time Traces of Conditioned Specimen SFEC10,4366-S3-H for Run 39 


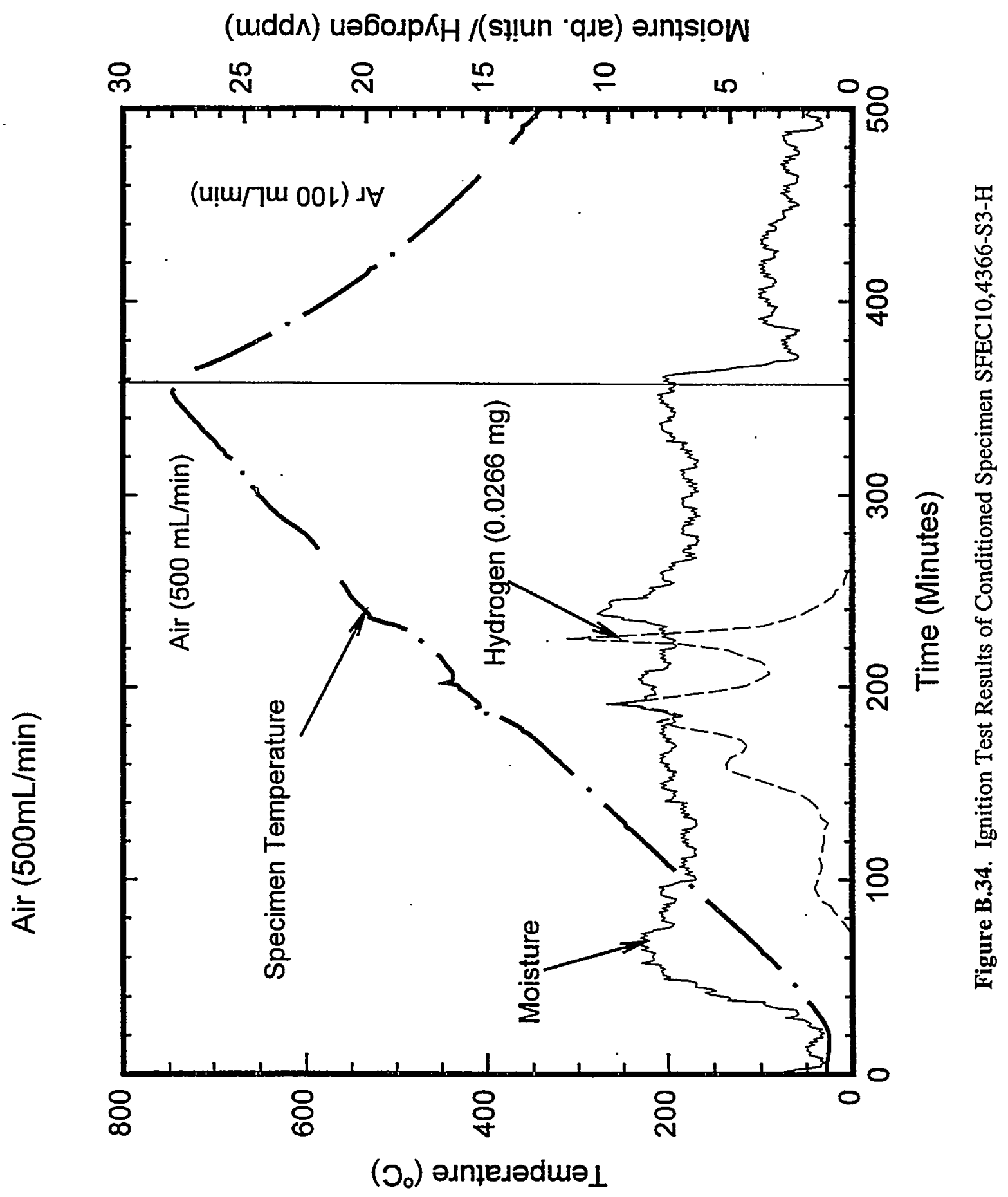




\section{Appendix C}

Summaries of Reported Uranium Metal Fuel

Pyrophoricity Incidents 


\section{Appendix C}

\section{Summaries of Reported Uranium Metal Fuel Pyrophoricity Incidents}

Instances of uranium metal ignition are variously reported to have been "spontaneous" (i.e., thermally induced), but in some reported cases the initiator of ignition was not identified. The fuel burning is sometimes slow ("burns like charcoal"), and sometimes spectacular" ("went off like a Roman candle"). Some accounts of these events provide detailed analyses and others merely observations. Some of these recorded events are summarized below.

\section{C.1 Lawrence Livermore Drum Explosion (Wood et al. 1994)}

In 1993, at Lawrence Livermore National Laboratory, a 55-gallon drum containing sections of unirradiated uranium-alloy fuel elements, clad in iron, experienced a "mild explosion" while being opened. The drum had been in storage at LLNL for about 5 years. The drum was one of 25 of a shipment of this type of fuel and was the only one that showed any pyrophoric behavior when handled.

The drum exploded while being "tapped" open to loosen a sticky ring seal at the top of the drum and at the approximate moment that ambient air entered the drum. After the initial explosion, it was observed the fuel itself had ignited and was burning vigorously with a yellow-orange flame. Within moments, the lid of the drum was loosely replaced, suppressing the flames but leaving the contents smoldering and emitting smoke. Three hours later the lid was clamped and sealed. After 83 days, the drum gas was sampled and found to be $75 \%$ nitrogen and $25 \%$ hydrogen. When the drum was reopened and the fuel exposed to air, the fuel once again spontaneously ignited, but this time the contents did not "explode." An analysis of the event concluded that it was caused by the ignition of uranium hydride upon sudden exposure to air. The hydride resulted from corrosion of the exposed uranium metal surfaces of the (sectioned) fuel elements during storage.

\section{C.2 West Valley Nuclear Fuel Services N-Fuel Ignition Events (Schulz 1972)}

A significant fraction of the spent (1000 and $3000 \mathrm{MWD} / \mathrm{MTU}) \mathrm{N}$-Reactor fuel elements sent to West Valley NFS in 1967-68 for reprocessing arrived in an unexpectedly corroded/broken condition. At the time of shipment from Hanford, the fuel was reported to be uncorroded, unruptured, and intact. Nineteen of the degraded fuel elements ignited at some time during processing at NFS; 14 during processing in the dissolvers; four in ambient air in the receiving bins during the dumping operation; and one when accidentally dropped on the receiving canyon deck. 
The dissolver fires were not visually observed, but were evidenced by large holes burned through the dissolver basket walls. It was concluded that the cause of the fires was the highly accelerated reaction of the nitric acid in the dissolvers with the broken/corroded fuel, most particularly with uranium hydride that had formed as a result of fuel corrosion in the sealed shipping casks. The bin fires were visually observed and had the physical appearance of "burning charcoal." It was concluded that ignition was due to mechanical shocking of zirconium hydride and/or uranium hydride near the "sensitized" weld-bead end caps of the fuel cladding. However, laboratory studies by Swanson et al. (1985) concluded that exothermic reactions of the metallic uranium were the dominant heat source for the ignition event.

\section{C.3 Redox Dissolver Incident (Harmon 1960)}

The lifetime of the multipurpose dissolver designed for the Redox plant at the Hanford Site was abruptly terminated in April 1960. This was caused by a spontaneous ignition and rapid oxidation of a large portion of metallic uranium that created extensive and irreparable damage to the dissolver. The spontaneous ignition of the irradiated uranium metal occurred when it was partly exposed to moist air above the surface of the water in the dissolver for 30 to 36 hours.

\section{C.4 British Nuclear Fuels Ltd. "Bottle" Study (Fisher and Knight 1993)}

Five "bottles" containing Magnox spent fuel were examined at Windscale. Four of the bottles contained intact or sectioned Tokai Mura fuel elements (bottle numbers 1,2,4, and 5) and one contained BNFL fuel element debris (bottle number 3). Bottle 5 contained a fuel element in two sections. The exterior of the bottle was extensively corroded. When the bottle was opened in air and tipped to remove the fuel element sections, the fuel ignited. The burn was suppressed, and the fuel cooled, by means of an argon purge. When the argon purge was stopped, the fuel re-ignited upon re-exposure to air. The argon purge was resumed and the burning stopped. After another cooling period, a small amount of oxygen was introduced into the argon purge to stabilize the fuel, presumably by oxidizing reactive metal and/or hydride surfaces. After this the fuel was re-exposed to air, it again re-ignited. After another argon purge, a second controlled oxygen stabilization successfully rendered the fuel inert without re-igniting it. The fuel was reexamined and two types of powder, one white and one black, were found adhering to or near the element sections. The black powder (uranium hydride?) ignited when separated and exposed to air.

\section{C.5 BNFL Dissolver Explosion (Brown 1976)}

Magnox fuel elements, which had been stored for 4 months in sealed bottles that had leaked air, dissolved unusually vigorously and rapidly in the dissolver trays during processing at Sellafield. The consequent rapid exothermic reaction rate in the nitric acid caused failure of the dissolver's internal cooling coils and seals and thereby flooded the fuel with the cooling water. 'This in turn resulted in a hydrogen buildup from the rapid corrosion of the uranium metal, which then resulted in a hydrogen/air explosion that separated and inverted the dissolver lid. When the dissolver was subsequently being drained, the upper half of the fuel in the trays was exposed to air and dried out, and the fuel ignited. The fuel ignition was attributed to sudden exposure of uranium hydride to the air. The uranium hydride had formed due to corrosion of the fuel in the leaking storage cans. 


\section{C.6 BNFL De-Bottling Ignition (Brown 1976)}

A Bradwell reactor Magnox fuel element, in what was supposed to be a sealed storage can delivered to Berkeley labs for examination, ignited in air at ambient temperature during de-bottling. When the bottle was opened, water was observed in it along with particulate material assumed to be corrosion product. The bottle had apparently leaked during storage and/or transport, allowing corrosion of the fuel element inside. This observation was shortly followed by self-sparking and ignition of the fuel element. Examination of the can after removal of the fuel element showed internal surface corrosion had occurred. It was concluded that the fuel element had ignited due to sudden exposure to air of uranium hydride, which had formed as a result of the corrosion.

\section{C.7 Chinon Transfer Can Explosion (Brown 1976)}

An aluminum "crimped can" storage container for Chinon reactor metallic uranium spent fuel elements, supposedly sealed, exploded during transfer from the storage pond to the decanning pond. No specific explanation of the accident sequence was provided, but it was concluded that uranium corrosion caused a hydrogen buildup and subsequent reaction with leaking air.

\section{C.8 Uranium Plate Explosions (Smith 1956)}

Three unirradiated, flat, 1/4-in.-thick uranium fuel plates (made by powder metallurgical techniques) were found to have become extremely swollen. The swelling was attributed to incomplete decomposition of uranium hydride (presumably the material precursor for the uranium metal plate) during hot pressing. This subsequently resulted in a buildup of hydrogen pressure within the plate, swelling it to nearly the shape of a rod. A day after the swollen plates were discovered, one spontaneously "exploded and took off like a rocket.".

\section{C.9 Fernald Drum Reactions (Solbrig et al. 1994)}

At Fernald, in 1992, two lids on drums containing depleted uranium metal spontaneously blew off. The drums were originally sealed in air. The explosions were blamed on a failure of the drum venting system, resulting in the accumulation of a hydrogen-oxygen mixture inside. The hydrogen was the product of corrosion of the uranium metal with the moisture in the drum air. Uranium hydride exposure was not thought to have been the ignition source; rather the ignition initiator was assumed to be a spark, although the source of the spark was not identified.

\section{C.10 Uranium Foil Ignition at ORNL (Solbrig et al. 1994)}

At ORNL, in 1992, a uranium metal foil was sealed with atmospheric air in a small bottle. After a period of time the water vapor and air inside the bottle were completely consumed, leaving the bottle containing uranium metal, uranium dioxide, uranium hydride, and the residual nitrogen from the air. Upon re-exposure to air at ambient temperature the uranium hydride ignited, causing the uranium metal to reach its ignition point and burn. 


\section{C.11 Irradiation-Swollen Magnox Element Ignition (BNFL 1995)}

Four instances of spontaneous ignition of Magnox spent fuel occurred in ambient air. The spent fuel had irradiation swelling in excess of $9 \%$. Two of these instances occurred when sections of fuel were heated in vacuum at $350^{\circ} \mathrm{C}$ to drive off hydrogen, then subsequently cooled and exposed to air. The other two occurred when sections that had been immersed in water were stored in sealed, air-filled containers for 12 days, then exposed to air.

\section{C.12 Spontaneous Ignition of Magnox Fuel Rod (BNFL 1995)}

It was concluded that the cause of ignition of a Magnox fuel rod in cave B38 was the exposure of uranium hydride in the corrosion product to air. Reference states that "badly corroded unirradiated uranium can catch fire in air and that this can happen even though no heat is being generated by friction."

\section{C.13 ZPPR Fuel Plates "Flashing" (Solbrig et al. 1994)}

In 1985, at Argonne National Laboratory, Zero Power Physics Reactor (ZPPR) fuel plates were found to be corroding in their storage canisters. The ZPPR fuel is uranium metal clad in stainless steel in the form of 1/16-in.-thick plates, but the cladding is vented such that the uranium fuel is in communication with the storage canister atmosphere. The initial storage container atmosphere was air, and an attempt was made to halt the corrosion by placing bags of desiccant in the containers. An examination of the canisters in 1990 showed further corrosion had occurred. The desiccant had not worked because the uranium had a greater affinity for the moisture than the desiccant. The containers were subsequently flushed with dry air, then evacuated, to halt the corrosion. When some of the drums were opened in 1993, more corrosion was observed, along with several instances of "flashing" of the fuel when it was exposed to air. The canisters were not designed to maintain vacuum, and over the 3 years experienced air in-leakage, which caused the corrosion of the uranium. Consequently, the uranium hydride formed and ignited upon exposure to air, which was the probable source of the "flashing." When the canister atmosphere was sampled and examined in 1992, it was found to be $100 \%$ nitrogen at atmospheric pressure. The "solution" to the corrosion problem adopted in 1993 was to leave the drums alone (since the cover gas was now $100 \%$ nitrogen at atmospheric pressure) and thus avoid further flashing if the drums were opened again.

\section{C.14 References}

British Nuclear Fuels Ltd. (BNFL). 1995. A Summary of BNFL's Experience in the Storage and Handling of Spent Metallic Fuel - Addendum: Summary of Reference Paper Contents. BNFL R\&D Report 0326.

Brown, V. 1976. Summary of Some Incidents Involving Uranium Fires. PAWP/111/41/P4, BNFL to SNFP (Commercial in Confidence), British Nuclear Fuels, Ltd. 
Fisher, D., and S. Knight. 1993. B30 Bottled Fuel Opening Option Study. AEA-D\&W-0566, Atomic Energy Agency.

Harmon, M. K. 1960. Redox Dissolver Incident Comprehensive Report. HW-66850, Hanford Atomic Products Operation, Richland, Washington.

Schulz, W. W. 1972. Shear-Leach Processing of N-Reactor Fuel-Cladding Fires. ARH-2351, Atlantic Richfield Hanford, Richland, Washington.

Smith, R. B. 1956. "Pyrophoricity - A Technical Mystery Under Vigorous Attack." Nucleonics 14(12):28

Solbrig, C. W., J. R. Krsul, and D. N. Olsen. 1994. "Pyrophoricity of Uranium in Long-Term Storage Environments." In Proceedings of Conference on DOE Spent Nuclear Fuel; Challenges \& Initiatives. Salt Lake City, Utah.

Swanson, J. L., L. A. Bray, H. E. Kjarmo, J. L. Ryan, C. L. Matsuzaki, S. G. Pitman, and J. H. Haberman. 1985. Laboratory Studies of Shear/Leach Processing of Zircaloy Clad Metallic Uranium Reactor Fuel. PNL-5708, Pacific Northwest National Laboratory, Richland, Washington.

Wood, D. H., S. A. Snowden, H. J. Howe, L. L. Thomas, D.W. Moon, H. R. Gregg, and P. E. Miller. 1994. "Regarding the Chemistry of Metallic Uranium Stored in Steel Drums." J. Nuclear Materials 209:113. 


\section{Distribution}

No. of

Copies

\section{OFFSITE}

C. L. Bendixsen

Idaho National Engineering and

Environmental Laboratory

P.O. Box 1625

Mail Stop 3135

Idaho Falls, ID 83415

A. W. Conklin

Washington State Department of Health

Airdustrial Park

Building 5, Mail Stop LE-13

Olympia, WA 98504-0095

M. A. Ebner

Idaho National Engineering and

Environment Laboratory

P.O. Box 1625

Mail Stop 3114

Idaho Falls, ID 83415

A. R. Griffith

U.S. Department of Energy, Headquarters 19901 Germantown Rd. (EM-65)

Germantown, MD 20585-1290

\section{T. J. Hull}

U.S. Department of Energy, Headquarters 19901 Germantown Road (EH-34)

Germantown, MD 20874-1290

M. R. Loutham

Savannah River Technology Center

Materials Technology Center

Aiken, SC 29808
No. of

Copies

T. E. Madey

Rutgers University

Bldg. 3865

136 Freylinghuysen Rd.

Piscataway, NJ 08854

B. K. Nelson

U.S. Department of Energy, Headquarters

19901 Germantown Road (EM-65)

Germantown, MD 20874-1290

R. G. Pahl, Jr.

Argonne National Laboratory

P.O. Box 2528

Idaho Falls, ID 83403

R. S. Rosen

Lawrence Livermore National Laboratory

20201 Century Blvd., 1st Floor

Germantown, MD 20874

D. Silver

Washington State Department of Ecology

P.O. Box 47600

Olympia, WA $98504-7600$

T. A. Thornton

Yucca Mountain Project M\&O Contractor SUM1/423

1261 Town Center Drive

Las Vegas, NV 89134 
No. of

Copies

\section{ONSITE}

6 DOE Richland Operations Office
R. M. Hiegel
S7-41
P. G. Loscoe
S7-41
C. R. Richins
E. D. Seller
J-S. Shuen
G. D. Trenchard
K8-50
S7-41
S7-41
S7-41

23 Duke Engineering and Services, Hanford, Inc.
C. B. Aycock
R. B. Baker
D. W. Bergmann
S. A. Chastain
D. R. Duncan
J. R. Frederickson
L. H. Goldmann
S. L. Hecht
B. J. Makenas
R. P. Omberg
A. L. Pajunen
R. W. Rasmussen
A. M. Segrest
J. A. Swenson
C. A. Thompson
D. J. Trimble (5)
D. J. Watson
J. H. Wicks, Jr.
SNF Project Files
R3-11
H0-40
X3-79
H0-40
R3-86
R3-86
R3-86
$\mathrm{H} 0-40$
HO- 40
$\mathrm{H} 0-40$
R3-86
X3-85
R3-11
R3-11
R3-86
$\mathrm{H} 0-40$
X3-79
X3-74
R3-11

3 Fluor Daniel Hanford
E. W. Gerber
D. A. Smith
M. J. Wiemers

No. of

Copies

7 Numatec Hanford Company

R3-11

T4-13

R3-11
G. P. Chevrier H5-25

T. Choho R3-86

E. R. Cramer H0-34

T. A. Flament H5-25

J. J. Irwin R3-86

C. R. Miska R3-86

J. P. Sloughter H5-49

2 Technical Advisory Group

J. C. Devine R3-11

R.F. Williams R3-11

35 Pacific Northwest National Laboratory

J. Abrefah (7) P7-27

S. T. Cebula K5-12

J. P. Cowin K8-88

S. R. Gano K2-12

W. J. Gray P7-27

B. D. Hanson P7-27

G. S. Klinger P7-22

D. K. Kreid K7-80

P. J. MacFarlan P7-27

S. C. Marschman (5) P7-27

B. M. Oliver P7-22

T. M. Orlando K8-88

L. R. Pederson K2-44

G. F. Piepel K5-12

R. L. Sell (2) P7-25

J. M. Tingey P7-25

J. C. Wiborg K7-74

Information Release (7)

B. \& W. Hanford

G. S. Barney

T5-12

2 Fluor Daniel Northwest

$\begin{array}{ll}\text { L. J. Garvin } & \text { R3-26 } \\ \text { G. A. Ritter } & \text { H0-40 }\end{array}$

Distr.2 